\title{
Implementing genetic tests
}

Citation for published version (APA):

Jansen, M. E. (2016). Implementing genetic tests: infertility and newborn bloodspot screening. [Doctoral Thesis, Maastricht University]. Maastricht University. https://doi.org/10.26481/dis.20160127mj

Document status and date:

Published: 01/01/2016

DOI:

10.26481/dis.20160127mj

Document Version:

Publisher's PDF, also known as Version of record

\section{Please check the document version of this publication:}

- A submitted manuscript is the version of the article upon submission and before peer-review. There can be important differences between the submitted version and the official published version of record.

People interested in the research are advised to contact the author for the final version of the publication, or visit the DOI to the publisher's website.

- The final author version and the galley proof are versions of the publication after peer review.

- The final published version features the final layout of the paper including the volume, issue and page numbers.

Link to publication

\footnotetext{
General rights rights.

- You may freely distribute the URL identifying the publication in the public portal. please follow below link for the End User Agreement:

www.umlib.nl/taverne-license

Take down policy

If you believe that this document breaches copyright please contact us at:

repository@maastrichtuniversity.nl

providing details and we will investigate your claim.
}

Copyright and moral rights for the publications made accessible in the public portal are retained by the authors and/or other copyright owners and it is a condition of accessing publications that users recognise and abide by the legal requirements associated with these

- Users may download and print one copy of any publication from the public portal for the purpose of private study or research.

- You may not further distribute the material or use it for any profit-making activity or commercial gain

If the publication is distributed under the terms of Article $25 \mathrm{fa}$ of the Dutch Copyright Act, indicated by the "Taverne" license above, 


\section{Implementing genetic tests}
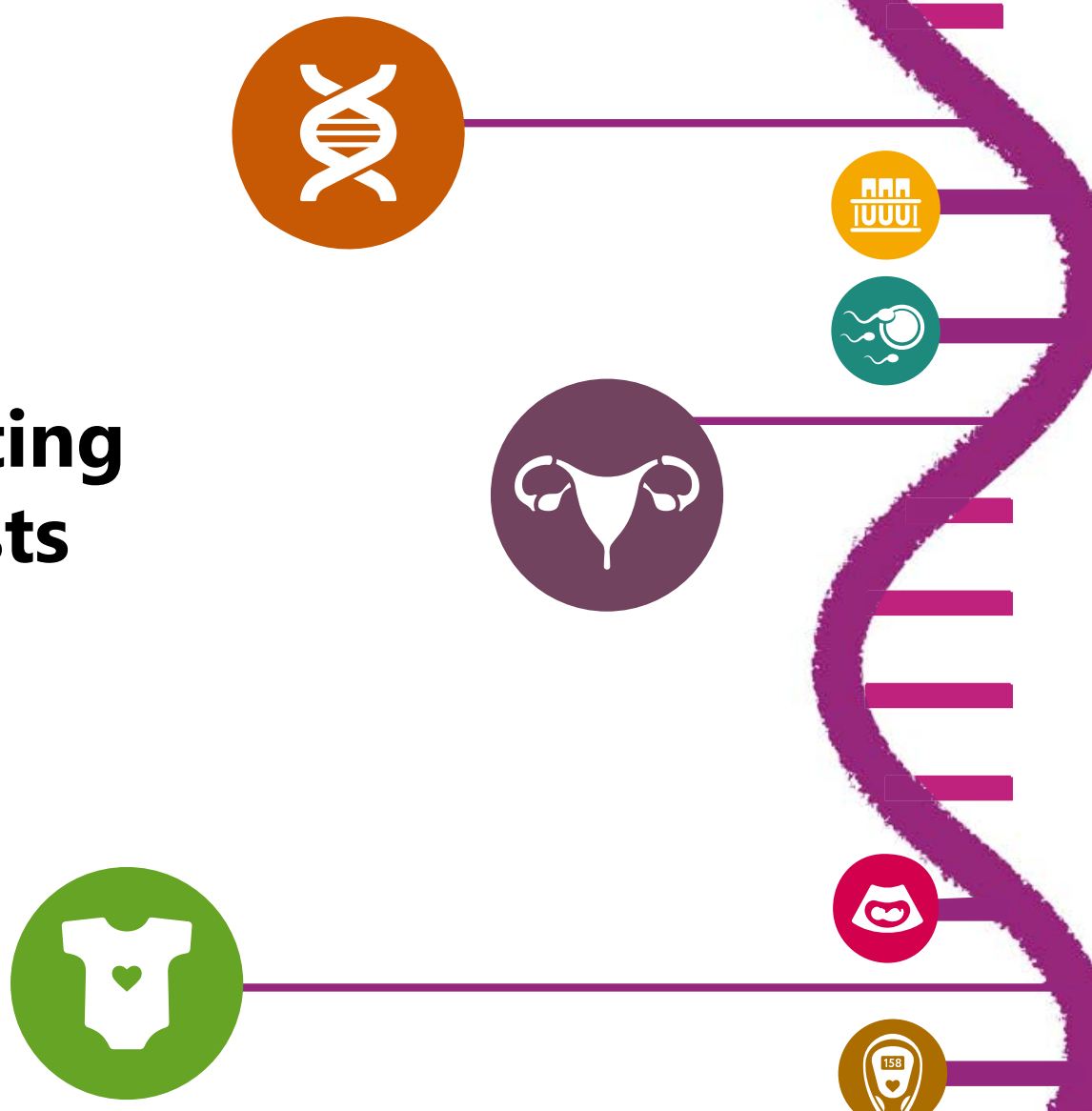

Infertility and newborn bloodspot screening

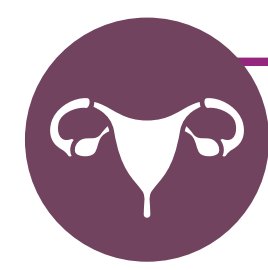

2 



\title{
Implementing genetic tests
}

\section{Infertility and newborn bloodspot screening}

\author{
M.E. Jansen
}


(C) M.E. Jansen, Maastricht 2016

ISBN: 978-94-028-0024-1

Cover design and lay-out: M.E. Jansen

Printed by Ipskamp Drukkers BV - www.proefschriften.net

Financial support: Haak Baastiaanse Kuneman Stichting, Amsterdam

All rights reserverd. No part of this thesis may be reproduced, stored in a retrieval system of any nature, or transmitted in any form or by any means, electronic, mechanical photocopying, recording or otherwise, without permission of the author. 


\title{
UNIVERSITEIT MAASTRICHT
}

\section{Implementing genetic tests \\ Infertility and newborn bloodspot screening}

\author{
ACADEMISCH PROEFSCHRIFT
}

Ter verkrijging van de graad van doctor aan de Universiteit Maastricht, op gezag van de Rector Magnificus, prof. dr. L.L.G. Soete volgens het besluit van het College van Decanen

in het openbaar te verdedigen

op woensdag 27 januari 2016

om 16:00 uur

door

Magdalena Elizabeth Jansen

geboren te Haarlem 


\section{Promotors}

Prof. dr. S.A. Morré

Maastricht University

Prof. dr. M.C. Cornel

VU University Medical Center Amsterdam

\section{Copromotors}

Dr. S. Ouburg

Dr. H.J. van Kranen

VU University Medical Center Amsterdam

Rijksinstituut voor Volksgezondheid en Milieu

\section{Beoordelingscommissie}

Prof. dr. P.H.M. Savelkoul (voorzitter)

Maastricht University

Prof. dr. D.D.M. Braat

Radboud Universiteit Nijmegen

Prof. dr. C.B. Lambalk

VU University Medical Center Amsterdam

Prof. dr. G.M.W.R. de Wert

Maastricht University 
"De rede biedt ons vele mogelijkheden, de intuitie kiest daaruit feilloos de beste." Arthur Japin in 'Een Schitterend Gebrek' 



\section{Table of contents}

Chapter 2. Prediction of tubal factor infertility based on Chlamydia trachomatis antibody testing combined with $\mathrm{C}$-reactive protein as a marker for persistent infection

Chapter 3. Potential protective effect of a G>A SNP in the $3^{\prime} U T R$ of $H L A-A$ for Chlamydia trachomatis symptomatology and severity of infection

Chapter 4. The attitudes of Dutch gynecologists towards the addition of genetic testing in screening of tubal factor infertility

Chapter 5. International differences in the evaluation of conditions for newborn screening: a review of scientific literature and policy documents

Chapter 6. Decision making in newborn screening needs a transparent approach with structured multidisciplinary stakeholder engagement in all phases

Chapter 7. Public involvement in policy development for newborn bloodspot screening: goals, definitions, mechanisms, levels, and evaluation.

Chapter 8. General discussion

Chapter 9. Summary

\section{Appendix}



Chapter 1

General introduction

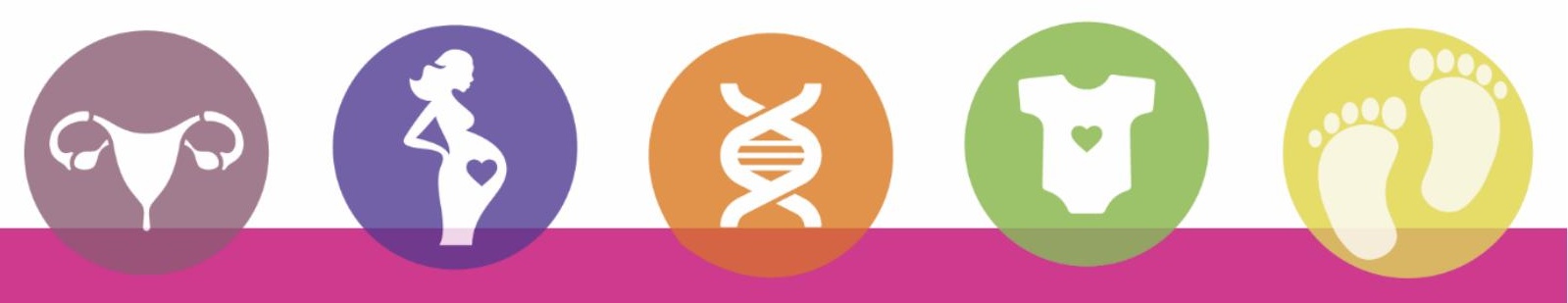




\section{Translation of genomic technologies into healthcare}

Sequencing the whole human genome was considered a major breakthrough in modern biological research. ${ }^{1}$ In the year 2000 the completion and publication of the human genome was presented to the press by the president of the United States of America (USA) together with leaders of public and private consortia. ${ }^{2}$ New developments in disease understanding through genomic information were predicted, in combination with possible test and treatment implications. So far the consequences for clinical medicine have been modest: five years ago Francis Collins stated that "it is fair to say that the Human Genome Project has not yet directly affected the health care of most individuals". ${ }^{2}$ Nonetheless, there are advances including diagnostics and treatment in cancer care. Some authors have claimed that the technological advances will bring about a paradigm shift predicting a health care system focused on personalized medicinei: a targeted approach to the prevention, diagnosis and treatment of disease based on an individual's specific profile, including the disease or pathogen they are carrying. ${ }^{3,4}$ The fast increase of knowledge on one of our most personal profiles - the human genome gave a boost to the expectations of personalized medicine, and genetic technologies are increasingly translated into health care practice. In the context of these developments, the emerging field of Public Health Genomics intends "to integrate genome-based knowledge and technologies into public policy and into health services". ${ }^{5}$

\subsection{Public Health Genomics}

Timely but responsible implementation is an important goal when translating genomebased information into practice. Responsible translation refers to verifying whether a new or adapted service is meaningful and appropriate. It is essential that implementation is efficient, effective, robust and sustainable. Implementation is efficient when waste of time, effort, and finances are minimized, and it is effective when it produces the intended results. Robust and sustainable implementation is approached with a framework that anticipates changes in the future. To provide guidance in the evaluation of genetic technologies, the Centers for Disease Control in the United States of America developed a framework and a complementary list of 44 targeted questions. ${ }^{6}$ Their framework described key factors in the field of Analytical validity, Clinical validity, Clinical utility, and associated Ethical, legal, and social implications: the ACCE-framework (figure 1).ii

\footnotetext{
i Personalized Medicine is also described with different terminology, such as 'precision medicine' or 'individualized care'.

ii In the meantime several follow-up activities on the ACCE-framework have taken place, for example the Evaluation of Genomic Applications in Practice and Prevention project
} 


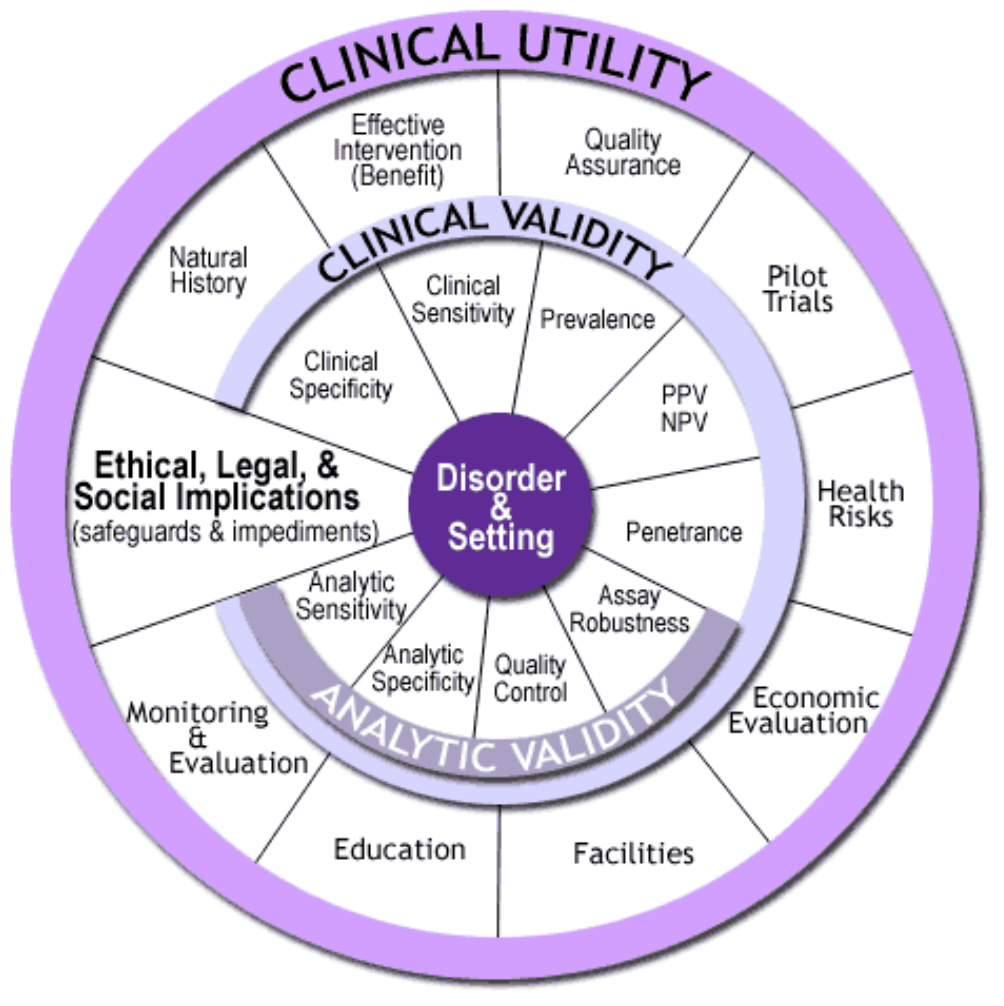

Figure 1. ACCE model to evaluate genetic tests. ${ }^{6}$

This framework aims to aid policy makers in decision making by allowing them to have access to up-to-date and reliable information on genetic testing specifically in the health care setting. The aspects in the framework focus on collecting, evaluating, interpreting, and reporting data in a specific setting about testing for a specific condition with a genetic component. ${ }^{6,7}$ Key factors to evaluate genetic tests in a specific setting are described in the ACCE model at various levels; examples of analytical validity, clinical validity, and clinical utility are summarized in figure 1 . Throughout the evaluation of a genetic test, ethical, legal, and social implications (ELSI) are central. Examples include privacy, confidentiality, and discrimination. ${ }^{8}$

\subsection{Developments in genetics and their effects}

Human genetics have historically been studied in chromosomal anomalies and Mendelian conditions. In this field a genetic test can be used to analyze a genetic variant and diagnose the accompanying disease due to the high penetrance of the variant. New methods have entered genetic diagnostics, such as comparative genomic hybridization to diagnose chromosomal anomalies, including gains or losses of sub-chromosomal 
regions through analyzing the copy number variants in a sample compared to a reference. ${ }^{9}$ More recently whole exome sequencing has emerged, which can identify variants contributing to rare monogenic diseases. The emergence of next generation sequencing (NGS) techniques have informed the field of genomics: the study of genes and their functions, and related techniques. ${ }^{10}$ However, since genomics can be used to imply untargeted sequencing and analyses instead of targeted sequencing for a known variant, in this thesis the term genetic test is preferred to specify that the discussed test is a targeted DNA test.

Emerging NGS technologies have shifted healthcare initiatives to focus on a more preventive rather than a reactive field. ${ }^{4}$ Currently, more applications are also aimed at predisposing factors for a number of health outcomes. As an example, genetic tests are used to prevent side effects of pharmaceuticals and ineffective treatment regimens in pharmacogenomics to predict the outcome of drug interventions. Genetic profiling may reveal a predisposition and appropriate action can be taken. For example, a patient's decreased enzyme activity in metabolizing drugs may make it necessary to vary the dose administered. If the test points out that their metabolism takes longer to process the drug in their body, they will receive a lower dose.

Most of the current applications of genetic testing take place in the traditional model of doctor-patient relationship in individual clinical medicine. However, genome-based technologies can also improve screening in public health through implementation in population screening programs. ${ }^{11}$ The implementation of genetic testing is expanding towards public health. An example of an ongoing implementation process of a new genome-based technology - at the border of screening and individual care - is antenatal screening for trisomy 13, 18, and 21 through non-invasive prenatal screening. Also newborn screening programs, traditionally organized in population health programs, have integrated more genetic diseases in many countries in the last decade. ${ }^{12}$ Furthermore, not only governmental screening programs consider the possibilities of genetic testing, there is already a broad offer to the population of direct-to-consumer tests available in the private sector. ${ }^{13}$

\subsection{Responsible translation?}

Numerous issues present themselves when the potential use of genome-based information in health care applications are discussed. Especially because our DNA-profile is one of our most personal ones, the safeguards for the information it holds need to be robust and future-proof. Discussions on storage and disclosure have been presented, and it is recognized that the infrastructure to ensure public empowerment in a responsible framework are not currently available. ${ }^{14}$ Moreover, when looking at implementation of genetic tests on a shorter term, significant gaps in knowledge exist in health care delivery. Health care professionals - who are not clinical geneticists - might need to be able to discuss more genetic information with their patients in the near future. ${ }^{1}$ As described 
earlier, some genetic technologies have already made their appearance in health care: genetic tests can predict if a patient with breast cancer needs chemotherapy and accurately predict the drug response of dozens of pharmaceuticals. ${ }^{2}$ It is expected that genetic technologies will have wider effects into the future.

\subsection{The impact of new technologies}

The dynamics in genetic research call for timely yet responsible translation of relevant technologies into clinical and public health care. Expanding biological knowledge on the roles of genetic factors in disease etiology is essential, but to implement a new technology, support has to be created amongst the relevant stakeholders. ${ }^{11}$ Stakeholders can be found at the other end of the translational pipeline. From discovery to health application, eliciting the worries and needs of these stakeholders is essential for the successful implementation of personalized medicine. Common understanding through dialogue with stakeholder groups will support decision making by taking on board perspectives from society, medicine, industry, and government. ${ }^{15}$

Trends in clinical health care show a combined effort from different fields such as science, biotechnology, and health care delivery by health professionals. For this thesis two developments have been selected for further analysis of the potential steps in responsible translation: (1) fertility care and (2) newborn screening. The next section will focus on female infertility due to tubal pathology, and the role Chlamydia trachomatis plays in the cause of tubal factor infertility. The third section will discuss innovations in newborn bloodspot screening.

\section{Added value of genetics in clinical health care}

Health care professionals always try to tailor interventions for the patient in front of them, so the general concept of personalized medicine is familiar to doctors as well as patients. However, the tools to provide personalized medicine have developed significantly over the past decades. Questionnaires on personal preferences as well as risk stratification modules have entered many fields of health care. Imaging techniques also aim to stratify healthy persons according to risk category. Not only has genetics in the traditional meaning of DNA testing entered the landscape of health care, also other technological developments facilitate state of the art laboratory analyses, such as tandem mass spectrometry, proteomics, and metabolomics. Furthermore, new insights in processes in the human body and the role different molecules have, offer new opportunities for understanding diseases and their diagnosis and treatment. Relevant molecules can be identified as biomarkers and used to analyze for example subtypes of cancer or subpopulations of patients. ${ }^{4}$ 


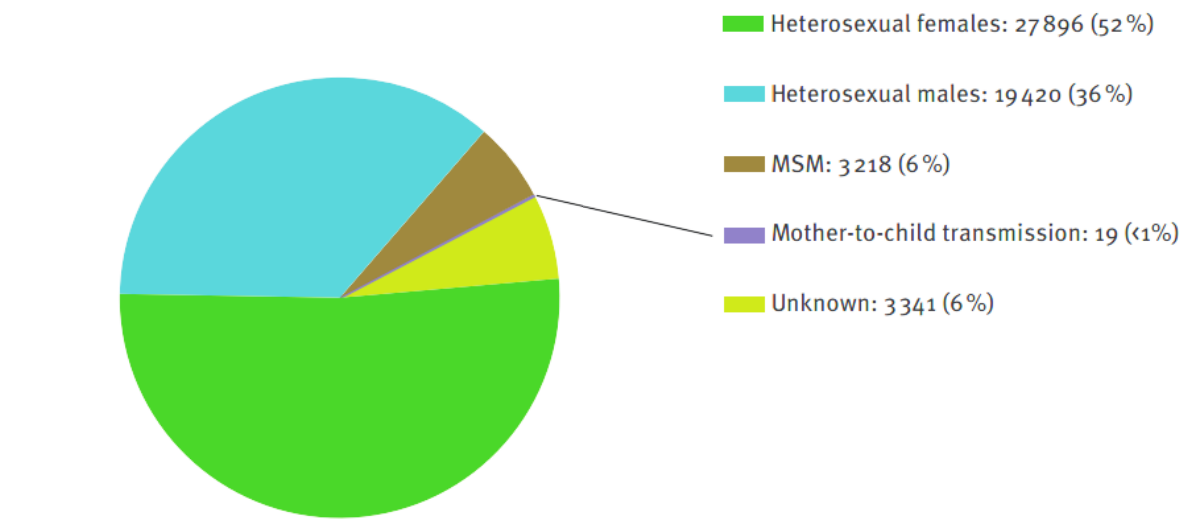

Note: Includes data from Greece, Latvia, Lithuania, Luxembourg, Malta, the Netherlands, Romania, Slovenia and Sweden.

Figure 2. Number and percentage of CT infections in 2013, stratified to category in participating EU/EEA countries. ${ }^{17}$

\subsection{Chlamydia trachomatis associated infertility}

When a couple fails to conceive a child after 12 months, despite regular unprotected intercourse, this is a first indication of possible male or female infertility. ${ }^{16}$ In the Netherlands the number of new couples with fertility problems caused by $C$. trachomatis is estimated at 1000 - 2000 per year. C. trachomatis is the most common sexually transmitted infection, with an estimated incidence of 146 million infections worldwide anually. ${ }^{17}$ In Europe over half of the cases of infection occur in women (figure 2). Furthermore, $C$. trachomatis primarily affects young women between the ages of 15 and 35 , with the highest prevalence between 18 and 25 years.

C. trachomatis often has an asymptomatic course, and therefore an infection is in most cases not picked up and treated. It is estimated that within a year more than half of women clear an asymptomatic C. trachomatis infection themselves. ${ }^{18}$ However, lack of either treatment or clearance of the infection increases the chance of pelvic inflammatory disease, ectopic pregnancy due to tubal pathology, and eventually will lead to tubal factor infertility (TFI) ${ }^{19}$ Possible explanations for these long term complications are: a chronic low-grade immune response (persistence of inflammation); an overactive immune response to the $C$. trachomatis infection, but also auto immune responses may play a role. ${ }^{20,21}$ These mechanisms are assumed to attack and destroy the host cells, leading to tubal adhesions. 
Tubal adhesions can occur unilateral or affect both tubes, i.e. a bilateral pathology. Bilateral pathology reduces the chance on spontaneous pregnancy severely, while unilateral pathology decreases the chance at least moderately. ${ }^{22}$ Finally, complications are usually categorized as proximal or distal (figure 3). ${ }^{23}$ Proximal occlusions can be caused by cesarean section or endometriosis. Midsegment tubal obstruction is usually a consequence from surgery to permanently prevent pregnancy. Distal occlusions are often associated with hydrosalpinx, typically caused by Chlamydia trachomatis infection in the urogenital track. Some studies suggest that $C$. trachomatis infection may be the cause of tubal adhesions in more than half of the cases ${ }^{16}$, and it has been found in bilateral tubal pathology that $80 \%$ of the women tested positive for $C$. trachomatis antibodies. ${ }^{24}$

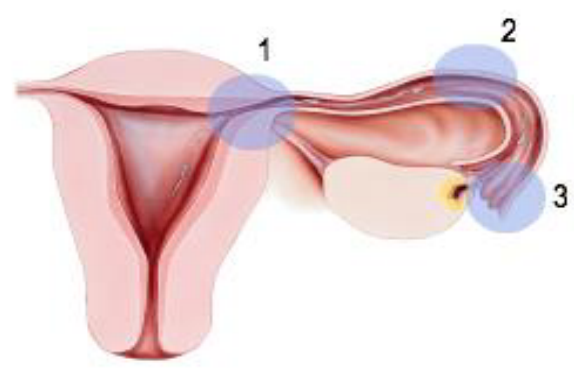

Figure 3. Common positions of tubal adhesions: 1. proximal, 2. midsegment, 3. distal. ${ }^{23}$

In couples male factor infertility causes $20-24 \%$ of the infertility, while female infertility is present in $48-50 \%$, and $40-62.5 \%$ caused by tubal pathology in women who enter secondary or tertiary care. ${ }^{16}$ Women who present themselves with fertility complaints are tested for the presence of $C$. trachomatis antibodies in their blood, because $C$. trachomatis infection can play an important role in the development of TFI. The aim of testing for a chlamydial infection is to select women with high risk of TFI. ${ }^{25}$ Only high risk women need to undergo an invasive laparoscopy to confirm or refute TFI. However, the sensitivity of a C. trachomatis antibody test (CAT) in predicting TFI is currently estimated at $45 \%(28-62 \%)$, which leaves room for improvement. ${ }^{26}$ Therefore possible factors that contribute to the development of TFI are discussed in the next section, since they might offer insights to increase the accuracy of predicting TFI.

\subsection{Possible factors contributing to TFI risk}

There are different models to explain how TFI can be caused by a C. trachomatis infection, which are comprehensively reviewed by Menon et al. (2015). ${ }^{21}$ The most important models discuss: an infection only ascends to the upper reproductive tract in some women (ascension); persistence of the chlamydial infection (persistence), the formation of a local lymphoid follicle resulting in cell damage and fibrosis or scarring (cellular paradigm), and 
cHSP60-induced delayed hypersensitivity. However, the CAT does not test for the course of the infection, instead it tests only for the presence of antibodies due to an infection at any moment in time. Different factors have been studied that could give an indication of the course of an infection. There is a considerable amount of literature that host or pathogen factors contribute to the important role of $C$. trachomatis infection in TFI. ${ }^{18,27}$ Clear individual differences regarding the course of a $C$. trachomatis infection have been illustrated: 1 . symptomatic or asymptomatic course; 2. clearance or persistence of untreated infection; and 3. development of late complications, such as TFI. To explain these differences, it has been documented that host genetic factors contribute to $39 \%$ of the clinical presentation of $C$. trachomatis. $^{28}$ In previous studies, single nucleotide polymorphisms (SNPs) have been associated with $C$. trachomatis infection, especially regarding the susceptibility to infection, presentation of symptoms, and severity of the infection. ${ }^{29}$ There is a convincing body of evidence regarding the importance of immunogenetic factors in the development of TFI. ${ }^{18,21}$

\subsection{Implementing a genetic test}

In the past, genetic advances have had clinical implications for gynecology practice. Genetic testing found some of its first applications in obstetrics and gynecology. More than three decades ago prenatal genetic screening for common birth defects during pregnancy were introduced, which has recently been renewed by the introduction of noninvasive prenatal screening. ${ }^{30,31}$ However, genetic information could potentially be applied to a greater extent in fertility work-up. The implementation of a new genetic test in standard fertility work-up might experience barriers. ${ }^{32}$ Health care professionals performing fertility care are therefore an important stakeholder in the development and application of a genetic test: if the gynecologist does not order the test, it will not be performed in clinical practice. There is no specific information on the attitude of gynecologists towards genetic testing for infertility, but in more general terms health care professionals have reservations about genetic tests, especially considering the clinical utility and cost-effectiveness of tests. ${ }^{33}$

\section{Pushing debate in public health care}

Developments in genetics have not only made their entrance in the clinical field of health care, the public health sector has also been challenged by new opportunities presented. The second field studied in this thesis is therefore population screening programs. New technologies often generate a technology-driven push to implement innovations. Since public health programs are usually funded by governments, this brings complex decisions in policy making to the surface. ${ }^{34}$ One program where these discussions are specifically flaring up is in newborn screening. In this thesis we will focus on bloodspot screening (NBS). In the following sections a historical perspective on NBS will be presented, as well 
as the challenges policy makers are currently debating under the influence of technological developments and stakeholder groups. Three major technological developments will be discussed through time to illustrate the technology-driven expansion in NBS (figure 4): filter paper cards, tandem mass spectrometry (MS/MS), and genetic technologies.

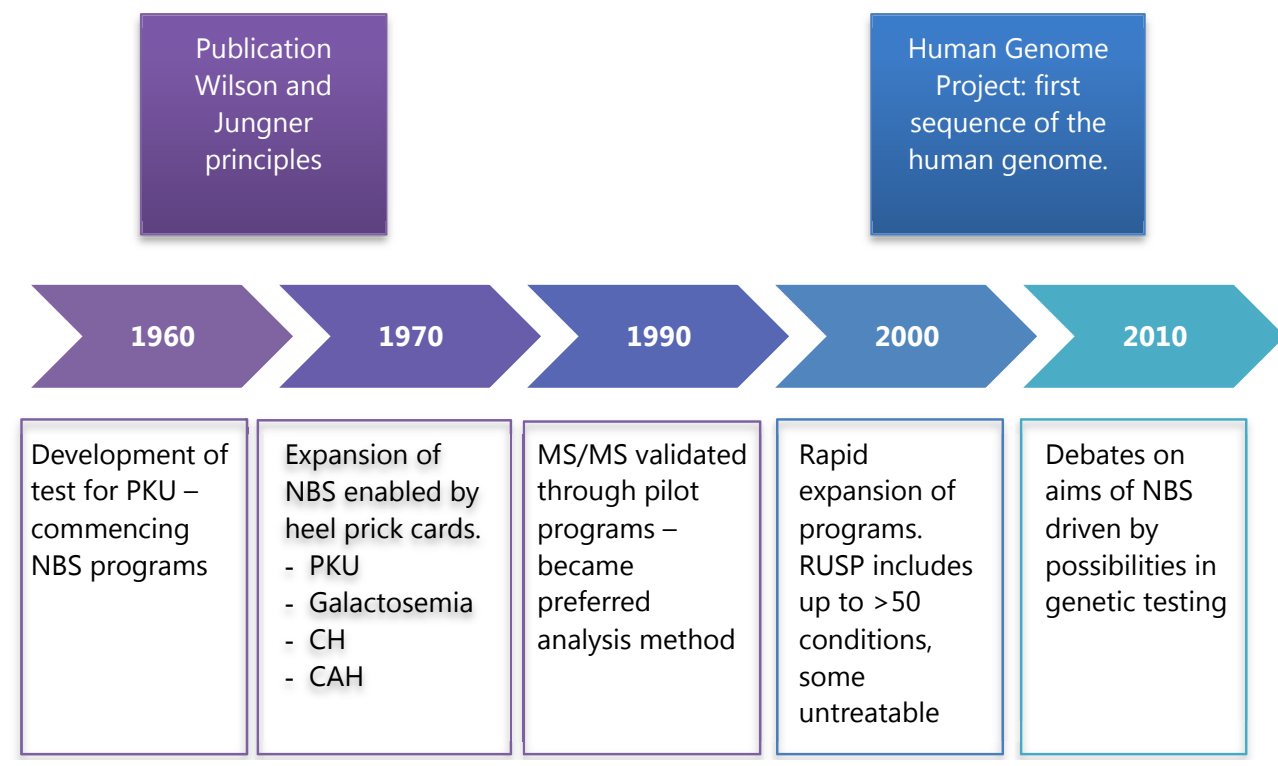

Figure 4. Overview of the technological developments influencing NBS.

$\mathrm{CAH}$ : congenital adrenal hyperplasia; $\mathrm{CH}$ : congenital hypothyroidism; MS/MS: tandem mass spectrometry NBS: newborn bloodspot screening; PKU: phenylketonuria; RUSP: recommended uniform screening panel in the USA.

\subsection{Traditions in newborn bloodspot screening}

NBS is one of the longest running and most successful population screening programs worldwide. ${ }^{35}$ In population screening a test is offered to a seemingly healthy population to identify individuals at high risk of a specific condition. These individuals are identified to offer early treatment, a more effective treatment, or information to improve health outcomes or inform decision making. Traditionally, NBS was focused on conditions that needed immediate treatment in the newborn period. It originated in 1960 from research into screening for phenylketonuria (PKU), a condition that results in mental retardation, unless treated with a restrictive diet from early childhood onwards. ${ }^{36}$ Commencing screening for PKU was largely enabled by the development of Guthrie's filter paper cards. On these cards bloodspots from a heel prick could easily be collected and a centralized approach made it possible to test a large population and facilitated logistics to get samples to the laboratories. 
After starting NBS for PKU, many programs expanded through new screening possibilities. $^{37}$ In the 1970's several countries included galactosemia, congenital hypothyroidism, and congenital adrenal hyperplasia in NBS. The expansion continued through time, with different countries including different conditions in their programs. Currently a great variety in programs exists, not only between countries, but also within countries. ${ }^{35}$ Decision making in NBS usually departs from the principles of Wilson and Jungner. These principles of Wilson and Jungner have been presented by the World Health Organization (WHO) in 1968 (Box 1). ${ }^{38}$ They provide stakeholders in decision making with standards to develop adequate screening programs, such as for cancer and tuberculosis. NBS is no exception to this rule, and the principles of Wilson and Jungner have also been a starting point for decisions on conditions appropriate for NBS.

These principles were designed to evaluate one disease at the time, while NBS screens for multiple diseases at once. Currently NBS is a complex system that can be used to detect over 50 conditions, mainly metabolic, endocrine, or hemoglobin disorders. ${ }^{39}$ The recent expansion in possible conditions for NBS was driven through the development of tandem mass spectrometry (MS/MS). Since the 1990's pilot programs validated MS/MS as an appropriate method for NBS, and it increasingly became the preferred method. As stated earlier, programs have taken different shapes, while they all departed from the same principles. ${ }^{40}$ Different policies as the end-result of policy making based on comparable principles illustrates the multiple ways in which the principles can be translated into health care and a range in approaches to take on this process.

Box 1. Screening principles as formulated by Wilson \& Jungner $(1968)^{38}$

1. The condition sought should be an important health problem.

2. There should be an accepted treatment for patients with recognized disease.

3. Facilities for diagnosis and treatment should be available.

4. There should be a recognizable latent or early symptomatic stage.

5. There should be a suitable test or examination.

6. The test should be acceptable to the population.

7. The natural history of the condition, including development from latent to declared disease, should be adequately understood.

8. There should be an agreed policy on whom to treat as patients.

9. The cost of case finding (including diagnosis and treatment of patients diagnosed) should be economically balanced in relation to possible expenditure on medical care as a whole.

10. Case finding should be a continuing process and not a "once and for all" project. 


\subsection{Tension on current frameworks}

Through the increased possibilities in technology, especially with the introduction of genome-based technologies in health care, the current frameworks of NBS are increasingly challenged. When a population screening program is developed, the benefits should always outweigh the harms. However, gathering information to assess a condition against screening criteria based on the Wilson and Jungner principles is increasingly difficult: the conditions are rare so high level scientific evidence is scarce. ${ }^{41}$ Moreover, harms such as false positives can usually not be completely prevented. Evaluating multiple conditions at once is difficult to enable, since not only the number, but also the type of conditions is developing. The available technologies are potentially allow screening for a wide range of conditions, and they do not always fit the traditional aim of NBS. ${ }^{14}$

Increasingly conditions that have limited treatment options are considered for NBS. The benefits to screen for these conditions stretch beyond the necessity of providing clinical treatment to the newborn, but focus for example on prevention of a diagnostic odyssey and providing parents with reproductive options. Rare and untreatable conditions are increasingly put on the agenda in the policy debate by advocacy groups, for example representing parents with an affected child or health care professionals. Some authors state that NBS will benefit most from a targeted approach ${ }^{42}$, while others claim that NBS is undergoing a shift from public health emergency to public health service. ${ }^{43}$

In practice, a shift from public health emergency to public health service means that other benefits besides direct clinical benefit for the child will be considered. That is, screening will not only be a necessity to prevent permanent health damage in the newborn, but also a service to inform parents about a genetic variant they carry, which may have relevance for future pregnancies. Possibly expanding NBS to include aims beyond the benefit of the child is fraught with complex questions. Not only the test will need to be adequate to implement in NBS, but the government will need to take an informed decision if they consider it their role to offer such a screening program.

A decision to expand the aim of NBS cannot be made solely by the government. ${ }^{11}$ As these programs have impact on healthcare and many people's lives, their perspectives should be included in decision making. Especially when NBS might include genetic tests, a range of ethical, legal, and social implications should be debated with relevant groups of stakeholders. ${ }^{15}$ As an example, the public often has misconceptions about genetic technologies, and concerns about privacy and confidentiality should be communicated. Moreover, when genetic testing for rare conditions is included, individualism may overrule collectivism ${ }^{44}$ : in theory testing all newborns for a condition that only a very small proportion will suffer from, can bring considerable harms to a large proportion of the population. Again, considerations to facilitate a screening program that ensures positive health outcomes for the population, needs perspectives that adequately represent this population. 
Different governments have handled the dynamics in the landscape of NBS differently. While all programs use the Wilson and Jungner principles as a starting points, all countries that have implemented NBS have different programs. ${ }^{35}$ These differences are not only found between countries, but also within countries when their NBS program is managed by different jurisdictions. Of course not all conditions are relevant in all populations due to differences in incidence and prevalence, but it seems that countries also do not use similar decision making to arrive at their policies. ${ }^{45}$ Since genetic technologies may offer screening for even a wider range of conditions, policy making in NBS needs harmonization to ensure equity in access to early care for relevant conditions. ${ }^{8}$

\section{Aim of thesis}

In this thesis possible developments in public health genomics through the availability of new technologies are explored. Fast technological changes are ready for implementation in health care, but evaluation is needed if their implementation will be effective, efficient, robust, and sustainable. Up-to-date and reliable information on key characteristics of new technologies need to be elicited to aid decision makers. As summarized in the ACCEframework, the analytical validity, clinical validity, clinical utility, and ethical, legal, and societal implications need to be studied before a test can be introduced in health care. Furthermore, to be able to include all relevant factors, stakeholders from different backgrounds need to be included in the evaluation process. To ensure successful implementation, stakeholder support is essential. Through incorporating their needs and perspectives in the decision making process this support can be enabled.

Currently C. trachomatis antibodies are tested in fertility work-up to screen for TFI, but the accuracy to identify high risk populations for TFI can be improved. In this clinical setting two new biomarkers to screen for TFI will be studied: one serological marker and one genetic marker. Secondly, screening in the public health sector will be exemplified by NBS. New technologies push debate in NBS to expand the programs globally. In this case, governance regarding NBS will be explored. Not only current policy decisions will be compared, a perspective on shaping policy processes for future review will be outlined.

\section{Outline of the thesis}

Potential innovations in health care based on genomic testing call for evaluation of the analytical validity, clinical validity, clinical utility, and ethical, legal, and societal implications from different stakeholders' perspectives before implementation.

Six research questions regarding innovation in clinical and public health care are addressed in this thesis. The first three questions study innovations in fertility care, looking at two possibilities to increase the accuracy of TFI screening: addition of a serological marker to current fertility work up and the addition of a genetic assay. Since these genetic tests are new to fertility care, the last chapter of part I studies the attitudes 
of gynecologists to use genetic tests in their daily routine. In part II recent and possible future developments in policy making for newborn bloodspot screening are discussed. The first chapter studies relevant topics to frame the policy for an NBS program. The second chapter discusses characteristics of a structured policy framework for NBS, and the third chapter specifically focusses on the public as a stakeholder group in decision making. The outline of both parts is summarized below, with the corresponding central research question per chapter.

Part I

Chapter 1

Chapter 2

Chapter 3

\section{Part II}

Chapter 4

Chapter 5

Chapter 6
Description of current screening for Chlamydia trachomatis-associated tubal factor infertility (TFI), opportunities, and the attitude of health care professionals on the barriers and facilitators to implement a genetic test in this setting.

How does adding the serological marker C-reactive protein to Chlamydia trachomatis antibody testing influence the accuracy of screening for TFI?

What relation can be found between G>A SNP in the 3'UTR of $H L A-A$ for Chlamydia trachomatis symptomatology and severity of infection? Which barriers and facilitators are considered relevant by gynecologists in fertility care regarding the implementation of a genetic test additionally to Chlamydia trachomatis antibody testing to screen for TFI?

Illustration of policy debates in newborn bloodspot screening (NBS) through an international comparison of current processes, and an overview of scientific literature regarding the complex issues facing policy development in NBS.

What are key topics influencing decision making for NBS and how are they discussed internationally in scientific literature and policy documents?

Which elements shape different phases in decision making and how do stakeholder groups play a role?

How can public involvement be defined for NBS policy making? 


\section{References}

1. Wilson BJ, Nicholls SG. The Human Genome Project, and recent advances in personalized genomics. Risk management and healthcare policy. 2015;8:9.

2. Collins F. Has the revolution arrived? Nature. 2010;464(7289):674-675.

3. FDA. Personalized Medicine. 2015; http://www.fda.gov/scienceresearch/special topics/personalizedmedicine/default.htm.

Accessed 27 October 2016

4. Horgan $D$, Jansen $M$, Leyens $L$, et al. An index of barriers for the implementation of personalised medicine and pharmacogenomics in Europe. Public health genomics. 2014;17(6):287-298.

5. PACITA. European Future Panel on Public Health Genomics. 2011;

http://www.pacitaproject.eu/public-healthgenomics/. Accessed 27 October 2015.

6. CDC. Genomic testing - ACCE Model Process for Evaluation Genetic Tests. 2010; http://www.cdc.gov/genomics/gtesting/AC CE/. Accessed 27 October 2015.

7. CDC. Genomic Testing. 2015; http://www.cdc.gov/genomics/gtesting/ind ex.htm\#EGAPP. Accessed 27 October 2015.

8. Potter BK, Avard D, Entwistle V, et al. Ethical, Legal, and Social Issues in Health Technology Assessment for Prenatal/Preconceptional and Newborn Screening: A Workshop Report. Public Health Genomics. 2009;12:4-10.

9. Pinkel D, Albertson DG. Comparative genomic hybridization. Annu. Rev. Genomics Hum. Genet. 2005;6:331-354.

10. WHO. WHO definitions of genetics and genomics. 2015. Accessed 1 November 2015.

11. Avard D, Stanton Jean $M$, Grégoire $G$, Page $M$. Public involvement in health genomics: the reality behind the policies. International
Journal of Consumer Studies.

2010;34(5):508-524.

12. Howard HC, Knoppers BM, Cornel MC, et al. Whole-genome sequencing in newborn screening? A statement on the continued importance of targeted approaches in newborn screening programmes. Eur J Hum Genet. 2015.

13. Borry $P$, Henneman $L$, Lakeman $P$, ten Kate LP, Cornel MC, Howard HC.

Preconceptional genetic carrier testing and the commercial offer directly-toconsumers. Human Reproduction. 2011;26(5):972-977.

14. Bailey DB, Skinner D, Davis AM, Withmarsh I, Powell C. Ethical, Legal, and Social Concerns About Expanded Newborn Screening: Fragile $X$ Syndrome as a Prototype for Emerging Issues. Pediatrics. 2008;121:e693-e704.

15. Andermann A, Blancquaert I, Déry V. Genetic screening: a conceptual framework for programmes and policy-making. J Health Serv Res Policy. 2010;15(2):90-97.

16. Evers JLH. Female subfertility. Lancet. 2002;360:151-159.

17. European Centre for Disease Prevention and Control. Sexually transmitted infections in Europe 2013. Stockholm: ECDC;2015.

18. Morré SA, Karimi O, Ouburg S. Chlamydia trachomatis. identification of susceptibility markers for ocular and sexually transmitted infection by immunogenetics. FEMS Immunology \& Medical Microbiology. 2009;55(2):140-153.

19. Paavonen J, Eggert-Kruse W. Chlamydia trachomatis. impact on human reproduction. Hum Reprod Update. 1999:5(5):433-447.

20. den Hartog JE, Land JA, Stassen FR, Kessels AG, Bruggeman CA. Serological markers of persistent $C$. trachomatis infections in 
women with tubal factor subfertility. Hum Reprod. 2005;20(4):986-990.

21. Menon S, Timms P, Allan A, et al. Human and Pathogen Factors Associated with Chlamydia trachomatis-Related Infertility in Women. Clinical Microbiology Reviews. 2015;28(4):969-985.

22. Trimbos-Kemper TCM, Hoek $A$.

Tubapathologie en kinderwens. 2005; http://www.nvogdocumenten.nl/index.php?pagina =/richtlijn /item/pagina. php\&id $=23962 \&$ richtlijn $\mathrm{id}=5$ $\underline{50 \& u n i q u e}=51 \mathrm{fa} 170 \mathrm{ab} 1768 \mathrm{~b} 54055796 \mathrm{f} 374$ 2fcdb1. Accessed 16 October 2015.

23. Blocked Fallopian Tubes. 2013;

http://natural-fertilitycenters.com/blocked-fallopian-tubes/ Accessed 16 October 2015.

24. Verweij SP, Kebbi-Beghdadi C, Land JA, Ouburg S, Morré SA, G. G. Waddlia chondrophila and Chlamydia trachomatis antibodies in screening infertile women for tubal pathology. Microbes and Infection. 2015; In press.

25. Branković I, van Ess EF, Noz MP, et al. NOD1 in contrast to NOD2 functional polymorphism influence Chlamydia trachomatis infection and the risk of tubal factor infertility. Pathogens and Disease. 2015;73(1):1-9.

26. Price MJ, Ades AE, Welton NJ, et al. How much tubal factor infertility is caused by Chlamydia? Estimates based on serological evidence corrected for sensitivity and specificity. Sexually transmitted diseases. 2012;39(8):608-613.

27. Malogajski J, Brankovic I, Verweij SP, et al. Translational Potential into Health Care of Basic Genomic and Genetic Findings for Human Immunodeficiency Virus, Chlamydia trachomatis, and Human Papilloma Virus. Biomed Research International. 2013:10.

28. Bailey RL, Natividad-Sancho A, Fowler A, et al. Host genetic contribution to the cellular immune response to Chlamydia trachomatis. Heritability estimate from a Gambian twin study. Drugs Today. 2009;45(Suppl B.):45-50.

29. den Hartog JE, Ouburg S, Land JA, et al. Do host genetic traits in the bacterial sensing system play a role in the development of Chlamydia trachomatis-associated tubal pathology in subfertile women? BMC infectious diseases. 2006;6:122.

30. Lippman A. Prenatal genetic testing and screening: constructing needs and reinforcing inequities. Am. JL \& Med. 1991;17:15.

31. McGowan ML, Burant CJ, Moran R, Farrell R. Patient education and informed consent for preimplantation genetic diagnosis: health literacy for genetics and assisted reproductive technology. Genet Med. 2009;11(9):640-645.

32. Teng I, Spigelman A. Attitudes and knowledge of medical practitioners to hereditary cancer clinics and cancer genetic testing. Fam Cancer. 2014;13(2):311-324.

33. ter Meulen V, Boccia S, Cornel M, et al. Direct-to-consumer genetic testing for health-related purposes in the European Union. EASAC Policy Report. 2012;18.

34. Abelson J, Giacomini M, Lehoux P, Gauvin F-P. Bringing 'the public'into health technology assessment and coverage policy decisions: from principles to practice. Health policy. 2007;82(1):37-50.

35. Therrell BL, Padilla CD, Loeber JG, et al. Current status of newborn screening worldwide: 2015. Seminars in Perinatilogy. 2015;39:171-187.

36. Dhondt J. Expanded newborn screening: social and ethical issues. J Inherit Metab Dis. 2010;33(Suppl 2):S211-S217.

37. Dezateux C. Evaluating newborn screening programmes based on dried blood spots: future challenges. British Medical Bulletin. 1998;54(4):877-890.

38. Wilson J, Jungner $G$. Principles and practice of screening. WHO: Geneva. 1968. 
39. ADCHDNC. Recommended Uniform Screening Panel. 2015;

http://www.hrsa.gov/advisorycommittees/ mchbadvisory/heritabledisorders/recomme ndedpanel/index.html. Accessed 27 October 2015.

40. Pollitt RJ. Introducing new screens: Why are we all doing different things? J Inherit Metab Dis. 2007;30:423-429.

41. Andermann A, Blancquaert I, Beauchamp S, Dery V. Revisiting Wilson and Jungner in the genomic age: a review of screening criteria over the past 40 years. Bull World Health Organ [online]. 2008.

42. Bombard Y, Miller FA, Hayeems RZ, et al. Public views on participating in newborn screening using genome sequencing. Eur J Hum Genet. 2014;22(11):1248-1254.
43. Grosse SD, Boyle CA, Kenneson A, Khoury MJ, Wilfond BS. From public health emergency to public health service: the implications of evolving criteria for newborn screening panels. Pediatrics. 2006;117(3):923-929.

44. Boccia S, Mc Kee M, Adany R, et al. Beyond public health genomics: proposals from an international working group. The European Journal of Public Health. 2014:cku142.

45. Burgard $P$, Rupp K, Lindner $M$, et al. Newborn screening programmes in Europe; arguments and efforts regarding harmonization. Part 2 - From screening laboratory results to treatment, follow-up and quality assurance. J Inherit Metab Dis. 2012;35:613-625. 


\section{Chapter 2}

Prediction of tubal factor infertility based on Chlamydia trachomatis antibody testing combined with C-reactive protein as a marker for persistent infection
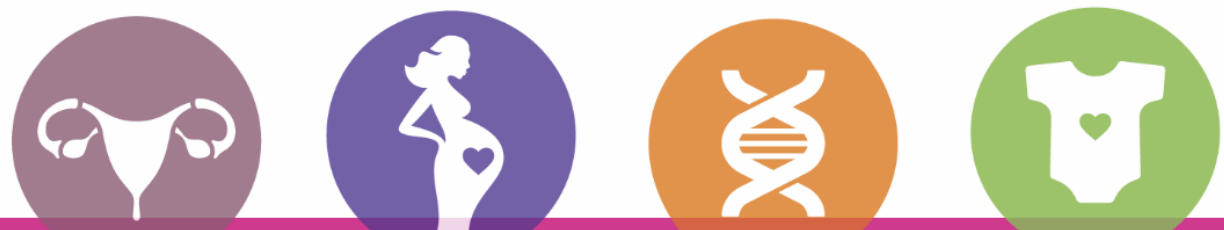

In preparation

Marleen E. Jansen

Eleanne F. van Ess

Sander Ouburg

Jolande A. Land

Servaas A. Morré 


\section{Extended abstract}

Study question: Can we reproduce the findings from Den Hartog et al. (2005) to increase the accuracy of screening for tubal factor infertility (TFI) by adding high sensitivity Creactive protein (hsCRP) to Chlamydia trachomatis antibody testing (CAT) in an independent cohort of women suffering from fertility complaints?

Summary answer: In our cohort we could not confirm the increase in predictive values in screening for TFI through addition of hsCRP to CAT.

What is known already: Untreated Chlamydia trachomatis (CT) infection can cause TFI. There have been promising results combining CAT and a persistent inflammation marker: C-reactive protein (CRP), which could increase accuracy in screening for TFI and may prevent unnecessary invasive laparoscopies.

Study design, size, duration: 613 female patients who visited the fertility clinic of the University Medical Center Groningen were included in the study between 2007 and 2012. 176 women met the inclusion criteria for the current analyses: most importantly they all underwent laparoscopy to test tubal abnormalities.

Participant/materials, settings, method: Serological data was collected by CAT for specific IgG with pELISA, and for CRP using hsCRP testing. TFI diagnosis was based on laparoscopy scores: there were 48 cases -10 suffered double sided TFI.

Main results and the role of chance: For the outcome TFI, we found the following ORs: CAT positive vs negative $1.1(0.6-2.2)$; hsCRP positive vs negative $0.6(0.3-1.1)$; and CAT and hsCRP positive vs negative combined 0.6 (0.2-1.6). Screening for double sided TFI showed significant results for CAT positive vs negative: 7.5 (1.5-36.2)

Limitations, reasons for caution: A different CAT was used than in the study of Den Hartog et al. (2005), furthermore the sample size was smaller, and a considerable amount of our participants were referred for laparoscopy while they had a negative CAT, indicating a possible confounding medical indication to suspect TFI. The study design indicates possible referral and selection bias.

Wider implication of the findings: The results in our study and additional information from literature suggest that re-evaluating the accuracy of pELISA as screening method, and selecting relevant inflammatory factors could prove beneficial in accurate screening for TFI.

Study funding/competing interest(s): This work was supported by: European EuroTransBio Grant [Reference number 110012 ETB]

Key words: Tubal factor infertility; Chlamydia trachomatis, C-reactive protein 


\section{Introduction}

An untreated Chlamydia trachomatis infection may ascend and cause severe upper genital tract pathology, such as tubal factor infertility (TFI) (Gerard, et al., 1998, Sellors, et al., 1988, Tiitinen, et al., 2006). The role of $C$. trachomatis in TFI is well established (Hjelholt, et al., 2011, Horner, et al., 2013, Keltz, et al., 2013, Tiitinen, et al., 2006); elevated levels of C. trachomatis antibodies can be detected in 30-70\% of women with TFI (den Hartog, et al., 2004, Freidank, et al., 1995, van den Broek, et al., 2014). Women who present with infertility are therefore often screened for high or low risk of TFI, based on C. trachomatis IgG antibody testing (CAT) (Coppus, et al., 2011, den Hartog, et al., 2004, Freidank, et al., 1995, Molano, et al., 2005, van den Broek, et al., 2014). Consequently, only CAT-positive women (high risk for TFI) are generally offered an invasive diagnostic procedure, i.e. laparoscopy (Keltz, et al., 2013, Logan, et al., 2003, Veenemans and van der Linden, 2002). This fertility work-up could prevent unnecessary invasive procedures in women in the TFI low risk group. (den Hartog, et al., 2004, Freidank, et al., 1995, van den Broek, et al., 2014) A previously widely used CAT ( $C$. trachomatis IgG micro-immunofluorescence (MIF) test) has been replaced by newer techniques, since MIF is labor intensive, sometimes has cross-reactivity with $C$. pneumonia, the reading is observer dependent, and interlaboratory variation in MIF tests is significant (Peeling, et al., 2000). The newer CAT is the protein enzyme-linked immunosorbent assay (pELISA). pELISA tests are favoured in the fertility work-up, since no significant cross-reactivity has been found with Chlamydia pneumoniae antibodies (Kodaman, et al., 2004, Land, et al., 2003, Price, et al., 2012). Though pELISA has a lower accuracy than MIF in predicting TFI (Horner, et al., 2013, Keltz, et al., 2013, Land, et al., 2003), it is preferred in clinics from a cost-effectiveness point of view (Fiddelers, et al., 2005).

Not all C. trachomatis infections lead to complications, and complications such as TFI are mainly seen after severe, recurrent, and/or persistent $C$. trachomatis infections (Hjelholt, et al., 2011, Molano, et al., 2005). Although the measured IgG antibodies by MIF or pELISA are species-specific for $C$. trachomatis, the presence of IgG antibodies does not reflect the course of infection (Budrys, et al., 2012). IgG C. trachomatis antibodies may be present in serum after a short, fast cleared infection that most likely did not cause TFI, but also after a long persistent infection or multiple infections that might have induced TFI (Hjelholt, et al., 2011). Since C. trachomatis IgG antibodies may be present in serum regardless of the course of infection, it is very difficult to distinguish between high and low risk patients based on CAT only, and a more accurate test (combination) is needed (Tiitinen, et al., 2006).

Several studies look at (combinations of) tests to predict TFI (Budrys, et al., 2012, den Hartog, et al., 2005, Hjelholt, et al., 2011, Logan, et al., 2003, Tiitinen, et al., 2006), e.g. Den Hartog et al. hypothesized that infertile women with slightly raised C-reactive protein (CRP) levels might be more likely to have tubal pathology, because slightly raised CRP levels (1.0-10.0 mg/L) could reflect a persistent inflammation (den Hartog, et al., 2005). 
CRP is an acute phase protein that is excreted by the liver in case of inflammation, and is a marker for tissue damage and infection (Koenig, et al., 1999). There are international reference standards for CRP levels; at concentrations $<1.0 \mathrm{mg} / \mathrm{L}$ acute infections are considered to be absent, and at values $>10.0 \mathrm{mg} / \mathrm{L}$ to be present (den Hartog, et al., 2006, Koenig, et al., 1999, van Woudenbergh, et al., 2013). Slightly elevated CRP levels can be interpreted as chronic low-grade inflammation (den Hartog, et al., 2005, van Woudenbergh, et al., 2013).

In the study of Den Hartog et al., combining a MIF test for C. trachomatis IgG antibody testing with a high-sensitivity (hs) CRP test significantly improved the prognostic value of the CAT. In their study OR increased from 13.9 (CAT only) to 39.7 (combination of CAT and hs-CRP test) (den Hartog, et al., 2005). Patients with a combination of IgG antibodies for $C$. trachomatis and slightly elevated CRP had the highest risk for tubal pathology (den Hartog, et al., 2005). The aim of this study is to evaluate the accuracy of combined testing of CT MOMP IgG with hs-CRP for the prediction of TFI. This will be studied by investigating if the study results from Den Hartog et al. can be confirmed in an independent cohort. However, in our study MIF is replaced by the currently commonly used pELISA. If a test combination with increased test accuracy could be found, the number of invasive and expensive laparoscopies for the evaluation of tubal function might be reduced (Hjelholt, et al., 2011, Molano, et al., 2005).

\section{Methods}

\section{TFI definition}

The following three definitions to cluster the infertility groups were used in this study (Verweij, et al., 2015):

1. TFI negative group: women who have no abnormalities at laparoscopy

2. Intermediate group: women who do have tubal pathology but do not fulfil the criteria to be defined as TFI positive. These women may have any periadnexal adhesions, and/or proximal occlusion of at least one tube.

3. TFI positive group: women who have extensive periadnexal adhesions and/or distal occlusion of at least one tube.

To allow for comparing the present results with those of the study by Den Hartog et al.(den Hartog, et al., 2005), all cases met definition 3, and controls definition 1 or 2. Additionally we compared women with severe TFI (double sided occlusion) to women in groups 1, 2, and women with single sided TFI.

\section{Sample collection}

This study was performed in 613 consecutive female patients who visited the fertility clinic of the University Medical Center Groningen (UMCG) between 2007 and 2012. In all female patients blood was drawn for a chlamydia IgG antibody test (CAT) at their initial visit, and 
spare serum was cryopreserved. If CAT was negative and the patient had an otherwise normal fertility work-up, hysterosalpingography (HSG) was performed to evaluate tubal status. And in case HSG showed abnormalities patients underwent laparoscopy. CATpositive women underwent laparoscopy immediately. To be included in the current study, patient had to have a laparoscopy. The exclusion criterion for the current study was previous pelvic surgery, except for a Caesarean section or an uneventful appendectomy. For all 613 patients CAT results were available (figure 1). After the initial CAT, 457 patients underwent HSG, 176 a laparoscopy. 46 underwent laparoscopy after an abnormal HSG, and 26 were lost to follow-up before evaluation of tubal function. Of the women who underwent laparoscopy, 48 fell in the TFI positive group, 38 in the intermediate group, and 90 had no abnormalities. Therefore, to reproduce Den Hartog's study, 48 cases could be compared to 128 controls.

\section{Ethical approval}

Couples attending the fertility clinic at the UMCG are informed about possible use for research purposes of their anonymised medical data and spare serum samples that have been initially used for diagnostic purposes, and a no-objection procedure is followed. Patients participating in the present study had not objected to their data and sera being used anonymously, and therefore no IRB approval was required (MEC Letter reference: \# 10.17.0046). This procedure is in concordance with the Dutch act "Medical Research Involving Human Subjects" (WMO, Dutch Law).

\section{Serological methods}

For CAT cryopreserved serum samples were used. IgG antibodies to C. trachomatis were detected using pELISA (Medac, Germany). pELISA determines IgG antibodies to the major outer membrane protein (MOMP) of $C$. trachomatis. Positive and negative results were defined according to the manual of the supplier, in line with the arbitrary cut-offs provided. Samples in the grey zone were considered to be negative.

hs-CRP was determined using the CRP ELISA kit (Alpha Diagnostics, USA). The test was used according to the manufacturer's instructions. hs-CRP was used in order to detect low CRP concentrations and levels between 1.0 and $10.0 \mathrm{mg} / \mathrm{L}$ are considered to represent a chronic low-grade inflammation (den Hartog, et al., 2006, van Woudenbergh, et al., 2013).

\section{Statistical analyses}

Descriptive statistics were performed and presented as numbers (\%) or median (range). For comparison of the prevalence of $C$. trachomatis antibodies and hs-CRP in cases and 


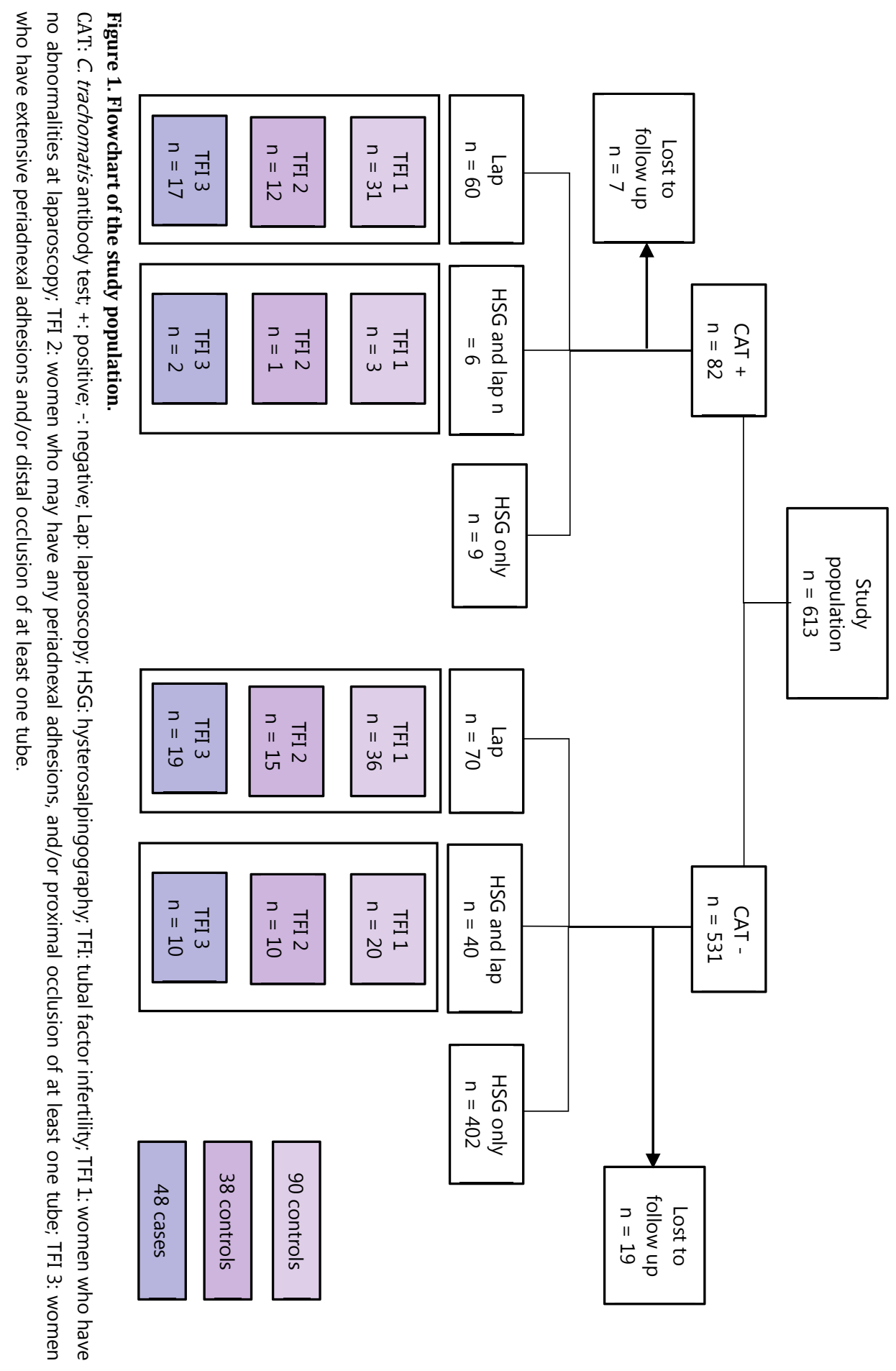


controls, and women with and without TFI respectively, the $\chi 2$-test was used. The prognostic value of single tests as well as test combinations for TFI was determined by calculating sensitivity, specificity, positive predictive value (PPV), negative predictive value (NPV), odds ratio (OR) and 95\% confidence interval (CI). A p-value $<0.05$ was considered statistically significant.

\section{Results}

\section{Study population}

Median age of the study population was 32 (18-41) years. The prevalence of $C$. trachomatis antibodies, hs-CRP and the combination of both was tested as can be seen in table 1. Of the 176 patients that underwent laparoscopy, 110 (62.5\%) were CAT negative and 66 (37.5\%) were CAT positive. Two additional patients were excluded because of missing values on the hs-CRP analyses, for example due to limited serum availability to run the analysis. Therefore the analysis of the hs-CRP test performance and the combined tests were evaluated on 174 sera.

\section{Analysis of seroprevalence}

In none of the groups a statistically significant difference was found between the amount of total TFI positive cases and TFI negative cases (table 1). I.e. the distribution of CT antibodies was not significantly different in cases or controls, as well as the distribution of CRP or the combination of CT antibodies and CRP. However, when comparing women with TFIds to women in the other TFI-groups, the distribution of CT antibodies did differ significantly between the groups ( $p=0.0129$; OR: 7.45; 95\% CI: 1.5-36.2).

Table 1. Seroprevalence (\%) of C. trachomatis and CRP in the study population

\begin{tabular}{llll}
\hline & $\begin{array}{l}\text { TFI + } \\
(\mathbf{n}=\mathbf{4 8})\end{array}$ & $\begin{array}{l}\text { TFIds } \\
(\mathbf{n}=\mathbf{1 0})\end{array}$ & $\begin{array}{l}\text { TFI - } \\
(\mathbf{n}=\mathbf{1 2 8})\end{array}$ \\
\hline CAT + (\%) & $19(39.6)$ & $8(80.0)$ & $47(36.7)$ \\
CRP + (\%) & $24(50.0)$ & $4(40.0)$ & $81(63.3)$ \\
CAT + CRP + (\%) & $9(18.8)$ & $4(40.0)$ & $29(22.66)$ \\
\hline
\end{tabular}

$\mathrm{nCT}=176 ; \mathrm{nCRP}=174 ;$ TFI: tubal factor infertility; + : positive; - negative; ds: double sided CAT: $C$. trachomatis antibody test; CRP: C-reactive protein; CTCRP: both C. trachomatis and C-reactive protein.

\section{Analyses of the test performance}

In table 2 the results of the test performance are summarized. As can be seen, CAT proves to be the best single test to predicts TFIds (OR 7.5; 95\% CI 1.5-36.2), compared to either hs-CRP solely or combined with CAT. Moreover, hs-CRP solely or in combination with CAT did not provide significant results in predicting TFI. When hs-CRP was added to CAT while screening for TFIds, the odds ratio decreased to non-significant prediction (OR 2.4; 95\% CI 0.2-7.7). 


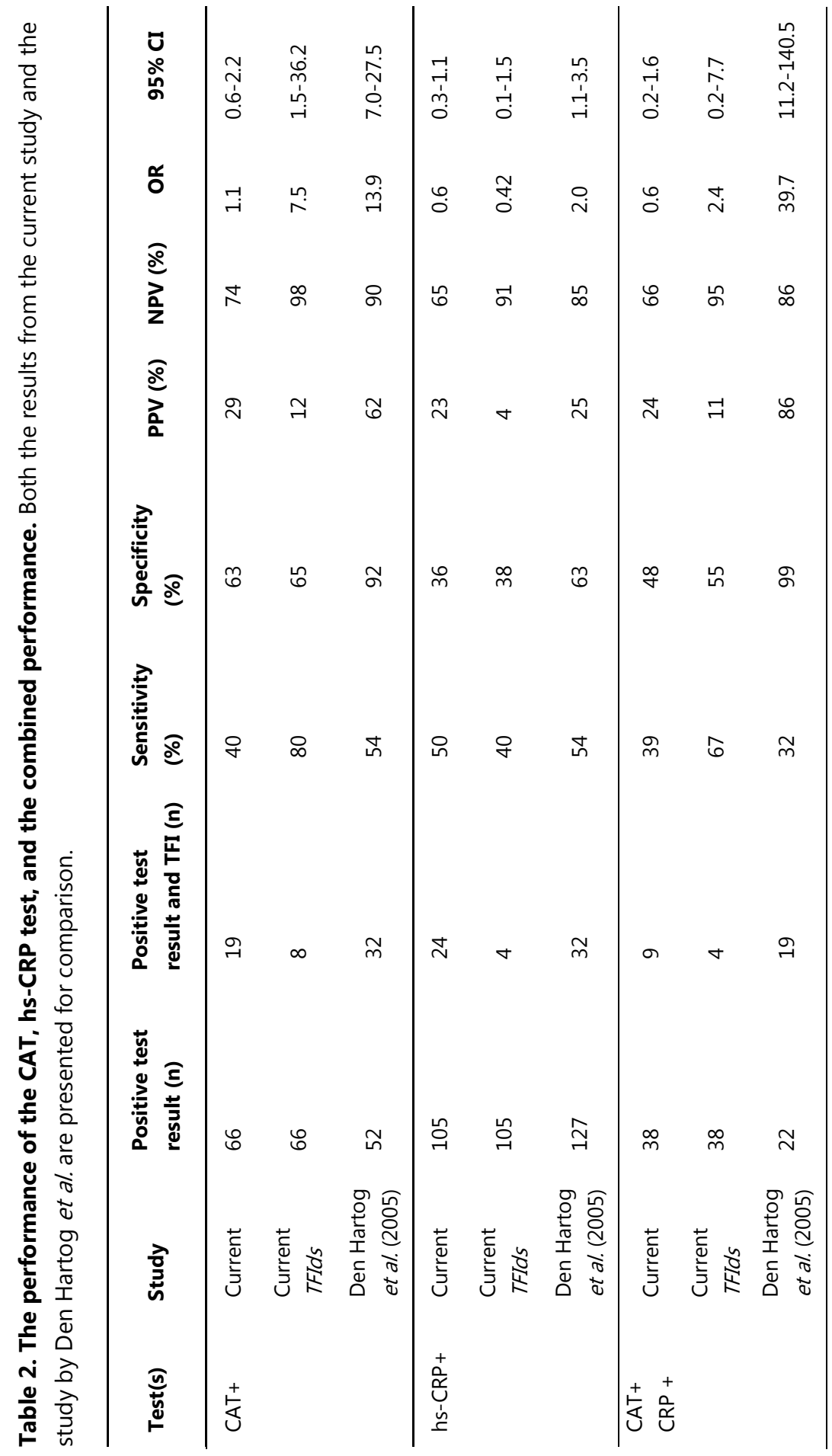




\section{Discussion}

In this study we aimed to evaluate if adding hs-CRP to CAT would improve the prediction of TFI. In doing so, we tried to reproduce the analyses of Den Hartog et al., which yielded promising results for the addition of hs-CRP. However, our study was unable to reproduce the findings of Den Hartog et al. When comparing the results to the results from the previous study (den Hartog, et al., 2005), there were some striking differences. The single CAT was less strong in predicting TFI status (OR 1.1 versus OR 13.9), and the increase in test performance by adding hs-CRP was not observed in our results (OR 0.6 versus $O R$ 39.7). In table 2 it is shown that the sensitivity and the specificity were not comparable, this trend was also observed in the positive predictive values (PPV). Since our definition of TFI was the same, the observed discrepancies may partly be explained by differences in our study population, the test used, and the amount of false positives and negatives, these factors will be explained in the following paragraphs.

First, we used the pELISA CAT, while in the study by Den Hartog et al. the MIF was used (den Hartog, et al., 2005). The MIF has been evaluated as a more accurate test (Horner, et al., 2013, Keltz, et al., 2013, Land, et al., 2003); which could explain why in our study we noticed more false positives, represented in the lower sensitivity (table 2). Furthermore, the hs-CRP test we used also differed from the test used by Den Hartog et al., but it is unlikely that this difference caused a noticeable difference.

Finally, a considerable amount of women who tested C. trachomatis negative, still suffered from TFI $(n=28)$, possibly caused by another medical indication, such as endometriosis (Kodaman, et al., 2004). In our sample all 110 women who tested CT negative, were still referred for a laparoscopy. Women who test CT negative are referred to laparoscopy based on the anamnesis. Since our controls are all referred for a laparoscopy, this could indicate an unknown confounding factor through other medical conditions that might have cause fertility issues.

Limitations for our study design are referral and selection bias. TFI was diagnosed through a laparoscopy, but in order to be eligible for a laparoscopy, women had to test positive for $C$. trachomatis or have another indication to suspect TFI. The referral bias between the determinant and the outcome is hard to prevent, since laparoscopy is not part of the routine fertility work up for all patients. In line with the referral bias, selection bias was hard to prevent in this study design. Since laparoscopy is invasive and expensive, a future study cannot be recommended to perform laparoscopy as a gold standard to evaluate tubal function. A multi-center trial to increase the sample size of both cases and control can be strived for.

Since we did not see a significant difference in women who tested positive for $C$. trachomatis antibodies, and could not increase the test performance to predict TFI, future research should focus on other factors that might be relevant in predicting either TFI in general. This study contributes to the discussed shortcoming of solely CAT-testing in screening for TFI in literature (Hubacher, et al., 2004). However, as we saw in our analysis 
for TFIds, CT antibodies remain an indicator for TFI and CAT might be able to predict severe cases of TFI.

New assays are recently developed to show CT antibodies in serum, for example an Pgp3 ELISA (Wills, et al., 2009), and other pathogen recognition proteins are under study, such as chlamydial type III-secreted effector protein (Wang, et al., 2009). Furthermore, several inflammatory factors to predict the course of CT infection and screen for TFI have been studied, such as heat shock protein 60 (Hjelholt, et al., 2011, Tiitinen, et al., 2006). In addition to the study from Den Hartog et al. and our study (data not shown), cut off values for chronic low-grade inflammation threshold using hs-CRP may also be valuable to vary (den Hartog, et al., 2005, Pearson, et al., 2003, Ridker, et al., 2008). Less invasive approaches have also been studied to predict TFI before doing laparoscopy (Logan, et al., 2003, Veenemans and van der Linden, 2002). Methods are for example taking medical history of past genital tract infections, and transvaginal ultrasound (Hubacher, et al., 2004, Logan, et al., 2003). Unfortunately none of these methods has reached consensus in literature.

Another study approach to assess the course of infection could be genetic markers of the host's immune system (Den Hartog, et al., 2006). 40\% of the variation in the course of infection by $C$. trachomatis can be explained by host genetic markers (Bailey, et al., 2009). If either an added serological or genetic test could reduce the number of invasive and expensive laparoscopic tubal testing, this would have considerable clinical implications, such as preventing unnecessary invasive procedures, cost-reduction, and time saving to diagnosis.

In conclusion, a large number of studies have discussed $C$. trachomatis infection as an important factor in the development of TFI (den Hartog, et al., 2004, Freidank, et al., 1995, Gerard, et al., 1998, Hjelholt, et al., 2011, Horner, et al., 2013, Keltz, et al., 2013, Sellors, et al., 1988, Tiitinen, et al., 2006, van den Broek, et al., 2014). Therefore we also hypothesize that the course of $C$. trachomatis infection still could be of important value to screen for TFI. Due to differences found in our study and the study by Den Hartog et al. (den Hartog, et al., 2005), re-evaluating the pELISA as adequate CAT for screening, and selecting relevant inflammatory factors could prove beneficial in accurate screening for TFI. 


\section{Author's roles}

MEJ performed the analyses and interpretation of the data, searched literature, wrote the article, and revised the article.

EFvE was involved in the literature search of the article.

SO was involved in the analysis of the data and providing statistical expertise.

JAL was involved in the conception and design of the study, provision of samples, and critical revision of the article.

SAM was involved in the conception and design of the study, facilitating laboratorial analysis of the samples, and critical revision of the article.

\section{Conflict of Interest}

Prof. dr. S.A. Morré, fulltime employee of the VU University Medical Center Amsterdam is Founder (2011) and CEO of TubaScan Ltd., a spin-in company of the VU University Medical Center, Dept. of Medical Microbiology and Infection Prevention, Amsterdam, the Netherlands. One on the lines inside TubaScan is one Female Reproductive Health, the line in which the work presented in this manuscript is linked to.

Marleen Jansen has an appointment at the Maastricht University and at TubaScan Ltd. Sander Ouburg has an appointment at the VU University Medical Center Amsterdam and TubaScan Ltd.

None of the other authors report a potential conflict of interest. 


\section{References}

Bailey RL, Natividad-Sancho A, Fowler A, Peeling RW, Mabey DC, Whittle HC, Jepson AP. Host genetic contribution to the cellular immune response to Chlamydia trachomatis. Heritability estimate from a Gambian twin study. Drugs Today 2009;45: 45-50.

Budrys NM, Gong S, Rodgers AK, Wang J, Louden C, Shain R, Schenken RS, Zhong G. Chlamydia trachomatis antigens recognized in women with tubal factor infertility, normal fertility, and acute infection. Obstet Gynecol 2012;119.

Coppus SF, Land JA, Opmeer BC, Steures P, Eijkemans MJ, Hompes PG, Bossuyt PM, van der Veen F, Mol BW, van der Steeg JW. Chlamydia trachomatis IgG seropositivity is associated with lower natural conception rates in ovulatory subfertile women without visible tubal pathology. Hum Reprod 2011;26: 3061-3067.

den Hartog JE, Land JA, Stassen FR, Kessels AG, Bruggeman CA. Serological markers of persistent $C$. trachomatis infections in women with tubal factor subfertility. Hum Reprod 2005;20: 986-990.

den Hartog JE, Land JA, Stassen FR, Slobbevan Drunen ME, Kessels AG, Bruggeman $C A$. The role of chlamydia genus-specific and species-specific IgG antibody testing in predicting tubal disease in subfertile women. Hum Reprod 2004;19: 1380-1384. den Hartog JE, Morré SA, Land JA. Chlamydia trachomatis-associated tubal factor subfertility: immunogenetic aspects and serological screening. Human Reproduction Update 2006;12: 719-730.

Den Hartog JE, Morré SA, Land JA. Chlamydia trachomatis-associated tubal factor subfertility: Immunogenetic aspects and serological screening. Hum Reprod Update 2006;12: 719-730.
Fiddelers AA, Land JA, Voss G, Kessels AG, Severens JL. Cost-effectiveness of Chlamydia antibody tests in subfertile women. Hum Reprod 2005;20: 425-432.

Freidank HM, Clad A, Herr AS, Weidmann-AIAhmad $M$, Jung $B$. Immune response to Chlamydia trachomatis heat-shock protein in infertile female patients and influence of Chlamydia pneumoniae antibodies. Eur J Clin Microbiol Infect Dis 1995;14: 1063 1069.

Gerard HC, Braningan PJ, Balsara GR, Heath C, Minassain SS, Hudson AP. Viability of Chlamydia trachomatis in fallopian tubes of patients with ectopic pregnancy. Fertil Steril 1998;70: 945-948.

Hjelholt A, Christiansen G, Johannesson TG, Ingerslev $\mathrm{HJ}$, Birkelund $\mathrm{S}$. Tubal factor infertility is associated with antibodies against Chlamydia trachomatis heat shock protein 60 (HSP60) but not human HSP60. Hum Reprod 2011;26: 2069-2076.

Horner PJ, Wills GS, Reynolds R, Johnson AM, Muir DA, Winston A, Broadbent AJ, Parker $D$, McClure MO. Effect of time since exposure to Chlamydia trachomatis on chlamydia antibody detection in women: a corss-sectional study. Sex Transm Infect 2013;89: 398-403.

Hubacher D, Grimes D, Lara-Ricalde R, de la Jara J, Garcia-Luna A. The limited usefulness of taking a history in the evaluation of women with tubal factor infertility. Fertil Steril 2004;81: 6-10.

Keltz MD, Sauerbrun-Cutler M-T, Durante MS, Moshier E, Stein DE, Gonzales E. Positive Chlamydia trachomatis serology result in women seeking care for infertility is a negative prognosticator for intrauterine pregnancy. Sex Transm Infect 2013;40: 842-845. 
Kodaman PH, Arici A, Seli E. Evidence-based diagnosis and management of tubal factor infertility. Curr Opin Obstet Gynecol 2004;16: 221-229.

Koenig W, Sund M, Fröhlich M, Fischer H-G, Löwel $H$, Döring A, Hutchinson $W L$, Pepys MB. C-Reactive Protein, a Sensitive Marker of Inflammation, Predicts Future Risk of Coronary Heart Disease in Initially Healthy Middle-Aged Men: Results From the MONICA (Monitoring Trends and Determinants in Cardiovascular Disease) Augsburg Cohort Study, 1984 to 1992. Circulation 1999;99: 237-242.

Land JA, Gijsen AP, Kessels AG, Slobbe ME, Bruggeman CA. Performance of five serological chlamydia antibody tests in subfertile women. Hum Reprod 2003;18: 2621-2627.

Logan S, Gazvani R, McKenzie H, Templeton A, Bhattacharya S. Can history, ultrasound, or ELISA chlamydial antibodies, alone or in combination, predict tubal factor inferility in subfertile women? Hum Reprod 2003;18: 2350-2356.

Molano M, Meijer CJ, Weiderpass E, Arslan A, Posso H, Franceschi S, Ronderos M, Muñoz $\mathrm{N}$, van den Brule AJ. The natural course of Chlamydia trachomatis infection in asymptomatic Colombian women: a 5-year follow-up study. J Infect Dis 2005;191: 907916.

Pearson TA, Mensah GA, Alexander RW, Anderson JL, Cannon RO, Criqui M, FadI YY, Fortmann SP, Hong Y, Myers GL et al. Markers of Inflammation and Cardiovascular Disease: Application to Clinical and Public Health Practice: A Statement for Healthcare Professionals From the Centers for Disease Control and Prevention and the American Heart Association. Circulation 2003;107: 499-511. Peeling RW, Wang SP, Grayston JT, Blasi F, Boman J, Clad A, al. e. Chlamydia pneumoniae serology: interlaboratory variation in microimmunofluorescence assay results. J Infect Dis 2000;181: S426S429.

Price MJ, Ades AE, Welton NJ, Macleod J, Turner K, Simms I, Horner PJ. How much tubal factor infertility is caused by chlamydia? Estimates based on serological evidence corrected for sensitivity and specificity. Sex Transm Infect 2012;39: 608613.

Ridker PM, Danielson E, Fonseca FAH, Genest J, Gotto AM, Kastelein JJP, Koenig W, Libby P, Lorenzatti AJ, MacFadyen JG et al. Rosuvastatin to Prevent Vascular Events in Men and Women with Elevated C-Reactive Protein. New England Journal of Medicine 2008;359: 2195-2207.

Sellors JW, Mahony JB, Chernesky MA, Rath DJ. Tubal factor infertility: an association with prior chlamydial infection and asymptomatic salpingitis. Fertil Steril 1988;49: 451-457.

Tiitinen $A$, Surcel $H-M$, Halttunen $M$, Birkelund $S$, Bloigu A, Christiansen G, Koskela P, Morrison SG, Morrison RP, Paavonen J. Chlamydia trachomatis and chlamydial heat shock protein 60-specific antibody and cell-mediated responses predict tubal factor infertility. Hum Reprod 2006;21: 1533-1538.

van den Broek IV, Land JA, van Bergen JE, Morré SA, van der Sande MA. Chlamydia trachomatis Antibody Testing in Vaginal Mucosal Material versus Blood Samples of Women Attending a Fertility Clinic and an STI Clinic. Obstet Gynecol Int 2014;2014.

van Woudenbergh GJ, Theofylaktopoulou D, Kuijsten A, Ferreira I, van Greevenbroek MM, van der Kallen CJ, Schalkwijk CG, Stehouwer CD, Ocké MC, Nijpels G et al. Adapted dietary inflammatory index and its association with a summary score for low-grade inflammation and markers of glucose metabolism: the Cohort study on Diabetes and Atherosclerosis Maastricht 
(CODAM) and the Hoorn study. The American Journal of Clinical Nutrition 2013;98: 1533-1542.

Veenemans LMW, van der Linden PJQ. The value of Chlamydia trachomatis antibody testing in predicting tubal factor infertility. Hum Reprod 2002;17: 695-698.

Verweij SP, Kebbi-Beghdadi C, Land JA, Ouburg S, Morré SA, G. G. Waddlia chondrophila and Chlamydia trachomatis antibodies in screening infertile women for tubal pathology. Microbes and Infection 2015; In press.

Wang J, Chen L, Chen F, Zhang X, Zhang Y, Baseman J, Perdue $S$, Yeh IT, Shain R, Holland $\mathrm{M}$ et al. A chlamydial type III- secreted effector protein (Tarp) is predominantly recognized by antibodies from humans infected with Chlamydia trachomatis and induces protective immunity against upper genital tract pathologies in mice. Vaccine 2009;27: 2967-2980.

Wills GS, Horner PJ, Reynolds R, Johnson AM, Muir DA, Brown DW, Winston A, Broadbent AJ, Parker D, McClure MO. Pgp3 Antibody Enzyme-Linked Immunosorbent Assay, a Sensitive and Specific Assay for Seroepidemiological Analysis of Chlamydia trachomatis Infection. Clinical and Vaccine Immunology 2009;16: 835-843. 


\section{Chapter 3}

Potential protective effect of a G $>$ A SNP in the 3'UTR of HLA-A for Chlamydia trachomatis symptomatology and severity of infection
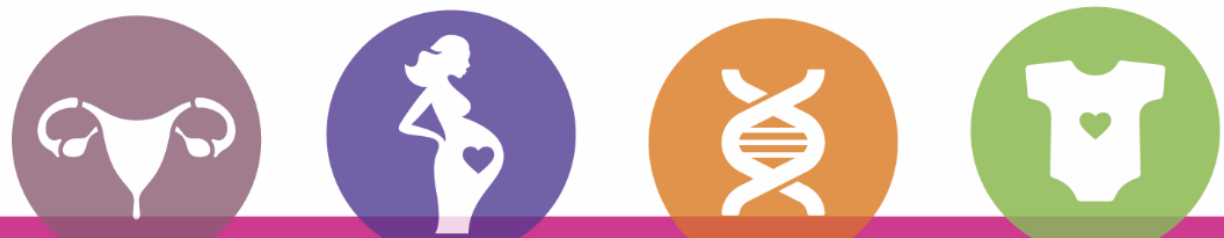

Pathogens and Disease (2015, pit: ftv116)

Marleen E. Jansen

Ivan Branković

Joke Spaargaren

Sander Ouburg

Servaas A. Morré 


\begin{abstract}
The inter-individual differences in response to Chlamydia trachomatis (CT) infections are for an important part based on the differences in our host genetic make-up. In the past, several genes and pathways have been identified and linked to protection against or risk for CT infection (i.e. susceptibility), and/or the severity of infection, with a major emphasis on the development of tubal pathology, one of the main causes of female infertility. In the current study we analyzed in Dutch Caucasian women whether the carriage of HLAA G > A SNP (rs1655900) was related to the susceptibility of CT infection in a STD cohort $(n=329)$ and to the severity of infection in a subfertility cohort $(n=482)$. We also investigated if this A-allele was linked to increase in severity of symptoms, from mild symptoms (lower genital infection) to lower abdominal pain (upper genital tract infection) to the most severe late complication of tubal pathology, including double sided tubal pathology. We showed that the carriage of HLA-A SNP rs1655900 studied is not associated with the susceptibility to CT infection based on the data from the STD cohort, but might be protective to the development of late complications $(p=0.0349)$, especially tubal pathology could be relevant.
\end{abstract}

Key words: Chlamydia trachomatis, SNP; HLA; host genetic factors; tubal pathology; susceptibility 


\section{Introduction}

Chlamydia trachomatis infection is the most prevalent sexually transmitted disease (STD), and the prevalence of the infection is on the rise globally, with roughly 100 million new infections occurring each year (Starnbach \& Roan, 2008, Vasilevsky et al., 2014). Untreated $C$. trachomatis can lead to pelvic inflammatory disease, ectopic pregnancy and infertility due to tubal pathology (Wizel et al., 2008). However, remarkable differences in the clinical course of infection with $C$. trachomatis are observed between different individuals (Morré et al., 2009). For these differences, environmental factors such as coinfections may play a role (Hillis et al., 1994), but the differences can also be attributed to immunogenetic characteristics of the host. Understanding the immune mechanisms that underlie the pathogenesis of $C$. trachomatis infection has major implications for diagnostic and therapeutic approaches.

During a $C$. trachomatis infection adaptive immune responses are initiated, activating CD4+ and CD8+ T cells (Geisler, 2010, Neefjes et al., 2011). The role of CD8+ T cells has received increased interest due to the intracellular nature of $C$. trachomatis (Starnbach et al., 2003, Wizel et al., 2008). Pathogen-derived factors of $C$. trachomatis that access the host's cytosol are explored by several studies, since intracellular proteins are presented on the cell surface by Human Leukocyte Antigen class I (HLA-I), triggering CD8 + T cell response (Kim et al., 1999, Fling et al., 2001, Starnbach et al., 2003, Gervassi et al., 2004). Fling et al. for example found CD8+ T cells to recognize a protein associated with the inclusion membrane of the vacuole $C$. trachomatis which is confined in within the host cell (Fling et al., 2001).A CD8 + T cell response involves induction of apoptosis of the infected cell through perforin and granzyme, enabling the cytolytic potential of CD8+ $T$ cells. However, it has been found that $C D 8+T$ cells in the female genital tract have limited perforin expression, downgrading their cytolytic potential during an initial $C$. trachomatis infection (Ibana et al., 2012). Variance in CD8+ T cell functionality was not found to have a significant influence on the clearance of a $C$. trachomatis infection, but it was found to influence the development of pathogenesis, including infertility (Igietseme et al., 2009, Murthy et al., 2011).

Adequate pathogen recognition is essential to initiate the immune response. There is substantial evidence that host genetic variation affects the clinical course of infection with C. trachomatis (Den Hartog et al., 2006, Bailey et al., 2009, Jiang et al., 2012, Al-Kuhlani et al., 2014). At this point these factors appear to be the most promising biological indicators of complication after a chlamydial infection (Ouburg et al., 2009, Malogajski et al., 2013, Brankovic et al., 2014). Associations with particular single nucleotide polymorphisms (SNPs) are typically confirmed for genes coding for a range of immunological factors, such as cytokines, chemokines, and antigen presentation components (Morré et al., 2000).

Successful presentation of chlamydial antigens enables the highly selective process of triggering a lymphocytic response. Determining the role of antigen 
presentation and elicitation of the immune responses is of crucial significance for the currently insufficient understanding of the immunopathology of genital infection with $C$. trachomatis (Geisler, 2010). A number of alleles and sub-alleles in HLA genes have been found to be associated with susceptibility to chlamydial infection or associated pathologies (Morré et al., 2009). Since CD8 + T cells have been found to play an important role in complications after a C. trachomatis infection (Igietseme et al., 2009, Murthy et al., 2011, Ibana et al., 2012), a SNP in the gene region coding for HLA-I will be the focus of this study. A previous study presented by Kapil et al. stated that HLA-DQB1*05 had a protective effect for reinfection ( $p=0.012$, OR 2.6, 95\% CI 1.2-5.6) (Kapil et al., 2013). In 2013 this work was presented orally at the STD \& Aids World Congress and the $H L A-A$ SNP rs 1655900 was also presented as a possible candidate in their study in 199 African American subjects. We found the presented rs number to link to an SNP in the 3'UTR of $H L A-A$ (ALFRED, 2014). We studied this SNP ( $H L A-A$ rs1655900) in relation to 1 ) the susceptibility of genital infection with $C$. trachomatis, 2) occurrence of symptoms, and 3) for the severity of symptoms to the most severe form of double sided tubal pathology in infertile women.

\section{Methods}

\section{STD cohort}

From a previous described cohort of 1150 Dutch Caucasian women, sufficient DNA was available from 329 samples to type the HLA-A SNP rs1655900 (Ouburg et al., 2005). In summary, between 2000-2004 data was collected from female patients who visited the STD outpatient clinic in Amsterdam, The Netherlands. Questionnaires responses were gathered about urogenital complaints, varying from increased discharge, having bloody discharge during and/or after coitus, recent lower abdominal pain (LAP) - not gastrointestinal or menstruation-related - and/or dysuria. C. trachomatis status was assessed by Roche Amplicor PCR as previously described (Ouburg et al., 2005). Out of the 329 women, 128 (28\%) were C. trachomatis positive (CT+) and 201 (61\%) were C. trachomatis negative (CT-). Out of the CT+ women, 72 (56\%) were asymptomatic, 56 (44\%) were symptomatic and 16 (13\%) had LAP.

\section{Subfertility cohort}

From 482 serum samples from Dutch Caucasian women SNP data were available. These women were attending the fertility clinic of the University Medical Center Groningen, the Netherlands, and met the inclusion criteria for this study: C. trachomatis antibody test (CAT) result available, laparoscopic and/or hysterosalpingography (HSG) data available. Of the 482 serum samples, 286 (88.0\%) were CT- and 58 (12.0\%) were CT+ (pELISA, Medac Diagnostika mbH, Hamburg, Germany). Tubal Pathology (TP) was defined as extensive periadnexal adhesions and/or distal occlusion of at least one tube. From 58 women who 
tested positive for $C$. trachomatis, 11 (19\%) were diagnosed with TP. In this group 55\% were diagnosed with single sided TP (TPss) and 45\% double sided TP (TPds). 348 (72\%) women were diagnosed TP negative (TP-) through HSG. Of the CT+ women, 13 did not fulfill the criteria of TP and were not analyzed, of the CT- women 77 belonged to the HSG-0 group, which means that they were either not assessed, had mild HSG positivity but without reference to laparoscopy or other reasons, and were therefore not analyzed.

\section{METC approval}

The act "Medical Research Involving Human Subjects" (WMO, Dutch Law), states that anonymous spare human materials and data may be used for research purposes after patients have been informed about this possible use and they have had the opportunity to object. All patients participating in the present study had not objected and therefore no ethical approval is required (MEC Letter reference: \# 10.17.0046).

\section{DNA isolation and SNP assessment}

DNA was isolated with the High Pure PCR Template Preparation Kit (HPPTP Kit) according to the manufacturer's instructions (Roche Molecular, Mannheim, Germany). For the STD cohort 200 microliter cervical swab was resuspended in $1 \mathrm{ml} 2 \mathrm{SP}$, and for the subfertility cohort 200 microliter sera. The HLA-A G>A SNP rs1655900 was assessed using RT-PCR with detection on the LightCycler II (Roche Diagnostics, Basel, Switzerland) for the GG, $A G$ and $A A$ genotypes.

\section{Statistical analyses}

In the STD cohort CT + and CT- women were compared to each other, and within the CT+ group women with and without symptoms were compared. In the subfertility cohort the CT-TP- and the CT+TP + were compared to each other, as well as women with and without tubal pathology within the $\mathrm{CT}+$ group. To study increased severity the following groups were compared for a trend in the occurrence of the $H L A-A$ SNP studied: $C T+$ women with symptoms, to CT+ women with LAP, to women with TPss, and to women with TPds.

Data were compared between groups using Chi-square test and Fisher's Exact test when appropriate. Risk factors were described as odds ratio (OR) with 95\% confidence interval (CI). P-values < 0.05 were considered statistically significant. Analyses were performed using IBM SPSS Statistics. The regression coefficient ( $\mathrm{r} 2)$ for the line between $\mathrm{CT}+$ women with symptoms, LAP, TPss, and TPds was calculated in Microsoft Office Excel. In general, the higher the $\mathrm{r} 2$, the better the model fits the data. $80 \%$ explained variation is considered good, $>90 \%$ is a very good fitting line and an association can be assumed. 


\section{Results}

The $H L A-A$ SNP G>A (rs1655900) are shown in Table 1. The STD and Subfertility cohorts were in Hardy Weinberg Equilibrium.

\section{STD cohort: susceptibility to infections}

There were no significant associations with the $H L A-A$ SNP studied, between the CT+ and $\mathrm{CT}$ - women enrolled in this cohort or between those with and without symptoms (table 1). The distribution of the genotypes ( $G G, G A, A A)$ is comparable in the two groups.

\section{Subfertility Cohort: severity of infection}

Women who tested negative for $C$. trachomatis and who had a negative result on the HSG were compared to women with $C$. trachomatis and tubal pathology for the occurrence of the $H L A-A$ rs $1655900{ }^{*} \mathrm{~A}$. In this comparison a protective trend is seen for women with the A-allele versus women with the G-allele (table 1 ), since there are relatively more women with the A-allele in the CT- group. In the CT-group there are $34 \%$ (127 GA\&AACT-HSG-/378 GG\&GA\&AACT-HSG-) versus 9\% (1 GA\&AACT+TP+/11 GG\&GA\&AACT+TP+). The same protective trend was observed when solely looking at CT+ women with and without tubal pathology 38\% (13 GA\&AATP-/34 GG\&GA*AATP-) versus 9\% (1 GA\&AACT+TP+/11 GG\&GA\&AACT+TP+). Remarkably, iIn all women with TP $(n=11)$, all women with TPds $(n=5)$ had the wildtype genotype (table 1 and figure 1$)$.

Table 1. Genotype distribution of rs1655900 in susceptibility and severity cohorts.

\begin{tabular}{|c|c|c|c|c|c|c|c|c|c|}
\hline & & & \multicolumn{7}{|c|}{ RS1655900 G>A } \\
\hline & & & GG & $\%$ & GA & $\%$ & AA & $\%$ & Tot. \\
\hline \multirow[t]{5}{*}{ Susceptibility } & CT- & & 139 & 69.2 & 54 & 26.9 & 8 & 4.0 & 201 \\
\hline & $\mathrm{CT}+$ & & 91 & 71.1 & 33 & 25.8 & 4 & 3.1 & 128 \\
\hline & & AS & 51 & 70.8 & 17 & 23.6 & 4 & 5.6 & 72 \\
\hline & & $\mathrm{S}$ & 28 & 70.0 & 12 & 30.0 & 0 & 0.0 & 40 \\
\hline & & LAP & 12 & 75.0 & 4 & 25.0 & 0 & 0.0 & 16 \\
\hline \multirow[t]{6}{*}{ Severity } & CT- & & 286 & 67.5 & 115 & 27.1 & 23 & 5.4 & 424 \\
\hline & & CT- HSG- & 229 & 66.0 & 97 & 28.0 & 21 & 6.1 & 347 \\
\hline & $\mathrm{CT}+$ & & 42 & 72.4 & 14 & 24.1 & 2 & 3.4 & 58 \\
\hline & & $C T+T P+s . s$. & 5 & 83.3 & 0 & 0.0 & 1 & 16.7 & 6 \\
\hline & & $C T+T P+$ d.s. & 5 & 100.0 & 0 & 0.0 & 0 & 0.0 & 5 \\
\hline & & TP- & 21 & 61.8 & 13 & 38.2 & 0 & 0.0 & 34 \\
\hline
\end{tabular}

CT: C. trachomatis, AS: Asymptomatic; S: Symptomatic; LAP: Lower Abdominal Pain; TP: Tubal Pathology; s.s.: Single-Sided occlusion; d.s.: Double-Sided occlusion; +: positive; -: negative 
Increasing severity of infection among $C T+$ women

The occurrence of the carriage of $H L A-A$ rs $1655900{ }^{*} \mathrm{~A}$ in patient groups with increasing severity - from $C T+$ women with symptoms to $C T+$ women with TPds - showed a statistically significant regression coefficient $(r 2)$ of $0.932(P=0.0349)$ (figure 1$)$. This suggests that there is a correlation between the mutant allele and a less severe disease progression.

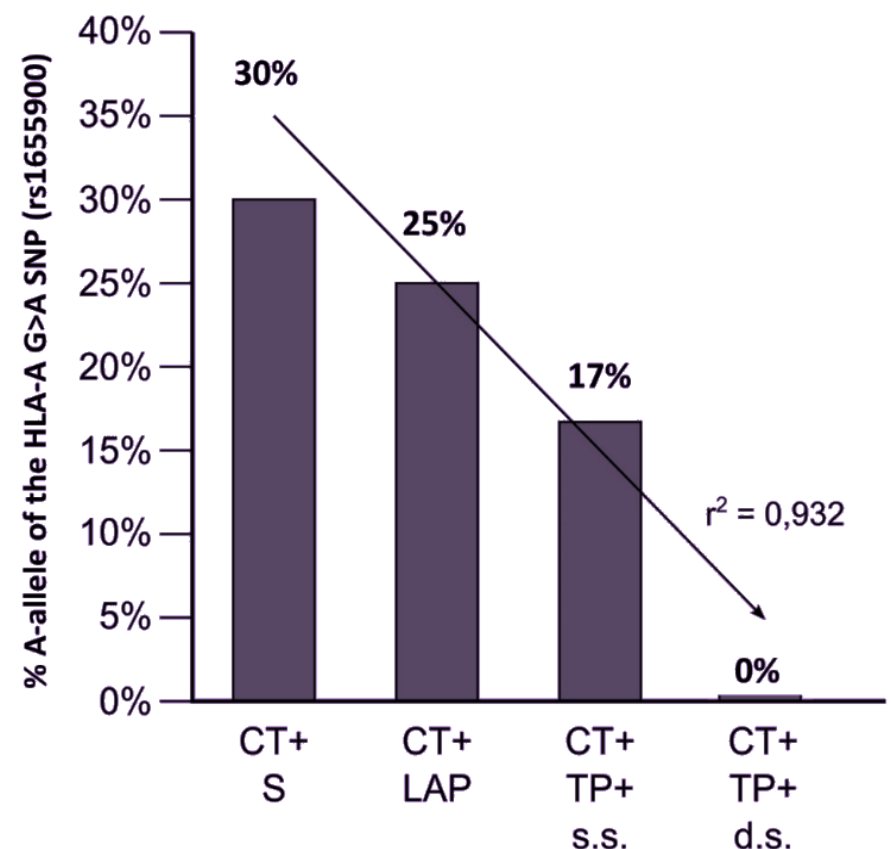

Figure 1: Carriership of rs1655900 *A (proportion GA and AA) in C. trachomatis negative and positive women shows a decreasing trend in $C$. trachomatis induced complications.

CT: C. trachomatis, HSG: Hysterosalpingography; AS: Asymptomatic; S: Symptomatic; LAP: Lower Abdominal Pain; TP: Tubal Pathology; s.s.: Single-sided occlusion of the tubae; d.s.: double-sided occlusion of the tubae. Black line: trend based on the severity of Chlamydia infections.

\section{Discussion}

When analyzing the carriage of $H L A-A$ rs $1655900{ }^{*} \mathrm{~A}$ in patient groups with respectively an increasing degree of general and mild symptoms, LAP, TPss and TPds, we observed a decreasing trend of carriage fo the A-allele in our cohorts. Our findings point to a protective role of allele $A$ over $G$, especially for symptoms and late complications in women who tested positive for $C$. trachomatis ( $r 2$ : 0.932; $\mathrm{P}=0.0349$ ). 
The SNP lies in the 3'UTR intergenic region of $H L A-A$ gene, which encodes for the heavy chain of the heterodimeric HLA-I molecule. The 3'UTR region is not translated into the protein sequence, hence the SNP is unable to lead to a change of amino acids. It may, however, work by changing the level of post-transcriptional expression. A seemingly protective effect observed in our study would correspond to a reduction of expression of $H L A-A$ transcript, resulting in less assembled HLA-I dimers and insufficient antigen presentation. A long-term consequence would be lower inflammation levels and less damage incurred by immune reactions to the local tissue. Even though chlamydial bodies are sequestered from the host cell cytosol by vacuole membranes, CD8+ T cells specific for the major outer membrane protein (MOMP) of $C$. trachomatis have been detected in the blood of patients with a genital infection (Kim et al., 1999). CD8+ T cells contribute to immune defense against $C$. trachomatis (Wizel et al., 2008), however excessive cytolytic activity of these cells and the accompanying inflammation may be a major factor to contribute to the tubal damage and scarring (Cohen \& Brunham, 1999, Vasilevsky et al., 2014). Nevertheless, what Reddy et al. reported is a significant increase in the number of CD8 + T cells in Chlamydia-positive infertile women versus Chlamydia-negative women (Reddy et al., 2004), which does point to their role in Chlamydia-related complications. Therefore, alleles of the HLA genes whose protein products present chlamydial antigens more successfully are expected to lead to a more pronounced inflammation and vice versa.

Our results indicate that the number of patients carrying $A$-allele increases based on the presence of symptoms, LAP, and the degree of tubal damage. These findings would be congruent with a carriage of such allele that impairs antigen presentation to CD8+ T cells. The CD8 + T cells are specifically important in the immune response leading to infertility, and less perforin and tumor necrosis factor $\alpha$ production could protect the host from tissue damage (Murthy et al., 2011, Ibana et al., 2012). The implications of this type of study are, however, insufficient to make firm conclusions about biological mechanisms at hand and the findings warrant further studies. In earlier studies, other immunogenetic factors such as SNPs have been showed to be associated with the course of infection of C. trachomatis (Den Hartog et al., 2006, Morré et al., 2009, Ouburg et al., 2009). The current study contributes to the promising implications of SNPs as biological indicators in the diagnosis of complicated chlamydial infection (Malogajski et al., 2013, Brankovic et al., 2014).

Our study has several limitations. Most importantly, the precise function of rs1655900 is unknown based on the available literature. The reported findings could well be the outcome of the base change in the region involved in regulation of translation, however we might instead be observing the effect of another polymorphism that is in strong linkage to the examined SNP. Since HLA-A is not simply an HLA class 1a locus, it is an HLA class Ia locus embedded within HLA class Ib genes and its tightest linkage to nonself is with HLA class $1 b$, meaning a simple explanation on neither its function nor its 
potential linkage is easy to be given or analyzed. Furthermore, despite the considerable size of our total cohort in comparison to previous studies, the size of our severity groups does not offer sufficient statistical power.

It would therefore be valuable to attempt a reproduction of this study in a cohort with a higher number of patients with increasing symptomatology and especially tubal pathology. Also, functional analysis of the consequence of the base substitute on $H L A-A$ expression levels would be useful to potentially corroborate these findings. In conclusion, the $H L A-A \mathrm{G}>\mathrm{A}$ SNP studied is not associated with the susceptibility to infection but appears protective to the development of late complications, especially tubal pathology, after a Chlamydia trachomatis infection.

\section{Funding}

This work was supported by the following grants: Dutch NGI Life Sciences Pre-Seed Grant [Registration number 93611006]; USA NIH R21 Grant Prime [award number 1R21AI.098660-01; subaward number 0025996 (120407-1)] the European EuroTransBio Grant [Reference number 110012 ETB], and the Eurostars grant [ESTAR15106].

\section{Conflict of Interest}

Ivan Branković has an appointment at Maastricht University and TubaScan Ltd. Marleen Jansen has an appointment at Maastricht University and at TubaScan Ltd.

Prof. dr. S.A. Morré, fulltime employee of the VU University Medical Center Amsterdam is Founder (2011) and CEO of TubaScan Ltd., a spin-in company of the VU University Medical Center, Dept. of Medical Microbiology and Infection Prevention, Amsterdam, the Netherlands. One on the lines inside TubaScan is one Female Reproductive Health, the line in which the work presented in this manuscript is linked to.

Sander Ouburg has an appointment at the VU University Medical Center Amsterdam and TubaScan Ltd.

None of the other authors report a potential conflict of interest.

\section{Acknowledgements}

We want to thank the Public Health Laboratory, Cluster Infectious Diseases, Public Health Service Amsterdam (Amsterdam, the Netherlands) for the STD cohort included in this study. We want to thank Prof. dr. J.A. Land for the tuba factor infertility cohort enrolled in this study. We want to thank R. Heijmans, BASc for advice on HLA. 


\section{References}

Al-Kuhlani M, Rothchild J, Pal S, de la Maza LM, Ouburg S, Morré SA, Dean D \& Ojcius DM (2014) TRAIL-R1 Is a Negative Regulator of Pro-Inflammatory Responses and Modulates Long-Term Sequelae Resulting from Chlamydia trachomatis Infections in Humans. PLoS ONE 9: e93939.

ALFRED (2014) Polymorphism Information. The Allele Frequency Database. Available through:

http://alfred.med.yale.edu/alfred/recordin fo.asp? condition = sites. site uid =\%27SI 224 $\underline{966 \mathrm{D}}$

Bailey RL, Natividad-Sancho A, Fowler A, Peeling RW, Mabey DC, Whittle HC \& Jepson AP (2009) Host genetic contribution to the cellular immune response to Chlamydia trachomatis. Heritability estimate from a Gambian twin study. Drugs Today (Barc) 45: 45-50.

Brankovic I, Malogajski J \& Morré SA (2014) Biobanking and translation of human genetics and genomics for infectious diseases. Applied \& Translational Genomics 3: 30-35.

Cohen CR \& Brunham RC (1999) Pathogenesis of Chlamydia induced pelvic inflammatory disease. Sexually transmitted infections 75: 21-24.

Den Hartog JE, Ouburg S, Land JA, Lyons JM, Ito JI, Peña AS \& Morré SA (2006) Do host genetic traits in the bacterial sensing system play a role in the development of Chlamydia trachomatis-associated tubal pathology in subfertile women? BMC infectious diseases 6: 122

Fling SP, Sutherland RA, Steele LN, Hess B, D'Orazio SEF, Maisonneuve J-F, Lampe MF, Probst P \& Starnbach MN (2001) CD8+ T cells recognize an inclusion membraneassociated protein from the vacuolar pathogen Chlamydia trachomatis.
Proceedings of the National Academy of Sciences 98: 1160-1165

Geisler WM (2010) Duration of untreated, uncomplicated Chlamydia trachomatis genital infection and factors associated with chlamydia resolution: a review of human studies. Journal of Infectious Diseases 201: S104-S113.

Gervassi AL, Grabstein $\mathrm{KH}$, Probst P, Hess B, Alderson MR \& Fling SP (2004) Human CD8+ T Cells Recognize the 60-kDa Cysteine-Rich Outer Membrane Protein from Chlamydia trachomatis. The Journal of Immunology 173: 6905-6913.

Hillis SD, Nakashima A, Marchbanks PA, Addiss DG \& Davis JP (1994) Risk factors for recurrent Chlamydia trachomatis infections in women. American journal of obstetrics and gynecology 170: 801-806.

Ibana JA, Myers L, Porretta C, Lewis M, Taylor SN, Martin DH \& Quayle AJ (2012) The major CD8 T cell effector memory subset in the normal and Chlamydia trachomatisinfected human endocervix is low in perforin. BMC immunology 13: 66.

Igietseme JU, He Q, Joseph K, Eko FO, Lyn D, Ananaba G, Campbell A, Bandea C \& Black CM (2009) Role of T lymphocytes in the pathogenesis of Chlamydia disease. Journal of Infectious Diseases 200: 926934Jiang J, Karimi O, Ouburg S, Champion CI, Khurana A, Liu G, Freed A, Pleijster J, Rozengurt N \& Land JA (2012) Interruption of CXCL13-CXCR5 axis increases upper genital tract pathology and activation of NKT cells following chlamydial genital infection.

Kapil R, Tang J, Press C \& Geisler W (2013) 001 1 Association of Genetic Variants with Chlamydia trachomatis Reinfection. Sexually Transmitted Infections 89: A26A26. 
Kim S-K, Angevine M, Demick K, Ortiz L, Rudersdorf $R$, Watkins $D$ \& DeMars $R$ (1999) Induction of HLA Class I-Restricted CD8+ CTLs Specific for the Major Outer Membrane Protein of Chlamydia trachomatis in Human Genital Tract Infections. The Journal of Immunology 162: 6855-6866.

Malogajski J, Brankovic I, Verweij SP, Ambrosino E, van Agtmael MA, Brand A, Ouburg S \& Morré SA (2013) Translational potential into health care of basic genomic and genetic findings for human immunodeficiency virus, Chlamydia trachomatis, and human papilloma virus. BioMed research international 2013. Article ID 892106

Morré S, Rozendaal L, Van Valkengoed I, Boeke A, van Voorst Vader P, Schirm J, De Blok S, Van den Hoek J, Van Doornum G \& Meijer C (2000) Urogenital Chlamydia trachomatis serovars in men and women with a symptomatic or asymptomatic infection: an association with clinical manifestations? Journal of Clinical Microbiology 38: 2292-2296.

Morré SA, Karimi O \& Ouburg S (2009) Chlamydia trachomatis. identification of susceptibility markers for ocular and sexually transmitted infection by immunogenetics. FEMS Immunology \& Medical Microbiology 55: 140-153.

Murthy AK, Li W, Chaganty BK, Kamalakaran S, Guentzel MN, Seshu J, Forsthuber TG, Zhong G \& Arulanandam BP (2011) Tumor necrosis factor alpha production from CD8+ $T$ cells mediates oviduct pathological sequelae following primary genital Chlamydia muridarum infection. Infection and immunity 79: 2928-2935.

Neefjes J, Jongsma ML, Paul P \& Bakke O (2011) Towards a systems understanding of $\mathrm{MHC}$ class I and MHC class II antigen presentation. Nature Reviews Immunology 11: 823-836.

Ouburg S, Spaargaren J, den Hartog JE, Land JA, Fennema JSA, Pleijster J, Peña AS, Morré SA \& the Ic (2005) The CD14 functional gene polymorphism $-260 \mathrm{C}>\mathrm{T}$ is not involved in either the susceptibility to Chlamydia trachomatis infection or the development of tubal pathology. BMC Infectious Diseases 5: 114-114.

Ouburg S, Lyons J, Land J, den Hartog J, Fennema J, de Vries $\mathrm{H}$, Bruggeman $\mathrm{C}$, Ito J, Pena A \& Lundberg P (2009) TLR9 KO mice, haplotypes and CPG indices in Chlamydia trachomatis infection. Drugs of Today 45: 83.

Reddy BS, Rastogi S, Das B, Salhan S, Verma S \& Mittal A (2004) Cytokine expression pattern in the genital tract of Chlamydia trachomatis positive infertile womenimplication for T-cell responses. Clinical \& Experimental Immunology 137: 552-558.

Starnbach MN \& Roan NR (2008) Conquering sexually transmitted diseases. Nature Reviews Immunology 8: 313-317.

Starnbach MN, Loomis WP, Ovendale P, Regan D, Hess B, Alderson MR \& Fling SP (2003) An inclusion membrane protein from Chlamydia trachomatis enters the $\mathrm{MHC}$ class I pathway and stimulates a CD8+ T cell response. The Journal of Immunology 171: 4742-4749.

Vasilevsky S, Greub G, Nardelli-Haefliger D \& Baud D (2014) Genital Chlamydia trachomatis. understanding the roles of innate and adaptive immunity in vaccine research. Clinical microbiology reviews 27 : 346-370.

Wizel B, Nyström-Asklin J, Cortes C \& Tvinnereim A (2008) Role of CD8+ T cells in the host response to Chlamydia. Microbes and Infection 10: 1420-1430. 


\section{Chapter 3}

The attitudes of Dutch gynecologists towards the addition of genetic testing in screening of tubal factor infertility
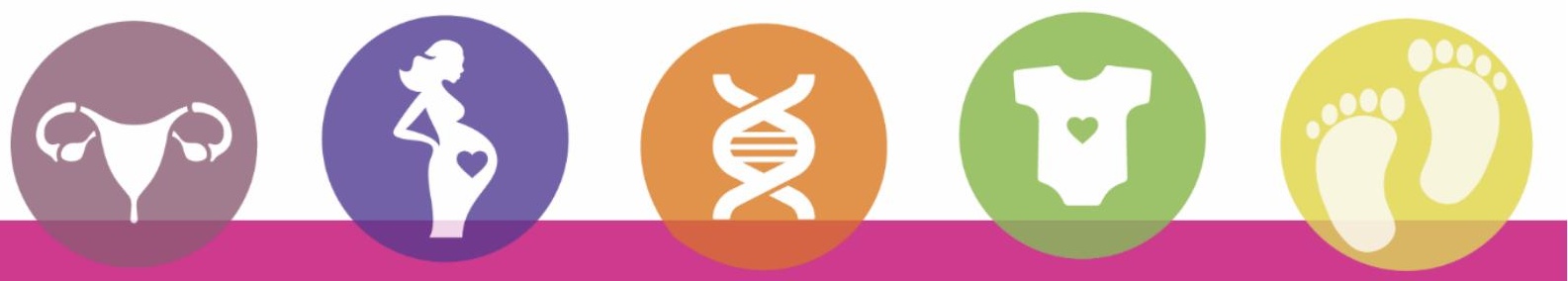

Submitted

Jelena Malogajski Marleen E. Jansen

Sander Ouburg Elena Ambrosino

Caroline B. Terwee Servaas A. Morré 


\section{Abstract}

Objective The aim of this study is to identify elements perceived by Dutch gynecologists as barriers and facilitators for the introduction of genetic testing in the routine screening for tubal pathology, and to identify respondents' attitudes toward the use of genetic information in the fertility work up.

Study design Both qualitative and quantitative methods (mixed method) were used in this study. The study was performed in two phases, qualitative interviews in the first phase, and quantitative questionnaires in the second. Within the first phase, experienced reproductive specialists working in four Dutch Academic Hospitals were interviewed. The results of these interviews were used to develop a questionnaire. This questionnaire was used in the second phase to survey medical doctors working at OB/GYN departments and providing fertility care in six (75\%) Dutch Academic hospitals.

Results $61.7 \%$ of respondents stated that the addition of genetic markers to the Chlamydia trachomatis antibody test (CAT) in the screening for tubal pathology would increase the screening accuracy. Asked about the need for additional training, aiming to refresh their knowledge of clinical genetics, prior to introduction of the test $68.8 \%$ of respondents agreed they would require it. Clinical utility was recognized as the most import indicator of the quality of a genetic test. Results showed that $94.7 \%$ the respondents, regardless of their position at the department or the hospital they work indicated cost-effectiveness as an important factor in gaining their support for the new screening strategy.

Conclusions In summary, respondents showed a positive attitude towards the implementation of a genetic test combined with CAT for tubal factor infertility (TFI) screening. To gain their support for the new screening strategy the majority of respondents agreed that cost-effectiveness is an important factor. Comprehensive research about economic implications of the introduction of genomic markers should be the next important step in the implementation strategy.

Key words: tubal factor infertility, Chlamydia trachomatis, genetic test, screening, attitudes 


\section{Introduction}

The importance of genetic information in appropriate clinical management of diseases is increasing. ${ }^{1,2}$ Using genetic information in routine clinical practice to provide high quality healthcare is one of the major hallmarks of personalized medicine. Advances in genetics have had clinical implications for gynecology practice. Indeed, genetic testing found its first application in obstetrics/gynecology (OB/GYN) more than three decades ago with prenatal genetic screening for common birth defects during pregnancy. ${ }^{3}$ More recently, preimplantation genetic screening has been introduced in the field of assisted reproductive medicine, aiming to improve pregnancy rates in women older than 35 undergoing in vitro fertilization. ${ }^{4}$ Additionally, genetic testing for the assessment of a patient's risk for hereditary breast and ovarian cancer is a routine in obstetric and gynecologic practice. ${ }^{5}$ However, to date genetic information has not been used in fertility work up.

One in six couples worldwide are suffering from infertility [6]. In up to $30 \%$ of all cases infertility is attributed to tubal factors. ${ }^{7}$ As much as $28-62 \%$ of tubal pathology can be linked to a previous Chlamydia infection. ${ }^{8}$ Despite the fact that chlamydial infections are in most cases asymptomatic, and therefore not treated with antibiotics, almost half of the women without symptoms clear the infection without any treatment within a year. ${ }^{9}$ However, other women are prone to persistent infections and consequent complications such as pelvic inflammatory disease, ectopic pregnancy and tubal factor infertility (TFI). ${ }^{10}$ Genetic variations, involved in the recognition of Chlamydia and in the initiation of an adequate immune response can contribute to higher or lower risk of Chlamydia induced TFI. ${ }^{11,} 12$ Identifying and correlating them with infection outcomes, offers an opportunity for the development of a new TFI screening strategy which could be more accurate in identifying patients at low or high risk of having tubal pathology. ${ }^{13-15}$

At the moment, Chlamydia trachomatis antibody test (CAT) and Hysterosalpingography (HSG) are the most commonly used screening tests for TFI in the routine fertility work up in the Netherlands. They are followed by laparoscopy as the reference diagnostic. Sensitivity and specificity of the most accurate CATs are assessed at approximately $60 \%$ and $85-90 \%$ respectively, ${ }^{16}$ for HSG these numbers are $53 \%$ and $87 \% .{ }^{17,} 18$ Therefore, there is room for an increase in accuracy of TFI screening. Combining CAT testing with genetic testing early in the fertility work up could increase the accuracy of such screening and contribute to better triage of women for laparoscopy.

Ultimately though, the ability of genomics to have an impact on clinical practice depends on clinicians' knowledge and attitudes regarding genetic tests. Clinicians make decisions about ordering genetic tests and they are also responsible for interpreting and explaining the results to the patients. ${ }^{19}$ Measuring their experiences and attitudes towards the use of genetic tests is increasingly recognized as an important tool for understanding barriers and facilitators for the use of genetic information in diagnosis and treatment of diseases. ${ }^{20-23}$ 
The aim of this study is to identify elements perceived by Dutch gynecologists as barriers and facilitators for the introduction of genetic testing in the routine screening for TFI and to identify respondents' attitudes toward the use of genetic information in the fertility work up.

\section{Materials and Methods}

The study was performed in two phases, qualitative interviews in the first phase, and quantitative questionnaires in the second. Within the first phase, experienced reproductive specialists working in four Dutch Academic Hospitals were interviewed. The results of these interviews were used to develop a questionnaire. This questionnaire was used in the second phase to survey medical doctors working at OB/GYN departments and providing fertility care in six (75\%) Dutch Academic hospitals.

\section{Interviews}

Four semi structured interviews were conducted with gynecologists working in Dutch academic hospitals in February and March 2013. The purpose of these interviews was twofold: establishing the status quo of fertility work up in the Netherlands, and gain insight into the barriers and facilitators of implementing a genetic test in this work up. The interviews explored a) the topic of infertility investigation in general, b) current guidelines and practices in the screening for TFI, and c) potential facilitators and barriers for broad implementation of genetic testing in the diagnosis of TFI. Three interviews were conducted face-to-face and one via Skype. All the interviews were recorded and later transcribed. The transcripts of interviews were analyzed by coding them for recurring topics. The topics resulting from the interview analysis served as basis to develop the questionnaire.

\section{Development of the questionnaire}

From the interviews four themes were identified as relevant for the quantitative questionnaire. Each of the themes was further elaborated by defining important elements within them. The themes were: 1) the added value of genetic testing for routine diagnostics, 2) the characteristics of the test, 3) patient's preferences for non-invasive testing, and 4) possible issues around gynecologists' roles and competences related to the introduction of genetic testing in routine fertility work up. For each theme several relevant barriers and facilitators were identified from the interview data. The elements were then translated into statements to elicit participants' attitudes through the perceived barriers and facilitators.

In order to assure content validity of the questionnaire the development followed an iterative process. The revisions of the questionnaire were based on multiple rounds of 
feedback from an experienced gynecologist and an epidemiologist with expertise in the development and evaluation of health care outcome measures.

The final draft of the questionnaire consisted of 10 questions and 14 statements, divided in 3 sections. In the first section we asked the respondents six questions about their demographics and level of professional experience. In the second section participants were asked four questions related to immunogenetic research of $C$. trachomatis and its possible implications for the clinical practice. Finally, in the third section we asked the respondents to express their attitudes regarding the possible introduction of a genetic test (see table 2 in Results). They scored each statement by expressing how strongly they agreed or disagreed with it. Each statement had a 5-point Likert scale (agree - disagree), and no opinion as response alternatives.

\section{Conducting the survey}

Data was gathered from Academic hospitals in Amsterdam, Groningen, Maastricht, Rotterdam, and Utrecht in the period from May 2014 to July 2015. These visits were organized during department meetings in consultation with the chiefs of the OB/GYN department of each hospital. The participation in the survey was voluntary. The questionnaire was distributed to the gynecologists and other health professionals attending the meetings, and was filled in and returned on the spot.

\section{Analysis}

First the demographics from section 1 were described followed by the answers to the questions on addressing genetic testing in TFI diagnosis in section 2. For section 3, each statement and corresponding answers are shown in bar diagrams, representing the relative responses on the statements. Furthermore, the items in section 3 were analyzed using SPSS 22.0 (IBM). Recommended descriptive analyses for Likert scales were performed, summarizing the mode and frequencies. Furthermore bivariate analyses were performed to study differences for scoring on each item between current position, years of experience, and hospital the respondents worked at.

\section{Results}

The questionnaire was answered by 94 medical doctors and other healthcare professionals working at the OB/GYN departments of 6 Dutch Academic Hospitals. Out of the total number of participants 7 worked at Academisch Medisch Centrum Amsterdam (AMC), 15 at Vrije Universiteit Medisch Centrum (VUMC), 17 at Universitair Medisch Centrum Groningen (UMCG), 19 at Maastricht Universitair Medisch Centrum (MUMC), 21 at Erasmus Medisch Centrum (Erasmus MC), and 12 at Universitair Medisch Centrum Utrecht (UMCU). 


\section{Demographics (questionnaire section 1)}

The main characteristics of the participants are summarized in table 1 . Answering the question about their position at the department most respondents checked the box "Other" (39.3\%), followed by resident physicians (25.5\%). Respondents who checked the box "Other" mostly worked as IVF and fertility specialists at OB/GYN departments. Categorized to age groups, most participants were between 25 and 35 years old $(51.1 \%)$, and $84 \%$ were female. $50 \%$ of the respondents had $0-5$ years of experience in their position, and $5.3 \%$ had more than 20 years of experience.

\section{Implications for the clinical practice (questionnaire section 2)}

$66.0 \%$ of participants agreed that genetic information could be used in the routine screening of $C$. trachomatis induced infertility. $69.1 \%$ of the respondents believed that a combination of CAT and genetic markers will increase the sensitivity of infertility diagnosis. $61.7 \%$ would support the introduction of a genetic test in the screening for TFI. Regarding the location where the combination of tests (CAT and genetic markers test) should be performed, $79.8 \%$ of respondents agreed that the testing should be performed by the gynecologist in the hospital.

Table 1. Respondents (\% male) per hospital categorized to position and years of experience $(n=$ 94).

\begin{tabular}{lcclllll}
\hline Hospital & AMC & VUMC & UMCG & MUMC & Erasmus MC & UMCU & Total \\
\hline Position & & & & & & & \\
\hline Intern & $1(0.0)$ & $1(0.0)$ & $2(0.0)$ & $5(20.0)$ & $1(0.0)$ & $0(0.0)$ & $10(10.0)$ \\
\hline Resident physician & $1(0.0)$ & $2(50.0)$ & $6(0.0)$ & $7(0.0)$ & $4(25.0)$ & $4(25.0)$ & $24(12.5)$ \\
\hline Physician & $0(0.0)$ & $0(0.0)$ & $1(0.0)$ & $2(50.0)$ & $0(0.0)$ & $0(0.0)$ & $3(33.3)$ \\
\hline Gynecologist & $2(0.0)$ & $4(50.0)$ & $5(0.0)$ & $3(66.7)$ & $3(66.7)$ & $3(33.3)$ & $20(35.0)$ \\
\hline Other & $3(33.3)$ & $8(0.0)$ & $6(16.7)$ & $2(0.0)$ & $13(7.7)$ & $5(0.0)$ & $37(8.1)$ \\
\hline Years of experience in current position & & & & & \\
\hline $0-5$ & $5(0.0)$ & $6(0.0)$ & $10(0.0)$ & $14(14.3)$ & $7(0.0)$ & $5(20.0)$ & $47(6.4)$ \\
\hline $5-10$ & $0(0.0)$ & $2(50.0)$ & $6(0.0)$ & $3(33.3)$ & $9(22.2)$ & $3(0.0)$ & $23(17.4)$ \\
\hline $10-20$ & $2(50.0)$ & $6(16.7)$ & $3(33.3)$ & $1(0.0)$ & $5(40.0)$ & $2(50.0)$ & $19(31.6)$ \\
\hline$\geq 20$ & $0(0.0)$ & $1(100)$ & $1(0.0)$ & $1(100)$ & $0(0.0)$ & $2(0.0)$ & $5(40.0)$ \\
\hline Total & $7(14.3)$ & $15(20.0)$ & $20(5.0)$ & $19(21.1)$ & $21(19.0)$ & $12(16.7)$ & $94(15.0)$ \\
\hline
\end{tabular}

AMC: Academisch Medisch Centrum Amsterdam; VUMC: Vrije Universiteit Medisch Centrum; UMCG: Universitair Medisch Centrum Groningen; MUMC: Maastricht Universitair Medisch Centrum; Erasmus MC: Erasmus Medisch Centrum; UMCU: Universitair Medisch Centrum Utrecht 


\section{Attitudes (questionnaire section 3)}

The mode of four statements holds more than $50 \%$ of the responses (table 2): established cost-effectiveness (statement 5); importance of clinical utility (statement 7); proven clinical validity and utility (statement 8); and patients' preference for non-invasiveness of testing (statement 9). In the bivariate analyses it was shown that neither position, years of experience, or hospital the respondents worked at significantly influenced the scoring on the items (data not shown).

$61.7 \%$ of the respondents found that genetic testing would increase the screening accuracy of TFI, but less than half agreed that genetic testing has a potential to lower the number of false negative and false positive results. When it comes to their opinion about the effect that genetic testing would have on the time to diagnosis $43.6 \%$ of participants disagreed with the statement that the combination of genetic test and CAT, would in fact prolong this time. $26.6 \%$ expressed the attitude that the combination of tests would increase the time to diagnosis.

94. $70 \%$ of the respondents would support the introduction of a genetic test in everyday clinical practice, prerequisite its cost-effectiveness (statement 5), more than half of them (56.4\%) also expressed that genome-based tests are too expensive (figure 1). Further, $91.5 \%$ of the respondents agreed or partially agreed that clinical utility and $89.3 \%$ that clinical validity are the main measures of quality for a genetic test (figure 1 ). $73.4 \%$ of participants stated that their patients have a preference for non-invasive testing. However, it appears that only $47.3 \%$ of respondents would honor their patients' preferences.

Although recognized in interviews as a potential barrier in acceptance of genetic testing, the diminished role of gynecologists in TFI screening in case of introduction of genetic testing was not identified as such by the majority of respondents. $16.1 \%$ of respondents found that the addition of genetic testing would diminish their role. Finally, $68.8 \%$ of the respondents stated that they would require additional training if a genetic test would be added to TFI screening (figure 1). 
Table 2. Each statement and the score that was given most (mode) with the related frequency $(n=$ 94).

\begin{tabular}{|c|c|c|c|}
\hline \multicolumn{2}{|c|}{ Statement } & \multirow{2}{*}{$\begin{array}{l}\text { Mode } \\
\text { Partly agree }\end{array}$} & \multirow{2}{*}{$\begin{array}{l}\text { Frequency (\%) } \\
43(45.7)\end{array}$} \\
\hline 1 & $\begin{array}{l}\text { Introducing genomic testing in the infertility investigation } \\
\text { would increase the diagnostic accuracy of the diagnosis of } \\
\text { tubal pathology. }\end{array}$ & & \\
\hline 2 & $\begin{array}{l}\text { Introducing genomic testing in the infertility investigation } \\
\text { would lower the number of false negative/false positive results. }\end{array}$ & Partly agree & $30(31.9)$ \\
\hline 3 & $\begin{array}{l}\text { The genome-based companion diagnostic would increase the } \\
\text { time to diagnosis of tubal pathology. }\end{array}$ & Disagree & $27(28.7)$ \\
\hline 4 & Genome-based tests are too expensive. & Partly agree & $39(41.5)$ \\
\hline 5 & $\begin{array}{l}\text { I would support the introduction of this genetic test in everyday } \\
\text { clinical practice if it is cost-effective. }\end{array}$ & Agree & $56(59.6)$ \\
\hline 6 & $\begin{array}{l}\text { The main measure of a quality of a genetic test is the strength } \\
\text { of association that determines the test's ability to accurately } \\
\text { and reliably identify or predict the disorder of interest (clinical } \\
\text { validity) }\end{array}$ & Partly agree & $46(48.9)$ \\
\hline 7 & $\begin{array}{l}\text { The main measure of quality of a genetic test is its improved } \\
\text { health outcome, based on diagnosis and subsequent } \\
\text { intervention (clinical utility) }\end{array}$ & Agree & $52(55.3)$ \\
\hline 8 & $\begin{array}{l}\text { I would support the introduction of this genetic test in everyday } \\
\text { clinical practice, prerequisite being proven clinical validity and } \\
\text { utility. }\end{array}$ & Agree & $61(64.9)$ \\
\hline 9 & My patients would have a preference for non-invasive testing. & Agree & $49(52.1)$ \\
\hline 10 & My patients would prefer a genetic test instead of an HSG. & Agree & $30(31.9)$ \\
\hline 11 & $\begin{array}{l}\text { My patients would prefer a laparoscopy instead of a genetic } \\
\text { test. }\end{array}$ & Disagree & 30 (31.9) \\
\hline 12 & $\begin{array}{l}\text { I would honor my patients' preference for testing in the } \\
\text { diagnosis of tubal patency. }\end{array}$ & Partly agree & $39(41.5)$ \\
\hline 13 & $\begin{array}{l}\text { I would need training if a genetic test is added to the } \\
\text { diagnostics of infertility. }\end{array}$ & Partly agree & $43(43)$ \\
\hline 14 & $\begin{array}{l}\text { If a clinical geneticist would be involved in the diagnosis of } \\
\text { subfertility, I would feel that the role of the gynecologists } \\
\text { would be diminished. }\end{array}$ & Disagree & $34(36.2)$ \\
\hline
\end{tabular}




\section{Opinions respondents}

\section{Statements}

1. Introducing genomic testing in the infertility investigation would increase the diagnostic accuracy of the diagnosis of tubal pathology.

2. Introducing genomic testing in the infertility investigation would lower the number of false negative/false positive results.

3. The genome-based companion diagnostic would increase the time to diagnosis of tubal pathology.

4. Genome-based tests are too expensive.

5. I would support the introduction of this genetic test in everyday clinical practice if it is cost-effective.

6. The main measure of quality of a genetic test is the test's ability to accurately and reliably identify or predict the disorder of interest (clinical validity).

7. The main measure of quality of a genetic test is its improved health outcome, based on diagnosis and subsequent intervention (clinical utility).

8. I would support the introduction of this genetic test in everyday clinical practice, prerequisite being proven clinical validity and utility.

9. My patients have a preference for non-invasive testing.

10. My patients would prefer a genetic test instead of HSG.

11. My patients would prefer a laparoscopy instead of a genetic test.

12. I would honor my patients' preference for testing in diagnosis of tubal patency.

13. If a clinical geneticist would be involved in the diagnostics of subfertility, I would feel that the role of the gynecologist would be diminshed.

14. I would need a training if a genetic test is added to the diagnostics of subfertility.

$\begin{array}{llllllllllllll}0 & 5 & 10 & 15 & 20 & 25 & 30 & 35 & 40 & 45 & 50 & 55 & 60 & 65\end{array}$

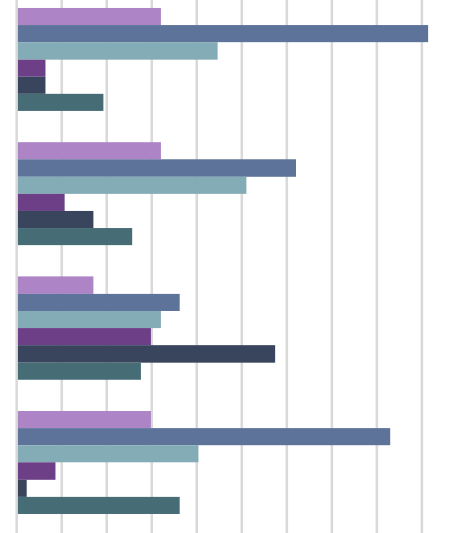

1
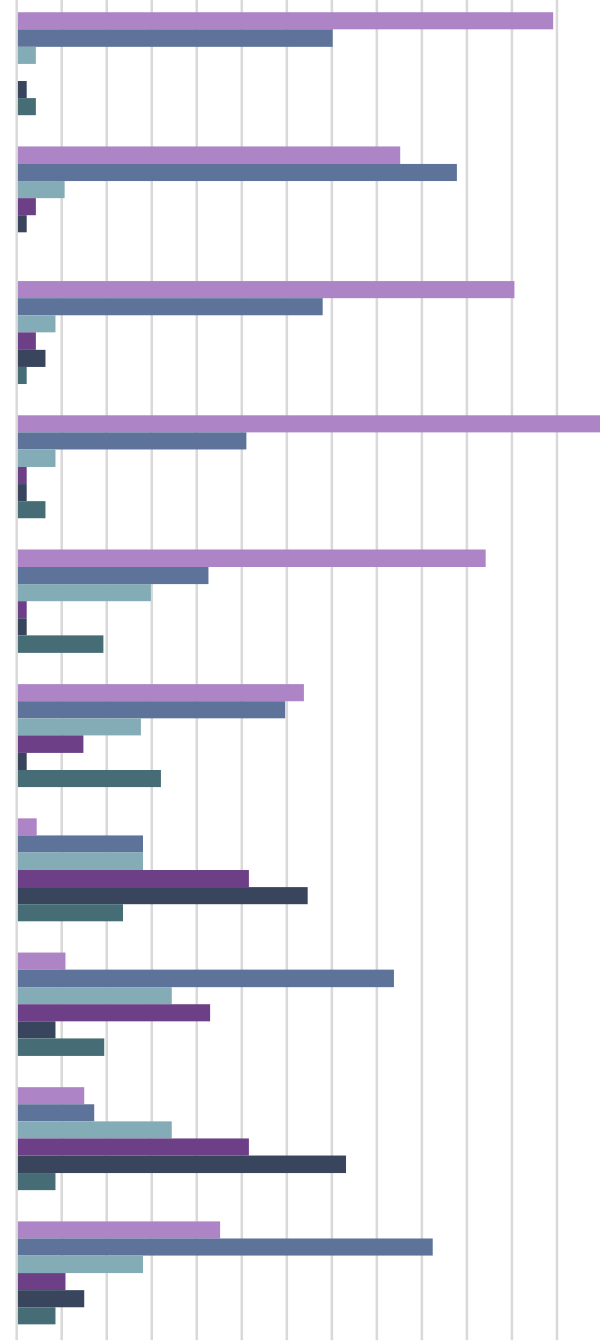

$\square$ Agree $\square$ Partly agree $\square$ Neutral $\square$ Partly disagree $\square$ Disagree $\square$ No opinion

Figure 1. Responses to the 14 statements (vertical axis) quantifying the barriers and facilitators relevant to the attitude towards supporting the introduction of a genetic test in TFI diagnostics. 


\section{Discussion and Conclusion}

The present study was designed to investigate factors and elements, perceived by health professionals working in fertility care as barriers and facilitators for the introduction of genetic testing in screening for tubal pathology. Several statements have been identified as the major unifiers of participants' attitudes toward genetic testing. Cost-effectiveness was indicated by $95 \%$ of participants as an important factor in gaining their support for the new addition to the screening strategy. These results are in concordance with the findings of an earlier study about physicians' attitudes toward genetic testing for cancer susceptibility, which reported cost effectiveness and clinical utility as major concerns [24]. Genetic tests were considered too expensive by over half of the participants. This perception could be a serious barrier in referring patients to genetic testing. This finding also offers a relevant insight for focus on price concerns in the implementation phase. We found no difference in opinions between participants in different academic hospitals. Recent research shows, however, that genetic testing may undeservedly be labeled as high-priced. A study reviewing the entire spectrum of economic evaluations associated with genetic testing used for guiding treatments and interventions, found no evidence that genetic testing is either inferior or superior in terms of cost-effectiveness to other medical interventions. Hatz et al. (2014) found that how the genetic test is used, rather than whether it was used, had the economic significance. ${ }^{25}$

When it came to the potential of chlamydial host genetic factors to improve the accuracy of the tubal pathology prediction, more than half of the participants were optimistic. Asked if the addition of genetic markers to the CAT in screening for tubal pathology could change the sensitivity of the diagnosis, more than two thirds of the respondents gave a positive answer.

The majority of respondents believe that genetic testing should be offered and performed by gynecologists in the hospital. However, responding to the statement about the need for additional training if a genetic test was added to TFI screening, the majority of respondents (almost 70\%) expressed preferences for an additional training in clinical genetics prior to the introduction of the test. This finding is in accordance with an earlier study, which identified education and training designed to enable health-care professionals to interpret more complex genomic data as very important facilitating factors in the translation of innovative genomic tests into clinical practice. ${ }^{26}$ This high percentage of participants expressing the need for additional training shows the clinician's awareness of the advancements in genetic knowledge, and consequent changes in diagnostic and treatment strategies.

Our study also found no significant differences in attitudes between respondents based on their current position, years of experience in their current position, or the hospital they work at. Although the hospitals used in our relatively large sample $(n=94)$ were all Dutch academic hospitals, we managed to gather a pool of respondents with a wide range of years and levels of experience. Still, a limitation of our study is selection bias, because we 
did not randomly select hospitals, but purposely sampled academic hospitals. Generally these hospitals are involved in more complex care than peripheral hospitals, which might have influenced the attitudes of the respondents. Furthermore, 37 of the respondents did not belong to the professional positions we defined, but in 'Other'. Most of these respondents characterized their position as 'IVF specialist' or 'fertility doctor'. The mixed positions in this category made our sample more heterogeneous, thus it could have influenced the internal validity. Lastly, some of the respondents mentioned in the comment section of the questionnaire that they felt they did not have enough information or knowledge about the genetic test to respond to all the questions and statements. Even though this may have hampered them in responding, knowing that some healthcare professionals feel they have insufficient knowledge on genetic testing is valuable information.

In conclusion, respondents showed a positive attitude towards the implementation of a genetic test combined with CAT for TFI screening. Nevertheless, respondents also perceived some barriers for the implementation of such a test. To gain their support for the new screening strategy the majority of respondents agreed that cost-effectiveness is an important factor. Furthermore, clinical utility was recognized as the most important indicator of the quality of a genetic test. In addition to the justified expectations of the proven cost-effectiveness and clinical utility of the new screening strategy, perceived high costs associated with genetic testing poses the biggest barrier in acceptance of genetic testing in the diagnosis of TFI. In order to alleviate these concerns comprehensive research about economic implications of the introduction of genomic markers in the routine fertility work up is needed.

\section{Acknowledgments}

We would like to thank all participants from the Dutch Academic Hospitals we visited.

This work was supported by European EuroTransBio Grant [Reference number 110012 ETB].

\section{Conflict of Interest}

Prof. dr. S.A. Morré, fulltime employee of the VU University Medical Center Amsterdam is Founder (2011) and CEO of TubaScan Ltd., a spin-in company of the VU University Medical Center, Dept. of Medical Microbiology and Infection Prevention, Amsterdam, the Netherlands. One on the lines inside TubaScan is one Female Reproductive Health, the line in which the work presented in this manuscript is linked to.

Marleen Jansen has an appointment at the University of Maastricht and at TubaScan Ltd. Sander Ouburg has an appointment at the VU University Medical Center Amsterdam and TubaScan Ltd.

None of the other authors report a potential conflict of interest. 


\section{References}

1. Collins FS, McKusick VA. Implications of the human genome project for medical science. JAMA. 2001;285:540-4.

2. Guttmacher AE, Porteous ME, McInerney JD. Educating health-care professionals about genetics and genomics. Nat Rev Genet. 2007;8:151-7.

3. Lippman A. Prenatal genetic testing and screening: constructing needs and reinforcing inequities. Am $J \mathrm{~L} \&$ Med. 1991;17:15.

4. McGowan ML, Burant CJ, Moran R, Farrell R. Patient education and informed consent for preimplantation genetic diagnosis: health literacy for genetics and assisted reproductive technology. Genet Med. 2009;11:640-5.

5. Force USPST. Genetic Risk Assessment and BRCA Mutation Testing for Breast and Ovarian Cancer Susceptibility: Recommendation Statement: United States Preventive Services Task Force. The Internet Journal of Oncology. 2004;3.

6. ESHRE. Assisted Reproductive Technology (ART) Factsheet.

7. Evers JL. Female subfertility. Lancet. 2002;360:151-9.

8. Price $M J$, Ades $A E$, Welton NJ, et al. How much tubal factor infertility is caused by Chlamydia? Estimates based on serological evidence corrected for sensitivity and specificity. Sex Transm Dis. 2012;39:608-13.

9. Morre $\mathrm{SA}$, van den Brule AJ, Rozendaal $\mathrm{L}$, et al. The natural course of asymptomatic Chlamydia trachomatis infections: $45 \%$ clearance and no development of clinical PID after one-year follow-up. Int J STD AIDS. 2002;13 Suppl 2:12-8.

10. Paavonen J, Eggert-Kruse W. Chlamydia trachomatis. impact on human reproduction. Hum Reprod Update. 1999;5:433-47.
11. Al-Kuhlani M, Rothchild J, Pal S, et al. TRAILR1 Is a Negative Regulator of ProInflammatory Responses and Modulates Long-Term Sequelae Resulting from Chlamydia trachomatis Infections in Humans. PLoS ONE. 2014;9:e93939.

12. Branković I, van Ess EF, Noz MP, et al. NOD1 in contrast to NOD2 functional polymorphism influence Chlamydia trachomatis infection and the risk of tubal factor infertility. Pathogens and Disease. 2015;73:1-9.

13. den Hartog JE, Ouburg S, Land JA, et al. Do host genetic traits in the bacterial sensing system play a role in the development of Chlamydia trachomatis-associated tubal pathology in subfertile women? BMC Infect Dis. 2006;6:122.

14. Morre SA, Karimi O, Ouburg S. Chlamydia trachomatis. identification of susceptibility markers for ocular and sexually transmitted infection by immunogenetics. FEMS Immunol Med Microbiol. 2009;55:140-53.

15. Lal JA, Malogajski J, Verweij SP, et al. Chlamydia trachomatis infections and subfertility: opportunities to translate host pathogen genomic data into public health. Public Health Genomics. 2013;16:50-61.

16. Land JA, Van Bergen JE, Morre SA, Postma MJ. Epidemiology of Chlamydia trachomatis infection in women and the costeffectiveness of screening. Hum Reprod Update. 2010;16:189-204.

17. Broeze KA, Opmeer BC, Van Geloven N, et al. Are patient characteristics associated with the accuracy of hysterosalpingography in diagnosing tubal pathology? An individual patient data meta-analysis. Hum Reprod Update. 2011;17:293-300.

18. Swart $P$, Mol BW, van der Veen $F$, van Beurden M, Redekop WK, Bossuyt PM. The accuracy of hysterosalpingography in the 
diagnosis of tubal pathology: a metaanalysis. Fertil Steril. 1995;64:486-91.

19. Baars MJ, Henneman L, Ten Kate LP. Deficiency of knowledge of genetics and genetic tests among general practitioners, gynecologists, and pediatricians: a global problem. Genet Med. 2005;7:605-10.

20. Klabunde CN, Willis GB, Casalino LP. Facilitators and barriers to survey participation by physicians: a call to action for researchers. Eval Health Prof. 2013;36:279-95.

21. Klitzman R, Chung W, Marder K, et al. Attitudes and Practices Among Internists Concerning Genetic Testing. J Genet Counsel. 2013;22:90-100.

22. Salm M, Abbate $K$, Appelbaum $P$, et al. Use of genetic tests among neurologists and psychiatrists: knowledge, attitudes, behaviors, and needs for training. J Genet Couns. 2014;23:156-63.

23. Teng I, Spigelman A. Attitudes and knowledge of medical practitioners to hereditary cancer clinics and cancer genetic testing. Fam Cancer. 2014;13:311-24.

24. Freedman AN, Wideroff L, Olson L, et al. US physicians' attitudes toward genetic testing for cancer susceptibility. Am J Med Genet A 2003;120A:63-71.

25. Hatz MM, Schremser K, Rogowski W. Is Individualized Medicine More CostEffective? A Systematic Review. PharmacoEconomics. 2014;32:443-55.

26. Simonds NI, Khoury MJ, Schully SD, et al. Comparative Effectiveness Research in Cancer Genomics and Precision Medicine: Current Landscape and Future Prospects. Journal of the National Cancer Institute. 2013. 


\section{Chapter 5}

International differences in the evaluation of conditions for newborn screening: a review of scientific literature and policy documents
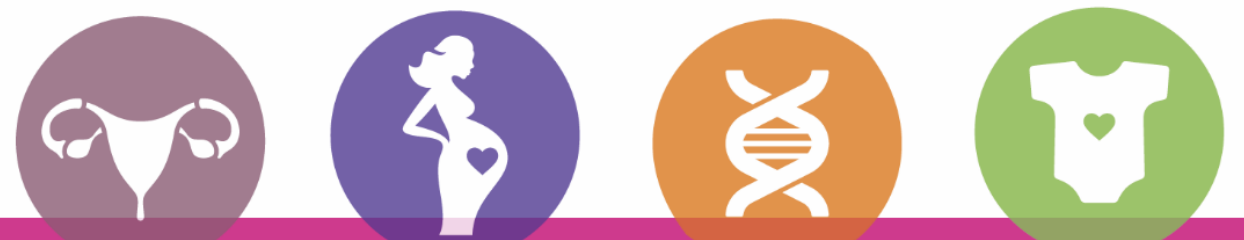

Submitted

Marleen E. Jansen

Selina C. Metternick-Jones

Karla J. Lister 


\section{Abstract}

Purpose Despite international adoption of newborn bloodspot screening (NBS), no two countries' screening programs are the same. This article aims to understand what factors influence NBS criteria and how conditions are assessed against them, and offers unique insights into the international landscape of NBS.

Methods A systematic review on NBS criteria in scientific literature was undertaken first. Through this, five topics were identified for consideration when analysing NBS decision making. Using these five topics as a template, a structured analysis was conducted on NBS in policy documents of eight countries.

Results Programs are using different approaches to explore the same policy issues, including: the beneficiary of NBS, definition of criteria, the way conditions are assessed, level of evidence required, and recommendations after assessment. These differences have the potential to result in increased disparity across NBS internationally. Ultimately, governments need to decide on their role and an approach to NBS decision making in line with this role.

Conclusion The analysis presented in this article highlights that despite programs' commonalities, no one 'NBS decision making solution' exists. Understanding the different approaches to decision making within the literature and policy settings, provides an objective lens to inform decision making approaches and the future direction for NBS programs.

\section{Key words}

Newborn screening; decision making criteria; policy development; review; international 


\section{Introduction}

Internationally, screening is recognized as an important population health initiative. ${ }^{1,2}$ Screening involves the systematic testing of an asymptomatic population for a specific condition. ${ }^{3-5}$ Its goal is to identify individuals who are at an increased risk of developing a condition, or who are in the early stages of a disease.6, 7 These individuals are then eligible for early intervention, with the aim of reducing morbidity and mortality. ${ }^{1,6,8}$ In addition to these individual benefits, screening also aims to minimize the negative societal and economic impacts of life threatening diseases., 5, 9 To maximize the health and wellbeing of a population through screening, governments worldwide implement screening programs for a range of conditions. ${ }^{10}$

While screening can have many benefits, it can also result in harm. ${ }^{11-13}$ These harms might be physical, from testing or treatment, or psychological, relating to anxiety due to receiving a false positive test result. ${ }^{14,}{ }^{15}$ Therefore, careful and transparent decision making is needed to ensure that the benefits of screening always outweigh the harms. ${ }^{1,}$ $11,14,16-20$ To maximize the benefits and minimize harms, policy makers use decision making criteria. ${ }^{1,9}$ These criteria provide a framework against which conditions can be assessed for their suitability for screening. $6,18,21,22$ The screening principles formulated by Wilson and Jungner (Box 1 ) are considered to be the gold standard and are regarded as a starting point to define decision making criteria for screening programs. ${ }^{13,23,24}$ However, they are not regarded as adequate for all screening programs, including for newborn bloodspot screening (NBS). $6,19,23,25,26$

\section{Box 1. The principles as formulated by Wilson \& Jungner ${ }^{27}$}

1. The condition sought should be an important health problem.

2. There should be an accepted treatment for patients with recognized disease.

3. Facilities for diagnosis and treatment should be available.

4. There should be a recognizable latent or early symptomatic stage.

5. There should be a suitable test or examination.

6. The test should be acceptable to the population.

7. The natural history of the condition, including development from latent to declared disease, should be adequately understood.

8. There should be an agreed policy on whom to treat as patients.

9. The cost of case finding (including diagnosis and treatment of patients diagnosed) should be economically balanced in relation to possible expenditure on medical care as a whole.

10. Case finding should be a continuing process and not a "once and for all" project. 
NBS is one of the longest running screening initiatives in the world. ${ }^{1,12,23,28}$ It screens newborns within the first days of life for multiple conditions. ${ }^{10,12}$ The conditions screened are often rare and need life-long treatment or management. This makes them difficult to assess against traditional decision making criteria originating from the Wilson and Jungner principles. When assessing conditions against the criteria, adhering to current standard of evidence-based policy making poses a challenge. ${ }^{29-33}$ While evidence from randomized controlled trials (RCTs) is considered the gold standard on which to base decisions, it is scarce for rare conditions. In addition, the multiplex technologies currently used in NBS, and the emergence of genomic technologies, mean it is possible to screen for an increasing number of conditions. ${ }^{1,9}$, 32, 34-36 This further challenges the existing decision making criteria. ${ }^{22,37}$ In response to this, many countries and local jurisdictions have translated the traditional screening principles into more detailed criteria, to suit both NBS and their local needs. ${ }^{21,23-25,31}$ As a consequence, countries and regions assess conditions for inclusion in their NBS programs differently, resulting in different conditions being included in NBS programs. ${ }^{10,13,22,26,38}$

In this study we aim to explore what factors influence decision making criteria in NBS and how conditions are assessed against them across the globe. This is achieved through a systematic review of scientific literature, and a review of relevant policy documents in Australia, Canada, Denmark, Germany, the Netherlands, New Zealand, the United Kingdom (UK), and the United States of America (USA). In doing so, this review provides an evidence-based template of topics that should be considered when translating the Wilson and Jungner screening principles into localized decision making. In line with this, the findings of this study provide essential information for those countries which are currently in the process of developing or revising their decision making processes.

\section{Methods}

To explore factors that influence NBS decision making criteria and how conditions are assessed against them, this study followed a two phased search strategy. The first phase involved a systematic review of scientific literature, and the second focused on relevant international policy documents (Figure 1). The aim of the first phase of the study was to identify high level topics that the literature recommended to be considered when revising decision making for NBS. These topics were then used to develop a template to analyze the policy documents and enable a structured comparison between different countries.

\section{Scientific literature}

In the first phase, MJ, SMJ, and KL searched and reviewed articles from PubMed and Web of Science. The key search terms 'newborn screening' and 'criteria' were used. These terms were combined with 'decision-making', 'assessment or evaluation', 'definition', 'expanding', 'removing', 'translation', 'Wilson and Jungner', 'framework', 'policy', and 
'implementation' (Figure 1). The search terms were selected based on terminology used in NBS literature and knowledge of the research team. Only articles in English were included, and the resultant literature database was checked for duplicates. Articles relating to other types of newborn screening (hip dysplasia and hearing screening) were excluded, because the aim of this study was to explore the evaluation process specific to NBS programs. Relevant articles were selected based on their title and abstract, and then read in full. Uncertainties about the relevance of an article for the final review were discussed among the team until consensus was reached.

\begin{tabular}{|c|c|c|c|c|c|}
\hline A. Phase & \multicolumn{3}{|c|}{ I: Systematic literature review } & \multicolumn{2}{|c|}{ II: Policy documents review } \\
\hline \multirow[t]{2}{*}{ B. Sources } & PubMed & \multicolumn{2}{|c|}{ Web of Science } & Government websites & Google \\
\hline & & & & Research team networ & \\
\hline \multirow[t]{6}{*}{ C. Search terms } & \multicolumn{2}{|c|}{ Newborn screening } & Translation & Newborn screening & Criteria \\
\hline & \multicolumn{2}{|c|}{ Decision-making } & Definition & Australia & Jew Zealand \\
\hline & Expanding & Policy & Criteria & Denmark & jermany \\
\hline & \multicolumn{2}{|c|}{ Wilson and Jungner } & Removing & Netherlands & Canada \\
\hline & \multicolumn{3}{|c|}{ Assessment or evaluation } & $\begin{array}{l}\text { United States of } \\
\text { America }\end{array}$ & \multirow{2}{*}{$\begin{array}{l}\text { United } \\
\text { Kingdom }\end{array}$} \\
\hline & Framework & $\operatorname{Imp}$ & mentation & & \\
\hline $\begin{array}{l}\text { D. Selection } \\
\text { process }\end{array}$ & \multicolumn{3}{|c|}{ Title and abstract: $\mathrm{n}=182$} & \multicolumn{2}{|c|}{$\begin{array}{l}\text { Most recent policy document and/or } \\
\text { recommendation on NBS: } \\
n=26 \text {, included: } n=21\end{array}$} \\
\hline
\end{tabular}

Figure 1. Overview of the two-phased search strategy used in the current study. In the first column the process is outlined; A. main focus of the search, B. sources consulted, C. search terms used to explore the databases, and $\mathrm{D}$. the amount of articles and documents before and after selection based on relevance. 
Once articles were identified as being appropriate for final review, they were analyzed for information regarding NBS decision making. The research team followed an iterative process, whereby they met on multiple occasions to identify common themes and content within the articles. Through this process of selection and refinement, five high level topics were identified as being present within the scientific literature. These five topics then were used to develop a template for analyzing the information within the policy documents in the second phase. Details of the topics within the template are provided within table 1 and the results section.

Table 1. Decision making template. The table outlines topics evident in the literature, which should be considered when developing a framework to assess conditions through NBS criteria.

\begin{tabular}{ll}
\hline Topic & Description \\
\hline $\begin{array}{l}\text { Screening beneficiaries } \\
\text { Definition of criteria }\end{array}$ & $\begin{array}{l}\text { Who stands to benefit the most from providing NBS for a condition. } \\
\text { Questions or statements against which evidence is assessed, to } \\
\text { consider the appropriateness of screening a condition. } \\
\text { The way the evidence and information are synthesized and used to } \\
\text { evaluate conditions. }\end{array}$ \\
$\begin{array}{l}\text { Level of evidence } \\
\text { required }\end{array}$ & $\begin{array}{l}\text { Summary of the type of evidence accepted to support the applied } \\
\text { score, such as a systematic review, RCT, and/or expert opinion. } \\
\text { Recommendation }\end{array}$ \\
& $\begin{array}{l}\text { The outcome of assessing a condition against the decision making } \\
\text { criteria, such as a recommendation for or against screening. }\end{array}$ \\
\hline
\end{tabular}

\section{Policy documents}

The second phase of the study focused on policy documents in various countries, to identify NBS criteria and how conditions are assessed against them internationally. To identify current relevant policy documents, MJ, SMJ, and KL searched Google and government websites, and contacted stakeholders. This resulted in 26 policy documents from across the globe. Policy documents were included only if: there was clear information on NBS decision making; and if they were in Dutch, English or German. This resulted in eight countries' policy documents being included in the study: Australia, Canada, Denmark, Germany, Netherlands, New Zealand, UK, and USA. The NBS policies from these countries were assessed against the five topics in the template developed in the first phase. Using this template, the information on the topics was compared, contrasted, and consideration given to the translation into current NBS policy.

\section{Results}

The following highlights similarities and differences in factors that influence decision making criteria in NBS and how conditions are assessed against the criteria (Table 1). Characteristics of the reviewed policy documents are summarized for each country in table 2 . 
Table 2. Background of the policy documents included in the review. This table provides background information relevant to the reviewed countries' policy documents. It outlines: if the country's decision making is aimed solely at NBS, as opposed to screening programs in general; if the reviewed decision making framework has been used to assess conditions for its NBS program; the year the guidelines were published or most recently revised; and the type of program structure in place, being either national or state based.

\begin{tabular}{|c|c|c|c|c|}
\hline $\begin{array}{l}\text { Country } \\
\text { (jurisdiction) }\end{array}$ & $\begin{array}{l}\text { Decision } \\
\text { making specific } \\
\text { to NBS }\end{array}$ & $\begin{array}{l}\text { Applied to current } \\
\text { NBS program }\end{array}$ & $\begin{array}{l}\text { Year of } \\
\text { publication or } \\
\text { revision }\end{array}$ & $\begin{array}{l}\text { Program } \\
\text { structure }\end{array}$ \\
\hline Australia & Yes & No & $\begin{array}{l}2008^{5} \\
2011^{1}\end{array}$ & State based $^{a}$ \\
\hline Canada (Ontario) & Yes & No & $\begin{array}{l}2011^{2} \\
2015^{3}\end{array}$ & State based ${ }^{a}$ \\
\hline Canada (Quebec) & No & No & $\begin{array}{l}2008^{4} \\
2007^{5}\end{array}$ & State based ${ }^{a}$ \\
\hline Denmark & Yes & Yes & $\begin{array}{l}2007^{6} \\
2012^{7} \\
2015^{8}\end{array}$ & National \\
\hline Germany & No & Yes & $\begin{array}{l}2007^{9} \\
2011^{10}, 11 \\
2014^{12} \\
2015^{13}\end{array}$ & State based ${ }^{a}$ \\
\hline Netherlands & No & Yes & $\begin{array}{l}2005^{14} \\
2008^{4} \\
2015^{15}\end{array}$ & National \\
\hline New Zealand & Yes & Yes & $2011^{16}$ & National \\
\hline United Kingdom & No & Yes & $\begin{array}{l}2015^{17} \\
2015^{18}\end{array}$ & National \\
\hline $\begin{array}{l}\text { United States of } \\
\text { America }\end{array}$ & Yes & Yes & $\begin{array}{l}2006^{19} \\
2014^{20} \\
2015^{21,22}\end{array}$ & State based ${ }^{a}$ \\
\hline
\end{tabular}

a includes 'provincial' programs

\section{Screening beneficiaries}

'Screening beneficiaries' refers to an individual or group of people who will benefit most as a result of screening for a condition. Beneficiaries could be the child, the family and/or society. $1,19,23,25,35,38,61-64$ The child is the beneficiary if the purpose is to support early clinical intervention and enhance the health outcomes for the newborn. ${ }^{38}$ The family is the beneficiary if the purpose of screening extends to: reducing a diagnostic odyssey; supporting the family to prepare for the onset of symptoms of a disease; or supporting future reproductive planning. $1,19,25,62,63$ Society could be considered the beneficiary if 
disease burden is reduced, hence decreasing costs for health care, and when knowledge about rare diseases is improved. ${ }^{35,64}$ Some literature recommends criteria that focus on families as the beneficiaries of screening. 1, 19, 25, 62 However, other literature states that the direct medical benefits to the child must always come first within NBS programs, primary to considering family benefits such as providing reproductive information. ${ }^{38}$

In the policy documents, all countries focused on the newborn as the primary beneficiary. This aligns with the traditional aim of NBS, which is to prevent serious implications for the newborn by offering timely treatment and management for early onset childhood conditions. ${ }^{5}$, 39, 45, 54, 57, 59 Policy documents from Ontario mention that there must be reasonable certainty that important clinical benefits for the child will come from screening ${ }^{41}$ In addition, recently released Dutch guidelines also focus on supporting clinical intervention(s) for the child..$^{53}$ While some countries consider family benefits, such as preventing a diagnostic odyssey, they are always considered secondary to direct medical benefit to the child. In the USA's assessment this is evident through its scoring system, which places greater weight on the benefit to the newborn than the benefit to family and/or society. ${ }^{57,60}$ Australia and New Zealand also explore family benefit within their decision making using a slightly different approach. The benefits to the family can be considered as part of the assessment of the benefits of screening, if the benefit for the newborn makes a strong case for screening, but the conditions does not fulfil all the criteria based solely on benefits to the newborn. However, this is only in the instance where the condition can be multiplexed onto the current panel. ${ }^{39,54}$

\section{Definition of criteria}

The 'definition of criteria' refers to those questions or statements against which evidence is assessed, to consider the appropriateness of screening a condition. The literature highlighted a range of different criteria used to assess conditions, 12, 20, 22-26, 32, 34, 36, 38, 58, 65, ${ }^{66}$ which vary in their level of detail. ${ }^{20,65}$ Most articles built on the principles of Wilson and Jungner, and translated the principles to more detailed criteria. The primary driver behind this translation appeared to be the need to define more detailed criteria to: make them more relevant to NBS; enable consideration of relevant technologies; and/or to support exploration of the ethical implications for NBS screening. ${ }^{17,} 22-26,32,34,36,38,58,66-68$ The articles that did not utilize the Wilson and Jungner principles, explored clinical scenarios or a risk-benefit model to consider the case-specific nature of each disorder. ${ }^{11,} 24$

Similar to the academic literature, differences exist in the criteria expressed in the policy documents. One key difference was the amount of detail used to describe the criteria. The criteria were mostly described in a list of high level criteria, $5,39,44,45,47,48,52,53,55,56$ with some countries including a more detailed checklist with specific aspects. ${ }^{42,54,59}$ Ontario was the sole example where criteria were presented as a set of specified questions. ${ }^{41} \mathrm{~A}$ second key difference amongst the countries was that some included criteria on the practical aspects of screening, such as the readiness of facilities to 
implement new conditions, and considerations on privacy. $4,41,55,59$ Lastly, the number of criteria per topic varied between countries. The number of criteria focusing on the condition, test, and treatment was higher in New Zealand, while the Dutch and UK's had more criteria addressing the practical aspects of the screening program, such as having a quality assurance program in place. $4,54,55$

In addition to the number of criteria on a similar topic of screening, the content of the listed criteria also differed between countries. The UK uniquely specified that screening must be a last resort after all other options are considered. ${ }^{55}$ Also, in contrast with other countries, the UK included a criterion on anticipating public pressure. ${ }^{55}$ In Ontario, unique questions existed which explored: case definition, such as heterogeneity in symptoms; treatment, including whether all diagnosed individuals candidates for an intervention; and need for data on the prevented diagnostic delay and possible overdiagnosis. ${ }^{41}$ Ontario and New Zealand both included questions on incidental findings in their policy documents.41, 54 Technological developments were also included in some countries criteria, for example if the analysis could be multiplexed on the technologies already in use. $^{40,53,56,58}$ One of the technological developments frequently discussed in the context of NBS is genomic technology. In contrast to most countries, New Zealand's policy documents lacked specification on technologies for genetic screening. ${ }^{54}$

\section{Condition assessment}

'Condition assessment' relates to the way the evidence and information is synthesized and used to consider the condition. In general a detailed description of the relevant evidence could be used to assess the criteria.36 Information was usually synthesized through summarizing relevant studies, sometimes combined with expert opinions, and weighing this evidence against each criterion. ${ }^{11}, 32,34,36,58,68$ Alternatively, in the articles stepping through American College of Medical Genetics' (ACMG) approach to decision making, a condition was assessed against each criterion using numerical scores. ${ }^{12,} 21.24,61$, 66

This quantitative ACMG system was illustrated in policy documents from the USA and Denmark. $45,57,59$ In this model, each criterion has categorical scoring options of either 0 , 50,100 , or 200. For example, the burden of disease can be assessed 'minimal' (score 0 ) to 'profound' (score 100).59 The ACMG's system also weighs criteria; with some criteria having a higher maximum score than others. ${ }^{57}$ This means that some criteria have more influence on whether a condition is recommended for screening or not, for example a multiplex test with a maximum score of 200 has more influence than the availability of a treatment with a maximum score of 50 . The Danish assessment is less technology driven than the USA's system, reflected in the selected six aspects from the ACMG's list of sixteen; less emphasis was placed on availability of a multiplex platform screening method and economic considerations. ${ }^{45}$ Despite the ACMG having established a quantitative system, the Wilson and Jungner criteria are subjective, and inherently hard 
to quantify. Therefore, most countries have not followed this example, and instead summarize relevant studies combined with expert opinions. ${ }^{4}$, 5, 39, 41, 42, 51, 53-55 Assessment against each criterion then occurs through a consensus process informed by discussions with stakeholders.

\section{Level of evidence}

'Level of evidence' refers to the types of information which might be used for assessment, such as clinical studies or systematic reviews. Within screening policy, RCTs are considered the gold standard for evidence to arrive at an evidence-based decision. ${ }^{14,25}$ However, the requirement for this level of evidence is challenged in the context of NBS. NBS screens for rare diseases, for which RCTs are often not possible due to limited numbers of individuals with a condition. ${ }^{19}, 25,31,69$ Given this, much of the literature recommends that alternative evidence should be used in the face of rare diseases or a scarcity of RCTs. ${ }^{14}, 19,20,24,25,33,58,66$ These alternatives include expert opinions, or conducting a systematic review of current evidence sometimes combined with a decision analytic model. Alternatively, new conditions can be introduced to NBS as pilot studies within a research paradigm to produce evidence on which a recommendation for ongoing screening can then be made. Furthermore, information is needed on ethical, legal, and societal implications, which could be studied using health technology assessment frameworks. ${ }^{17,} 69$

Several policy documents acknowledge that, while high levels of evidence should be strived for, complete evidence for NBS will be scarce. ${ }^{5,41,58}$ Most countries therefore use a combination of several types of evidence, and only the UK specifies a criterion that evidence from high quality RCTs must be available. ${ }^{55}$ Australia, New Zealand, and the USA, use categories to rank the level of evidence, with higher levels preferred. ${ }^{39,54,58}$ It is unclear how the ranking of the evidence weighs for the assessment against each criterion. The levels between these three countries are comparable and include, from high to low: a) systematic review, meta-analysis and/or RCT; b) high quality case-control or cohort; c) well conducted case-control study; d) non-analytical study; and e) no evidence. ${ }^{39,54,57,58}$ There are some countries where the system to assess the level of evidence is not specified. 48,53

\section{Recommendation}

'Recommendation' refers to the outcome of assessing a condition against the decision making criteria, such as a recommendation for or against screening. The format of these recommendations regarding whether to commence screening for a condition varied from a binary outcome (yes/no), to an extensive ranking or categorical outcome, with up to eight categories. ${ }^{12,15,20,32,67}$ Thus, the reviewed literature highlights that there are numerous ways of formulating and presenting recommendations. The numerous ways of 
formulating recommendations was also represented in the policy documents. In the policy documents some countries did not specify categories, ${ }^{41}, 42,44,49,50$ however, the majority did. 4,5 , 53-55, 58 Most of the outcomes reflected recommendations: a) to commence screening; b) to commence screening within specific contexts; c) against screening based on the current available evidence, or d) against screening, but suggested a pilot study. $5,54,55,58$

Despite similarities in the recommendation categories, some differences were found between countries. Two significantly different categories can be found between the UK and the USA. Where the UK has a unique category that specifies when screening is not recommended, clinical practice guidelines will be developed..$^{55}$ On the other hand, the outcome categories for USA have a strong focus on either support screening, or recommending approaches that will enable screening in the future. ${ }^{58}$ For example, where screening is not supported, a pilot study is recommended or specific steps are provided to improve feasibility or readiness for implementation of the assessed condition in NBS. The Netherlands also advises further study when a test of proven quality is not yet available or cost-effectiveness is unclear. ${ }^{53}$

\section{Discussion}

This review aimed to explore the current status of decision making for NBS internationally, through considering the factors that influence NBS criteria and the assessment of conditions (figure 2). The review highlights what is commonly experienced within the translation divide; government policy lags behind the scientific debate. Nonetheless, it is clear from both mediums that a shift in the purpose of NBS is under discussion, and evidence-based and transparent decision making is needed to shape programs in the future.

Internationally the use of the Wilson and Jungner principles persists as a starting point for decision making. Wilson and Jungner's high level criteria were translated to more detailed criteria in both the scientific literature and the policy documents. However, factors influencing these criteria and assessment of conditions against them differed in terms of: who benefits from screening; how evidence is assessed against each criterion; and how recommendations are made. Importantly, the criteria and their use in the assessment of conditions are responsible for shaping the programs; therefore understanding how they differ internationally provides an insight into what NBS might hold in the future. 


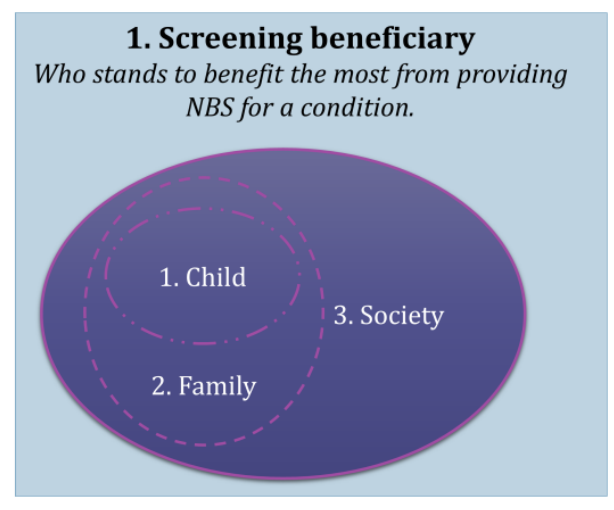

\section{Condition assessment}

The way the evidence and information are synthesized and used to evaluate conditions.

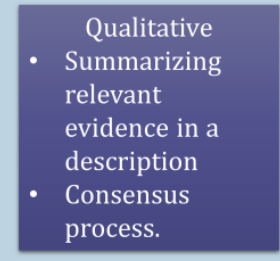

Quantitative
Attach
categorised score
based on
evidence
- Numerical score
per criterion

\section{Definition of criteria}

Questions or statements against which evidence is assessed, to consider the appropriateness of screening a condition.

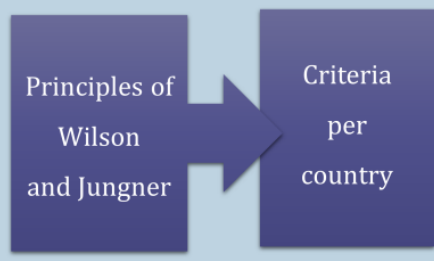

\section{Level of evidence}

Summary of the type of evidence accepted to support the applied score, such as a systematic review, $R C T$, and/or expert opinion.

A. Systematic review, meta-analysis

B. High quality case-control or cohort studies

C. Well conducted case-control studies.

D. Non-analytical studies

E. No evidence.

\section{Recommendation}

The outcome of assessing a condition against the decision making criteria, such as a recommendation for or against screening.

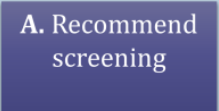

A. Recommend B. Recommend screening within specific contexts
C. Recommend against screening at the current state of evidence
D. Recommend against screening but suggested for instance a pilot study

Figure 2. Summary of the five evidence based topics in the template and their content. A description of each topic is provided in italic. A summary of the most frequently discussed content in the policy documents is given in the light blue areas under each of the topic areas. 


\section{Beneficiary of screening}

Since the inception of NBS, there has been a gradual shift in the definition of beneficiary from solely the child, to also include the family. 1, 19, 25, 62 Who benefits from screening is a fundamental concept, which is linked with the purpose of the program, and heavily influences decision making. The purpose of screening in general is to provide better health outcomes for an individual, through early detection of a disease. 2, 6, 7 NBS has traditionally been implemented in line with this ethos, and has evolved from screening for PKU, where the sole direct beneficiary is the newborn. However, particularly the literature highlights a shift away from newborns as the sole beneficiary. In the context of policy for NBS programs this shift is less applied, because expanding the beneficiary to also include the family involves an explicit decision for governments to move away from the classic definition of screening.

At the core of the incongruity between the beneficiary of screening within the scientific literature and policies explored, are the purpose of the program and the role of governments. ${ }^{62}$ The role of government in the context of traditional NBS has been clear; to support early identification of conditions which respond to treatment. ${ }^{62}$ Expanding the definition of beneficiary screening, to include concepts of for example reproductive planning, challenges this understanding. In the context of tax-payed funded public health approaches, the appropriateness of governments to support such a concept is unclear. Further, expanding the beneficiary to include family benefit requires additional counselling services and facilities, and has wide-reaching implications that need appropriate consideration since they could potentially threaten the success of a program. Therefore, if governments support expanding the concept of beneficiary as a public health priority, they must also be in a position to implement the programs in a way that ensures quality of screening.

\section{Screening criteria}

Despite the shift away from the historical concept of beneficiary of NBS, the Wilson and Jungner principles have stood the test of time. Within almost all the documents reviewed, Wilson and Jungner's principles were the starting point for decision making, providing high level criteria that were then adapted to more detailed criteria. These adapted criteria increase the transparency of decision making; this is because the resultant requirements to fulfil a criterion are more straightforward and well-defined. The adaptations made to the Wilson and Junger criteria tailored decision making for NBS, to enable assessment of relevant technologies, and support ethical considerations. ${ }^{21,23-25,31}$ In addition to having increased level of detail, several countries adapted the criteria to support consideration of issues relating to the implementation of the program. ${ }^{4,55}$ This enables a more complete assessment of NBS, from a program-wide perspective. It enables exploration of essential components, which in the past have been neglected in decision making, including: quality assurance, timely follow-up and capacity of the health system to 
respond to a condition. ${ }^{14,22,69,70}$ This system-wide approach is in line with the modern understanding of a screening program, whereby it is necessary to consider the program as the sum of its parts, and no one component in isolation. Further, there is the risk that without this inclusive point of view a recommendation for screening could be arrived at, but not be able to be implemented. $14,22,70,71$

Within their decision making criteria, countries also expressed differences in their focus on relevant technologies. As an example, New Zealand did not specifically address genomic testing, despite it being the technological drive for much debate in NBS. ${ }^{18,} 22,28$, 61, 71 Genomic tests present a challenge for NBS worldwide, because their possible application poses a complex set of questions regarding ethical, legal, and societal issues. ${ }^{71}$ For example, who should be informed, what information should be given, and where this information needs to be stored. ${ }^{71}$ Through genomic testing there is also the potential to screen for a wider range of conditions, including those which are untreatable. However, this means that the need to diagnose in the newborn period is not always black and white. $^{72}$ The appropriateness of screening these conditions through NBS is questionable, and is the source of much debate in the academic and policy landscapes. There is also the fear that the use of genomic tests in NBS might reduce participation when testing for untreatable conditions is started. ${ }^{53,} 73$ Based on these concerns, governments may not regard it as appropriate to offer NBS testing for untreatable conditions. However, it is argued that the introduction of genomic testing into NBS is inevitable, either through government or direct-to-consumer tests. Therefore, governments need to have decision making processes in place to evaluate tests and protect citizens against the risks of unsound testing. ${ }^{74}$

\section{Assessment and recommendation}

It is important to assess conditions for NBS in a structured and transparent way against defined criteria. ${ }^{4}$ USA and Denmark have tried to make their systems more robust by applying quantitative scores. However, assessment through quantitative scores can be challenging due to lack of scientific data to assess the criteria. It has also been argued to be unsuitable for balancing benefits and harms of screening. ${ }^{11,} 61$ Therefore, most countries used a flexible system, processing gathered evidence through summarizing relevant studies, sometimes combined with expert opinions, and weighing this evidence against each criterion. In the documents reviewed, it was common for evidence to be ranked, taking into account expert opinions. This approach leaves more room for considerations of ethical, legal, and societal issues. ${ }^{11}{ }^{19}$ Recommendations for or against screening a condition, following assessment against the criteria, are often not 'binary' and include a range of option. Given that evidence is often scarce, recommendations also included the need to gather more evidence on feasibility and suitability of NBS through pilot studies. In the recommendations, the UK seemed to steer away from screening, since 
their recommendations uniquely included a category on developing clinical guidelines instead of focussing on screening. ${ }^{55}$

\section{Limitations and strengths}

One of the limitations of our study is that not all decision making criteria presented in the policy documents have been used in decision making for NBS programs. This hampered an international comparison between programs that took into account the impact of decision making on the resultant conditions included in a program. A further limitation is that only eight countries were reviewed, due to language barriers experienced by the research team. This means relevant information was possibly excluded. Regardless of the limitations, the research team was able to include countries with different program structures, and use a unique combination of scientific literature and policy documents to assess decision making criteria. This enabled a highly structured approach resulting in key topics to guide policy development. This is timely, given that several countries are developing decision making policies to guide program development, including in Australia and Canada. Further, as was evident in a recent review from Therrell et al., a considerable number of countries worldwide are commencing NBS or expanding their programs. ${ }^{10}$

\section{Conclusion}

There is no one decision making solution when it comes to NBS. However, there are some clear issues that each country needs to address to guide decision making, including: who will benefit from the program, how to ensure transparent decisions, and the role of the government. This review provides a valuable framework for governments responsible for decision making for NBS, to support safe and effective future development of programs. This is especially valuable given the potential of genomic technologies. Further, this review highlights the need for governments to better understand the academic debate and guidance, to ensure that NBS decision making frameworks are contemporary, and support assessment of the current and future issues facing NBS. While this article identifies area for further review, such as how to assess evidence, it provides insight into the driving principles that underpin decision making for NBS.

\section{Acknowledgements}

MJ acknowledges APOGEE-Net/CanGèneTest (Canada, P.I. prof. A. Brand, PhD MD) and Haak Bastiaanse Kuneman Stichting (Netherlands, P.I. M.E. Jansen, MSc) for their financial support. 


\section{References}

1. Grosse SD, Boyle CA, Kenneson A, Khoury $\mathrm{MJ}$, Wilfond BS. From public health emergency to public health service: the implications of evolving criteria for newborn screening panels. Pediatrics. 2006;117(3):923-929.

2. World Health Organization. Early detection of cancer.

http://who.int/cancer/detection/en/.

Accessed 3 March 2015.

3. Dezateux C. Newborn screening for medium chain acyl-CoA dehydrogenase deficiency: evaluating the effects on outcome. European journal of pediatrics. 2003;162 Suppl 1:S25-28.

4. Gezondheidsraad. Screening: tussen hoop en hype. Den Haag: Gezondheidsraad;2008. 978-90-5549-706-5.

5. Australian Population Health Development Principal Committee: Screening Subcommittee. Population Based Screening Framework. 2008.

6. Elliman DAC, Dezateax C, Bedford HE. Newborn and childhood screening programmes: criteria, evidence, and current policy. Arch Dis Child. 2002;87:6-9.

7. UK National Screening Committee. What is screening?

http://www.screening.nhs.uk/cms.php?fold er=2436. Accessed 29 March 2015.

8. National Institute for Public Health and the Environment. Bevolkingsonderzoeken en screeningen.

http://www.rivm.nl/Onderwerpen/B/Bevolki ngsonderzoeken en screeningen. Accessed 29 March 2015.

9. Andermann A, Blancquaert I, Beauchamp S, Dery V. Revisiting Wilson and Jungner in the genomic age: a review of screening criteria over the past 40 years. Bull World Health Organ online. 2008.
10. Therrell BL, Padilla CD, Loeber JG, et al. Current status of newborn screening worldwide: 2015. Seminars in Perinatilogy. 2015;39:171-187.

11. Wilfond BS, Parad RB, Fost N. Balancing Benefits and Risks for Cystic Fibrosis Newborn Screening: Implications for Policy Decisions. J Pediatr. 2005;147:S109-S113.

12. Petros M. Revisiting the Wilson-Jungner criteria: how can supplemental criteria guide public health in the era of genetic screening? Genet Med. 2012;14(1):129-134.

13. Pollitt RJ. Introducing new screens: Why are we all doing different things? J Inherit Metab Dis. 2007;30:423-429.

14. Moyer VA, Calonge N, Teutsch SM, Botkin JR. Expanding newborn screening: process, policy, and priorities. The Hastings Center report. 2008;38(3):32-39.

15. Plass AMC, van El CG, Pieters T, Cornel MC. Neonatal Screening for Treatable and Untreatable Disorders: Prospective Parents' Opinions. Pediatrics. 2010;125(1):e99-e106.

16. Maxwell SJ, O'Leary P. Newborn bloodspot screening: setting the Australian national policy agenda. The Medical Journal of Australia. 2014;200(3):142-143.

17. Seymour CA, Thomason MJ, Chalmers RA, et al. Newborn screening for inborn errors of metabolism: a systematic review. Health technology assessment (Winchester, England). 1997;1(11):i-iv, 1-95.

18. Pollitt RJ. Newborn blood spot screening: New opportunities, old problems. J Inherit Metab Dis. 2009;32:395-399.

19. Avard D, Vallance $H$, Greenberg C, Potter B. Newborn Screening by Tandem Mass Spectrometry: Ethical and Social Issues. Canadian Journal of Public Health. 2007;98(4):284-286.

20. Calonge N, Green NS, Rinaldo P, et al. Committee report: Method for evaluating 
conditions nominated for population-based screening of newborns and children. Genet Med. 2010;12(3):153-159.

21. Borte $S$, von Döbeln U, Hammarström L. Guidelines for newborn screening of primary immunodeficiency diseases. Curr Opin Hematol. 2013;20:48-54.

22. Dhondt JL. Expanded newborn screening: social and ethical issues. J Inherit Metab Dis. 2010;33(Suppl 2):S211-S217.

23. Botkin JR. Assessing the new criteria for newborn screening. Health matrix (Cleveland, Ohio: 1991). 2009;19(1):163-186.

24. Pollitt RJ. International perspectives on newborn screening. J Inherit Metab Dis. 2006;29:390-396.

25. Green A, Pollitt RJ. Population newborn screening for inherited metabolic disease: current UK perspectives. J Inherit Metab Dis. 1999;22(4):572-579.

26. Forman J, Coyle F, Levy-Fisch J, Roberts P, Terry $S$, Legge M. Screening criteria: the need to deal with new developments and ethical issues in newborn metabolic screening. Journal of community genetics. 2013;4(1):59-67.

27. Wilson JMG, Jungner G. Principles and Practice of Screening for Disease. Geneva: World Health Organization;1968.

28. Potter BK, Avard D, Wilson BJ. Newborn blood spot screening in four countries: stakeholder involvement. Journal of public health policy. 2008;29(1):121-142.

29. Accetta Pedersen DJ, Verbsky J, Routes JM. Screening newborns for primary T-cell immunodeficiencies: consensus and controversy. Expert review of clinical immunology. 2011;7(6):761-768.

30. Lantos JD. Dangerous and Expensive Screening and Treatment for Rare Childhood Diseases: The Case of Krabbe Disease. Dev Disabil Res Rev. 2011;17:15-18.

31. Bonham JR. Impact of new screening technologies: should we screen and does phenotype influence this decision? J Inherit Metab Dis. 2013;36:681-686.

32. Ross LF. Newborn screening for lysosomal storage diseases: an ethical and policy analysis. J Inherit Metab Dis. 2012;35:627634.

33. Grosse SD, Kalman L, Khoury MJ. Evaluation of the validity and utility of genetic testing for rare diseases. Advances in experimental medicine and biology. 2010;686:115-131.

34. Feuchtbaum L, Faulkner L, Verghese S. Tandem Mass Spectrometry Program Implementation Challenges for State Newborn Screening Programs: National Survey of Barriers and Issues. Pediatrics. 2006;117:S253-S260.

35. Ross LF. Predictive genetic testing for conditions that present in childhood. Kennedy Institute of Ethics journal. 2002;12(3):225-244.

36. Waggoner DJ, Tan CA. Expanding Newborn Screening for Lysosomal Disorders: Opportunities And Challenges. Dev Disabil Res Rev. 2011;17:9-14.

37. Ross LF, Moon MR. Ethical issues in genetic testing of children. Archives of pediatrics \& adolescent medicine. 2000;154(9):873-879.

38. Cornel MC, Rigter T, Weinreich SS, et al. A framework to start the debate on neonatal screening policies in the EU: an Expert Opinion Document. European Journal of Human Genetics. 2014;22:12-17.

39. Human Genetics Society of Australasia. Newborn Bloodspot Testing. 2011; https://www.hgsa.org.au/documents/item/ 29. Accessed 18 March 2015.

40. Morrison A, Dowler J. Newborn Screening for Disorders and Abnormalities in Canada. Environmental Scan issue 262011 ; https://www.cadth.ca/newborn-screeningdisorders-and-abnormalities-canada. Accessed 18 March 2015.

41. Potter B. Personal communication on the addition process of conditions to NBS in Ontario. 2015. 
42. Blancquaert I, Beauchamp S, Andermann A. Decision support guide for populationbased genetic screening. 2008;

http://www.cangenetest.org/en/publication s.html. Accessed 16 April 2015.

43. Renaud J, Dagenais P. Summary: The Relevance of the Neonatal Urine Screening for Inborn Errors of Metabolism Performed in Québec. 2007;

http://collections.banq.qc.ca/ark:/52327/bs 1839792. Accessed 15 March 2015.

44. Norgaard-Pedersen B, Hougaard DM. Storage policies and use of the Danish Newborn Screening Biobank. J Inherit Metab Dis. 2007;30:530-536.

45. Norgaard-Pedersen B, Hougaard DM. Newborn Screening for Congenital Disorders in Routine and Research. In: Hollar D, ed. Handbook of Children with Special Health Care Needs. New York: Springer Science+Business Media; 2012.

46. Statens Serum Institut. http://www.ssi.dk/English.aspx. Accessed 3 April 2015.

47. Gemeinsamer Bundesausschuss. Bericht der Arbeitsgruppe Zuzahlung des UA Prävention zum Regelungsauftrag des par. 62 Abs. 1 Satz 3 SGB V. Berlin: Gemeinsamer Bundesausschuss;2007.

48. Gemeinsamer Bundesausschuss. KinderRichtlinien. 2011;

https://www.g-

ba.de/informationen/richtlinien/15/. Accessed 21 March 2015.

49. Lindner M, Gramer G, Haege G, et al. Efficacy and outcome of expanded newborn screening for metabolic diseases - Report of 10 years from South-West Germany. Orphanet Journal of Rare Diseases. 2011;6(44).

50. GKV. Antrag auf Bewertung eines Screenings auf schwere angeborene Immundefekte ("SCID-Screening) bei Neugeborenen gemäB par. 135 Abs. 1 SGB
$\mathrm{V}$ i. V. m. par. 26 SGB V. Berlin: GemeinsamerBundesausschuss;2014.

51. Axmann B. Personal communication on the addition of SCID to NBS in Germany. 2015.

52. Gezondheidsraad. Neonatale screening. Den Haag, Gezondheidsraad; 2005.

53. Health Council of the Netherlands. Neonatal screening: new recommendations. The Hague: Health Council of the Netherlands, 2015; publication no. 2015/08. ISBN 978-94-6281-050-1

54. Ministry of Health. Newborn Metabolic Screening Programma Policy Framework. https://www.nsu.govt.nz/system/files/page /newborn metabolic screening programm e policy framework june 2011.pdf. Accessed 24 March 2015.

55. UK National Screening Committee. Evidence Review Process. http://www.screening.nhs.uk/evidencerevie w. Accessed 29 March 2015.

56. UK National Screening Committee. The UK NSC recommendation on Glutaric Aciduria Type 1. http://www.screening.nhs.uk/ga1. Accessed 29 March 2015.

57. American College of Medical Genetics and Genomics. Newborn Screening: Toward a Uniform Screening Panel and System. http://www.hrsa.gov/advisorycommittees/ mchbadvisory/heritabledisorders/uniforms creening.pdf?bcsi scan 313cddce030931be =SJDAuBRJsYN3KikbNsRKIvykOCYRAAAAG AF9sg $==$ \&bcsi scan filename $=$ uniformscre ening.pdf. Accessed 3 March 2015.

58. Kemper AR, Green NS, Calonge N, et al. Decision-making process for conditions nominated to the recommended uniform screening panel: statement of the US Department of Health and Human Services Secretary's Advisory Committee on Heritable Disorders in Newborns and Children. Genet Med. 2014;16(2):183-187.

59. Discretionary Advisory Committee on Heritable Disorders in Newborns and Children. Form for Nomination of a 
Condition for Inclusion in the Uniform Screening Panel.

http://www.hrsa.gov/advisorycommittees/

mchbadvisory/heritabledisorders/nominate

condition/nominationform.pdf. Accessed 3

March 2015.

60. Discretionary Advisory Committee on Heritable Disorders in Newborns and Children. Advisory Committee on Heritable Disorders in Newborns and Children.

http://www.hrsa.gov/advisorycommittees/ mchbadvisory/heritabledisorders/index.ht ml. Accessed 3 March 2015.

61. Bailey DB, Jr., Beskow LM, Davis AM, Skinner D. Changing perspectives on the benefits of newborn screening. Mental retardation and developmental disabilities research reviews. 2006;12(4):270-279.

62. Bombard Y, Miller FA, Hayeems RZ, Avard D, Knoppers BM. Reconsidering reproductive benefit through newborn screening: a systematic review of guidelines on preconception, prenatal and newborn screening. European Journal of Human Genetics. 2010;18:751-760.

63. Buchbinder M, Timmermans S. Newborn screening and maternal diagnosis: Rethinking family benefit. Social Science \& Medicine. 2011;73:1014-1018.

64. Natowicz M. Newborn screening--setting evidence-based policy for protection. The New England journal of medicine. 2005;353(9):867-870.

65. Botkin JR, Clayton EW, Fost NC, et al. Newborn screening technology: proceed with caution. Pediatrics. 2006;117(5):17931799.

66. Watson $M$, Mann MY, Lloyd-Puryear $M$, Rinaldo P, Howell RR. Newborn screening: toward a uniform screening panel and system--executive summary. Pediatrics. 2006;117(5 Pt 2):S296-307.

67. Kemper AR, Kus CA, Ostrander RJ, et al. A framework for key considerations regarding point-of-care screening of newborns. Genet Med. 2012;14(12):951-954.

68. Pollitt RJ. Principles and performance: assessing the evidence. Acta Paediatr Suppl. 1999;432:110-114.

69. Zwahlen $M$, Low $N$, Borisch $B$, et al. Population based screening - the difficulty of how to do more good than harm and how to achieve it. Swiss medical weekly. 2010;140:w13061.

70. Fischer KE, Grosse SD, Rogowski WH. The role of health technology assessment in coverage decisions on newborn screening Intl. J. of Technology Assessment in Health Care. 2011;27(4):313-321.

71. Therrell BL. U.S. Newborn Screening Policy Dilemmas for the Twenty-First Century. Molecular Genetics and Metabolism. 2001;74:64-74.

72. Howard HC, Knoppers BM, Cornel MC, et al. Whole-genome sequencing in newborn screeningquest A statement on the continued importance of targeted approaches in newborn screening programmes. Eur J Hum Genet. 2015.

73. Bombard Y, Miller FA, Hayeems RZ, et al. Public views on participating in newborn screening using genome sequencing. Eur J Hum Genet. 2014;22(11):1248-1254.

74. Borry $P$, Henneman L, Lakeman $P$, ten Kate LP, Cornel MC, Howard HC. Preconceptional genetic carrier testing and the commercial offer directly-to-consumers. Human Reproduction. 2011;26(5):972-977. 


\section{Chapter 6}

\section{Decision making in newborn screening}

needs a transparent approach with structured multidisciplinary stakeholder engagement in all phases
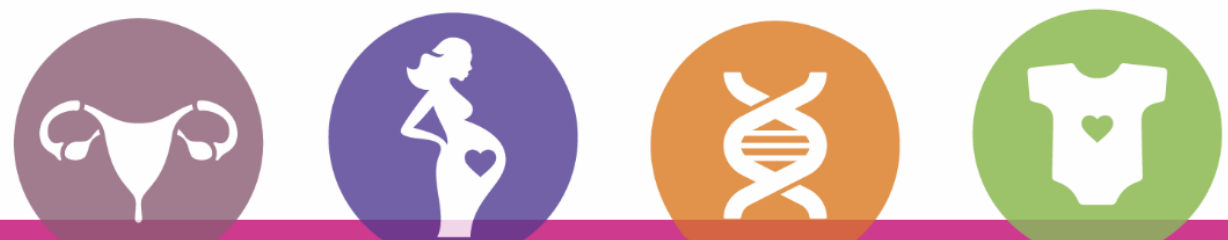

Submitted

Marleen E. Jansen

Henk J. van Kranen

Karla J. Lister

Martina C. Cornel 


\begin{abstract}
Newborn bloodspot screening (NBS) programs have expanded significantly in the past years, and are expected to expand further with the emergence of genetic technologies, such as next generation sequencing. Historically, NBS expansion has often followed an ad hoc consideration of conditions, instead of a structured, transparent, and evidencebased approach. In this review we aim to summarize relevant elements for NBS policy making, following the steps in the policy cycle: a) agenda setting, b) policy advice, c) policy decision, d) implementation, and e) evaluation. A literature search was conducted to gather information on the elements specific to NBS and its policy making. Policy making in NBS could benefit from moving towards a process that has its origin in health technology assessment, but is adjusted to the potential of genetic information. A framework to enable stakeholder involvement, and accessible information in scientific literature from different countries should be strived for. Through combining international knowledge supported by different stakeholder groups can NBS policies be harmonized to ensure equity in access to early care for relevant conditions. Only by making careful and considered decisions, can we ensure that NBS of the future is as successful as the programs we know today.
\end{abstract}

Key words: Newborn screening; HTA; policy cycle; ELSI; genetic technologies

\title{
Key messages:
}

1. Consideration of conditions for newborn screening should follow a process of horizon scanning, resulting in evidence based nominations of relevant conditions.

2. Structurally engaging stakeholders in policy making is fundamental to modern healthcare agenda setting and program design, to safeguard the programs and their future development.

3. By balancing competing influences and demands, ultimately support for implementation can be created through stakeholder engagement.

4. Countries should report on their policy processes and outcomes of NBS in international literature to enhance transparency, learning experiences, and harmonization across borders. 


\section{Introduction}

Newborn bloodspot screening (NBS) is the longest running and most successful screening program worldwide (Therrell et al. 2015). NBS screens newborns within the first days of life for multiple serious conditions.(Health Council of the Netherlands 2015) The traditional aim of NBS is to prevent serious consequences for the newborn by enabling timely diagnoses and treatment for early onset childhood conditions (Bombard et al. 2010). In recent years, technological developments have fueled the expansion of NBS. A key example has been the advent of tandem mass spectrometry (MS/MS), which emerged in the 1990s and made it possible to test for several conditions at once in a cost-effective manner (Moyer et al. 2012; Therrell 2001). Correspondingly, programs worldwide adopted the technology and significantly increased the number of conditions screened. While decision making was informed by the same aim and principles, current practices are highly different, suggesting a difference in processes to arrive at a NBS policy (Dezateux 1998; Pollitt 2007; Pollitt 2009; Potter et al. 2008). In line with this, the current paper aims to explore the underlying structures that could facilitate harmonized policy making based on best practice evidence.

In each country or jurisdiction, NBS policy is the result of a decision making process that generally follows the policy cycle, consisting of: a) agenda setting (consideration of a condition), b) policy advice (assessment of the condition), c) policy decision, d) implementation, and e) evaluation (Buse et al. 2005). To progress through these steps, and enable weighing the benefits and harms of screening, most countries use the Wilson and Jungner principles which have been adapted to suit their local settings (Elliman et al. 2002; Therrell 2001; Therrell 2008), and more recently to act on advances in genetic testing (Andermann et al. 2011; Petros 2012). These adapted criteria, while different between countries, all generally focus on areas concerning the a) condition, b) test, c) treatment, and d) screening programme, and can be considered to form the basis of policy recommendations worldwide (Bailey et al. 2006; Elliman et al. 2002). The four areas covered by the screening criteria, highlight that NBS is not just a laboratory test; it is a comprehensive system that involves a wide range of stakeholders and is under constant development (Arn 2007; Bailey et al. 2008; Moyer et al. 2012; Therrell 2001).

The emergence of MS/MS has had a significant impact on NBS, and several authors describe recent debates on further expanding NBS, a debate that has increased relevance given the emergence of genetic technologies, such as next generation sequencing (Roberts et al. 2014). Even more than MS/MS, genetic technologies may enable screening for a broad range of conditions which do not always fit within the traditional aim of NBS. Under influence of the possibilities that genetic technologies offer, attention has moved to an explicit shift away from the traditional aim of NBS (Grosse et al. 2006). This possible shift is now being played out in the academic and policy settings, as experts and decision makers consider the role of the programs and their potential to screen for conditions that do not always have a clear cut direct benefit for the child (Bailey et al. 2006; Bombard et 
al. 2010). Previous expansions, and the divergent programs which have evolved, suggest that the emergence of this policy debate is a unique turning point for NBS, and should be carefully considered across the globe.

Internationally there are increasing calls to move further beyond the traditional aim, and screen for rare and 'untreatable' conditions (Bailey 2009; Clayton 1999). These conditions do not always have a certain treatment benefit or treatment is not urgently needed in the newborn period. For untreatable conditions to be implemented in NBS, some argue that the aim has to shift from clinical benefits solely for the child, to include family benefits (Dhondt 2010; Elliman et al. 2002). Family benefits can be reproductive options for the parents. Expanding the beneficiary of NBS challenges decision making, and has significant implications for policy development and program implementation. Nonetheless, some countries are moving slowly towards the shift in the aim of NBS: the United States of America's (USA) Recommended Uniform Screening Panel already includes untreatable conditions (ACMG 2006; Roberts et al. 2014). Furthermore, the Dutch Minister of Health, Well-being, and Sports recently stated to initiate an exploration of an optional NBS program for untreatable conditions, parallel to the current program (Schippers 9 July 2015). This initiative was also welcomed by the Dutch Collaboration of Parent and Patient Organizations (VSOP) (Oosterwijk 2015).

Based on past experience it can be expected, that this shift occurring in the Netherlands will become an example of what is possible. Experts, consumers and advocacy groups in other countries are likely to also increase calls for screening for other conditions. As a result, other countries will either follow to remain at the forefront of what is possible, or will at a minimum facilitate a debate on the pros and cons (Metternick-Jones et al. 2015). While continued progress is vital, it remains to be explored whether screening for untreatable condition in the newborn period would be appropriate (Howard et al. 2015). The emergence of this policy debate presents decision makers worldwide with the challenge of weighing the benefits and harms of screening, in the changing landscape of NBS.

In this review we provide an overview of different types of decision making with regard to NBS, and the role of stakeholder groups. This overview will inform stakeholders involved in NBS about relevant factors in decision making. Several elements of decision making frameworks and processes from the scientific literature are summarized, such as criteria for screening and quality assurance. These elements provide a framework that can then be applied to future decisions within NBS. Evidence-based decision making frameworks will be essential for policy makers facing the challenge to decide on screening options, including untreatable genetic conditions. The changing landscape for NBS implies that it is essential that careful consideration is given to how and why decisions are made, to ensure that the programs continue to be able to maintain their benefits to the population. 


\section{Methods}

To be able to conduct a structured comparative analysis, we explored scientific literature to summarize relevant factors influencing decision making for NBS. Within this search we focused on four stakeholder groups suggested by Andermann et al.(Andermann et al. 2010): society, medicine, industry, and government. Society for example includes community groups; an example in the stakeholder group medicine are health professionals; industry focuses on biotechnology; and government mainly encompasses the health sector (table 1) (Andermann et al. 2010). In current policy making processes, these actors are involved in addressing issues on different levels. For example the general public, individual patients and families, and their advocacy groups, will be more involved in agenda setting, while politicians and governmental agencies are more involved in issues of deciding which conditions in practice will be added to NBS programmes (Cornel et al. 2012).

Table 1. Key stakeholders and subgroups in NBS decision making.

\begin{tabular}{llll}
\hline Society & Medicine & Industry & Government \\
\hline - Patient (support) & - Individual patients & - Biotechnology & - Health sector: \\
advocacy groups & and families & - Pharmaceutical & regulatory, \\
- Community & - Health care & - Biomedical & advisory/HTA, and \\
groups & professionals & & other agencies, \\
- General public & - Scientists; scientific & & national/regional \\
& and professional & & - Politicians; ministers \\
& societies & & of Health \\
\hline
\end{tabular}

Note: Adapted from Andermann et al. and Expert opinion document from the EU Tender on NBS (Andermann et al. 2010; Cornel et al. 2012)

We gathered scientific literature by searching PubMed and Web of Science for articles regarding newborn screening and policy. We combined these key search terms with the following search terms: 1. program development, 2. decision-making, 3. governance, 4. management, 5. perspective, 6. future, and 7. disease or condition. A first selection was made based on title and abstract, and only articles written in Dutch and English were included. We only included publications on dried bloodspot screening. Articles concerning other types of newborn screening (e.g. hearing, hip dysplasia) were excluded, because we wanted to focus on the complex decision making regarding the multiple conditions included in bloodspot screening.

Articles considered for review were assessed on the information they provided about elements important for stakeholders consulted in decision making. The assessment consisted of selecting information on relevant policy factors: consideration of a condition; assessment of the condition; policy decision; implementation; and evaluation. Furthermore, overarching elements structuring policy-making were summarized, such as applied frameworks. Based on this assessment, relevant stakeholders were pinpointed 
that influence decision making in NBS. After initial review by MJ the factors derived from scientific literature were deliberated with HvK to discuss their relevance in decision making. After consensus, the factors were described in detail.

\section{Results}

The search and selection process resulted in 27 articles to be included in the overview of relevant processes in decision making for NBS and the stakeholders involved (table 2). Most literature originated from western societies, predominantly the USA (13 of 27 articles), and was initiated from a clinical background rather than a public health background. Of the first authors $64 \%$ had a hospital, clinical research centre, or laboratory affiliation; and $36 \%$ a health policy, economics, or bioethics background (figure 1). The main technology discussed in the articles show a gradual shift through time from MS/MS towards solely discussing genetic technologies as the challenge for NBS: 3 of 13 articles until 2008, and 6 of 14 published since 2009 discuss mainly genetic technologies (table 2). The recent articles discussing MS/MS report on results from current screening programs16 or previous decision making processes (Fischer et al. 2011). The following sections will highlight the key factors that were found regarding overarching elements to approach policy-making and the specified steps for NBS in the policy cycle.

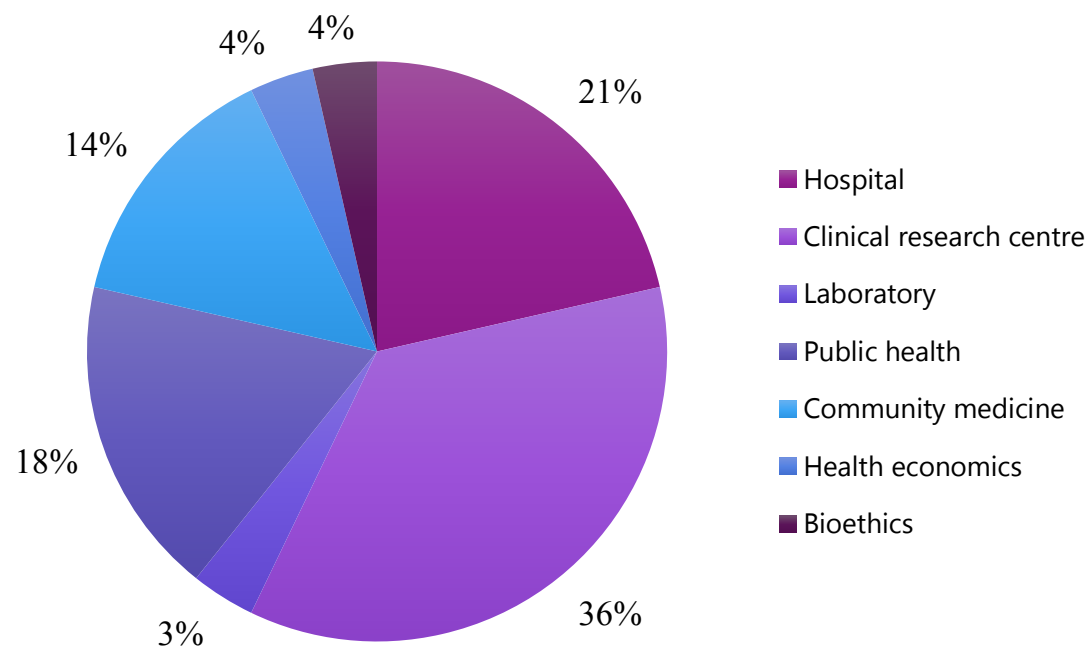

Figure 1. Division of the affiliation of the first author from the articles in the review. 


\section{Overarching elements to approach policy-making}

Many authors argued that decision making concerning NBS should be a structured, evidence-based, and transparent process, attentive to important social values and making use of standardized methods (Benkendorf et al. 2010; Grosse et al. 2006; Hayeems et al. 2013). Several frameworks were mentioned in literature that could guide decision making processes in a structured, evidence-based, and transparent way (Fischer et al. 2011; Pollitt 2006; Simopoulos 2009; Therrell 2001). Of the frameworks, a structured approach based on health technology assessment (HTA), was regarded appropriate by several authors (Borowski et al. 2007; Fischer et al. 2011; Little et al. 2008; Potter et al. 2009). HTA was defined as: 'a multidisciplinary field of policy analysis. It studies the medical, social, ethical, and economic implications of development, diffusion, and use of health technology'(Potter et al. 2009).

HTA has been successfully used by several countries in decision making processes with regard to NBS, and offers a structured, standardized yet flexible framework to decide about NBS policy (Fischer et al. 2011; Grosse et al. 2006). HTA by default includes considerations on ethical, legal, and social implications (ELSI) (Potter et al. 2009). The expansion of NBS including potential future applications of genetic technology raises numerous ELSI-related issues that need to be addressed, such as information and counselling needs of patients or their families (Bailey et al. 2006; Dhondt 2010; Potter et al. 2009; Therrell 2001). The use of an HTA-framework has been concluded to positively influence the structuring of a decision making-process on several levels (Fischer et al. 2011): how the decision making process is triggered; assessment of conditions against screening criteria; and participation of stakeholders in the process. First, in countries that did not have an HTA-framework in place the consideration of a new condition appeared to be more ad hoc instead of based on an objective threshold of criteria before a condition is considered. Secondly, in these instances the evidence used to assess conditions was mainly expert opinion instead of high level evidence-base. Thirdly, the participation of stakeholders was higher in countries that did have an HTA-framework in place (Fischer et al. 2011).

A range of stakeholders involved in decision making is mentioned in literature. They include representatives from society, medicine, industry, and government (table 1). Most literature describes a structure where a national government advisory body and/or local governments act on the advice from a multidisciplinary working group (table 2). There are different ways to involve stakeholders, in general they are included in the process through workshops, working groups, meetings, and consultations (Potter et al. 2008). Ideally, the involved organisations represent a range of stakeholders including consumer and patient representatives (Plass et al. 2009). As can been seen in table 2, consumer and/or patient representatives are not always reported as stakeholders in the decision making process ( $n=19$ of 27). The participation of different stakeholders is relevant, since the involved parties in policy development can influence the outcome of the evaluation. 
For example, government agencies may have more stringent criteria than experts in the field of NBS (Dhondt 2010).

Several levels of governance can be involved in developing policy for NBS, both local and national (Cornejo et al. 2010; Hiller et al. 1997). Governance involves decision makers that aspire to achieve a national health policy objective. It is a process that focusses on balancing competing influences and demands (WHO 2015). Therefore, the need for harmonization in national policies is often referred to in literature, to ensure equity in access to early interventions (Elliman et al. 2002). In countries with multiple jurisdictions or health regions, a central body like a federal government should play a larger role in overseeing NBS. This type of central body would have responsibilities such as facilitating collaboration (Arn 2007; Bailey et al. 2008). An advisory committee could advise them on implementation, development, review, modification, and cessation of (parts of) NBS (Atkinson et al. 2001; Cornejo et al. 2010; Elliman et al. 2002).

\section{Consideration of a condition}

Discussions around expansion of screening are usually fuelled by new technologies, broader disease definition or growing insight into pathophysiology, and advocacy towards health and wellbeing outcomes (Bailey et al. 2008; Dhondt 2010; Hayeems et al. 2013; Therrell 2001; Therrell 2008). In the past NBS policy direction and program expansion has been strongly influenced by technological drivers, evaluated ad hoc. Therefore, current NBS programmes might contain conditions that have not been robustly evaluated through an agreed decision making process. It can be argued that a more robust process would be for an independent body to undertake horizon scanning, to identify any range of conditions, to support expansion through an evidence-based process (Atkinson et al. 2001; Bailey et al. 2006; Grosse et al. 2006). Decisions about NBS should follow the standards of evidence-based public health, and therefore include systematic assessment of evidence on effectiveness using standardized methods. 


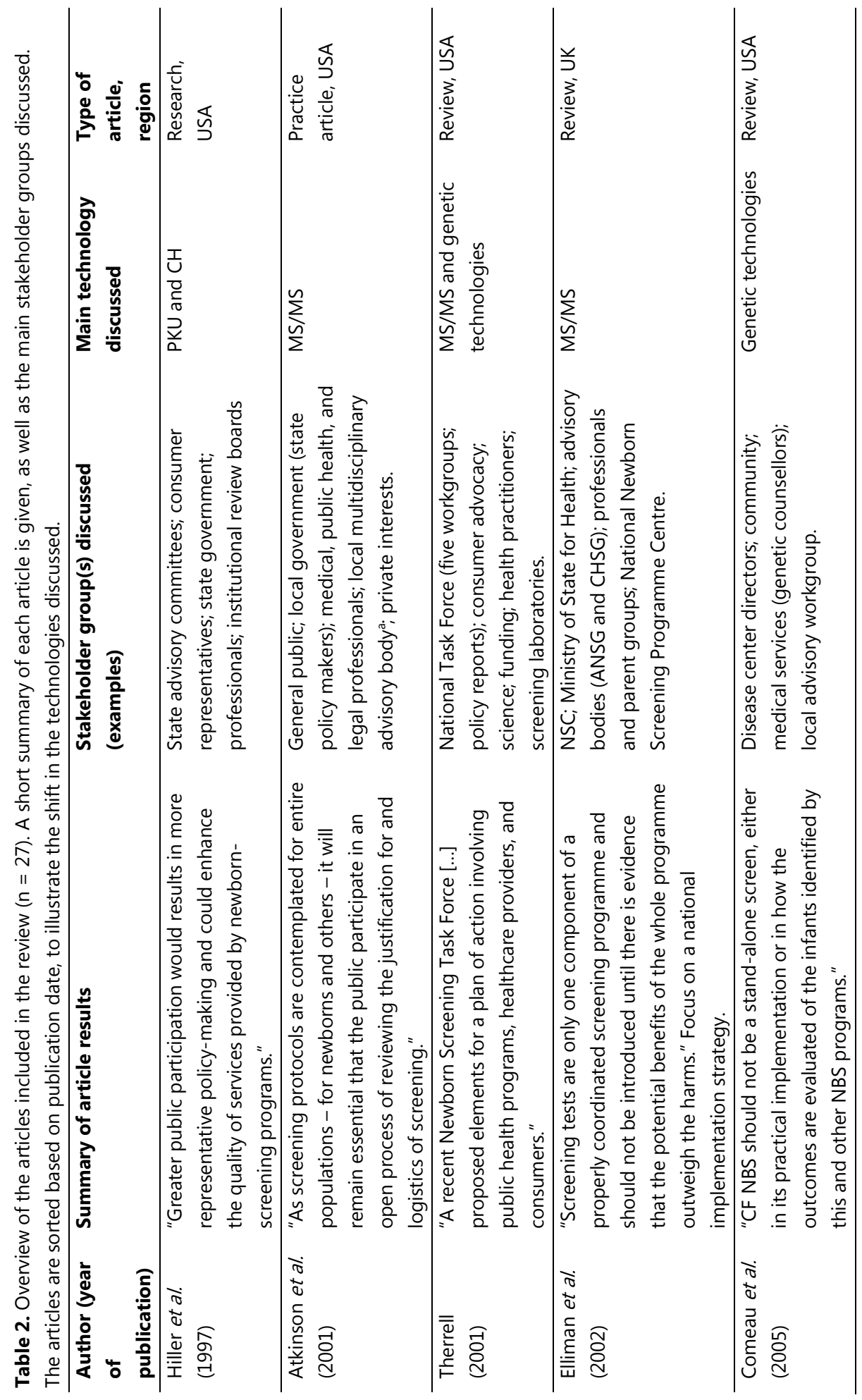




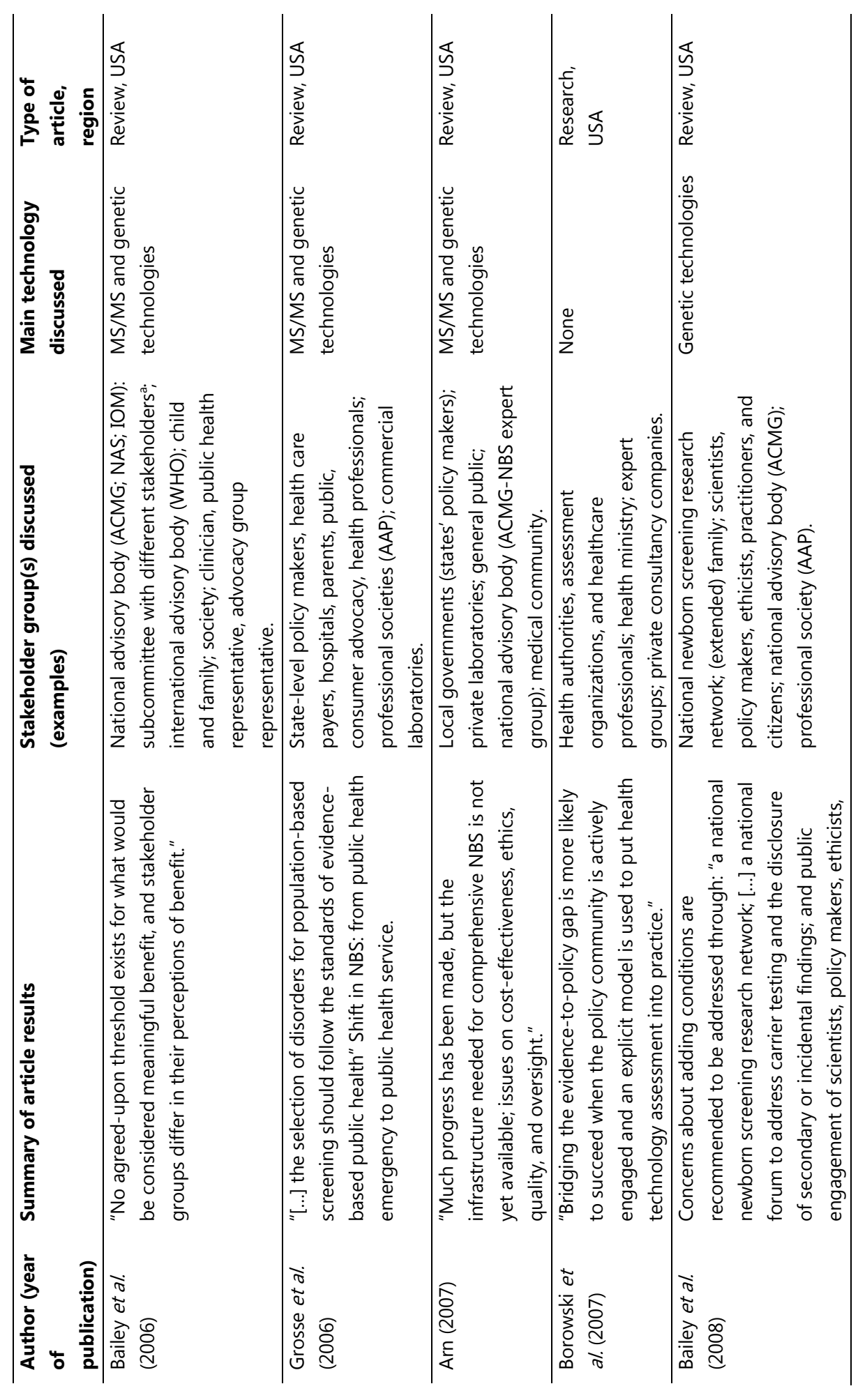




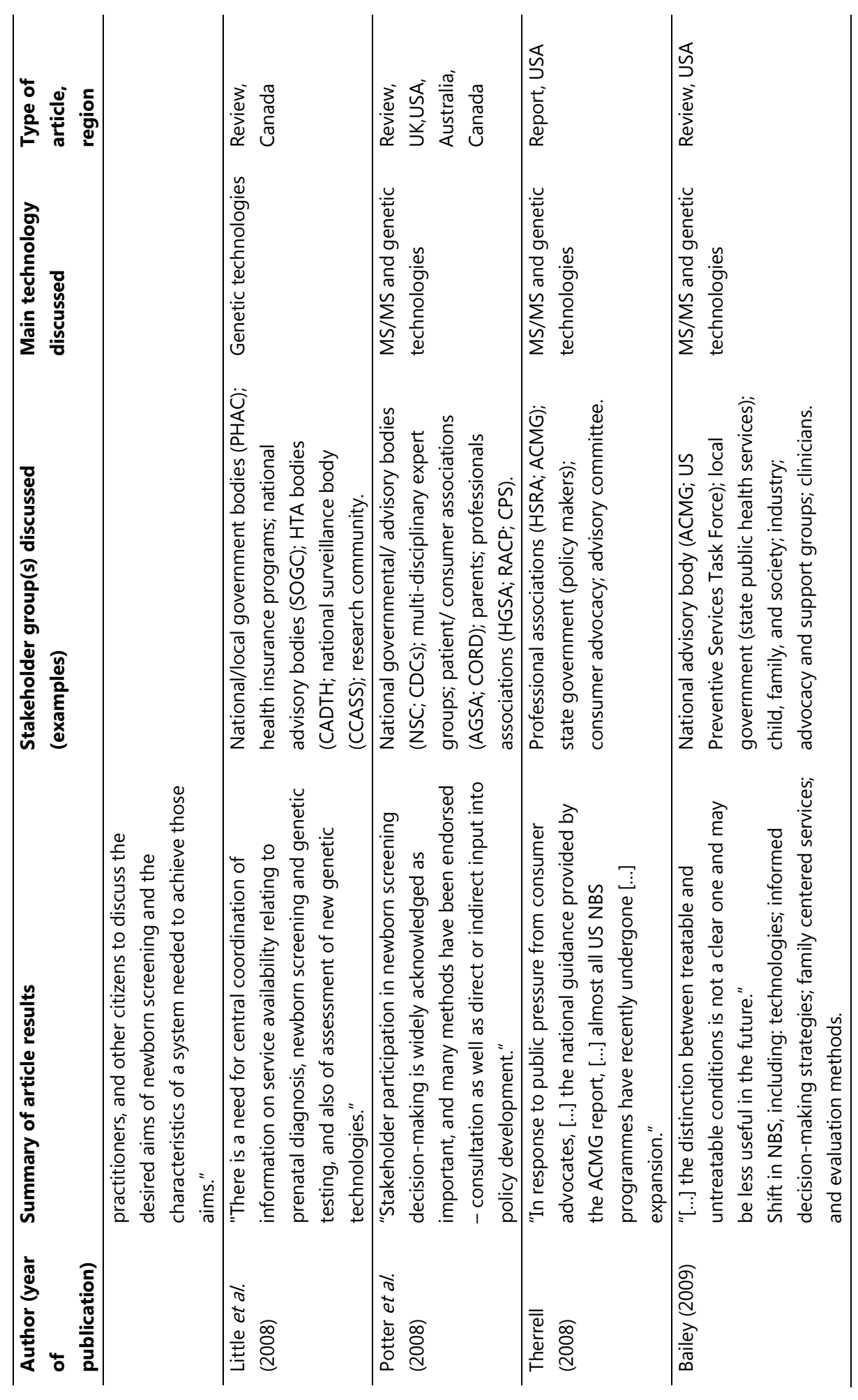




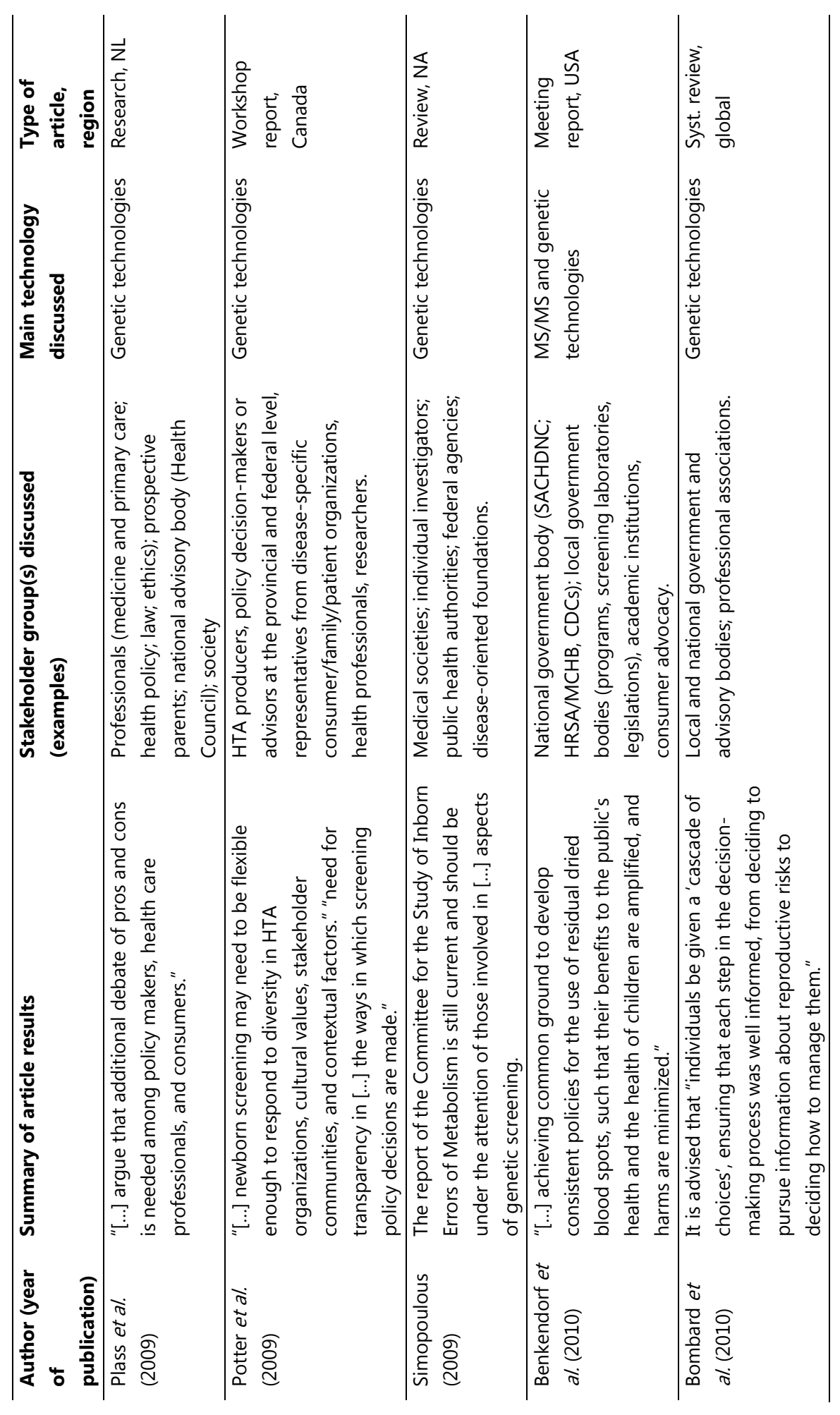




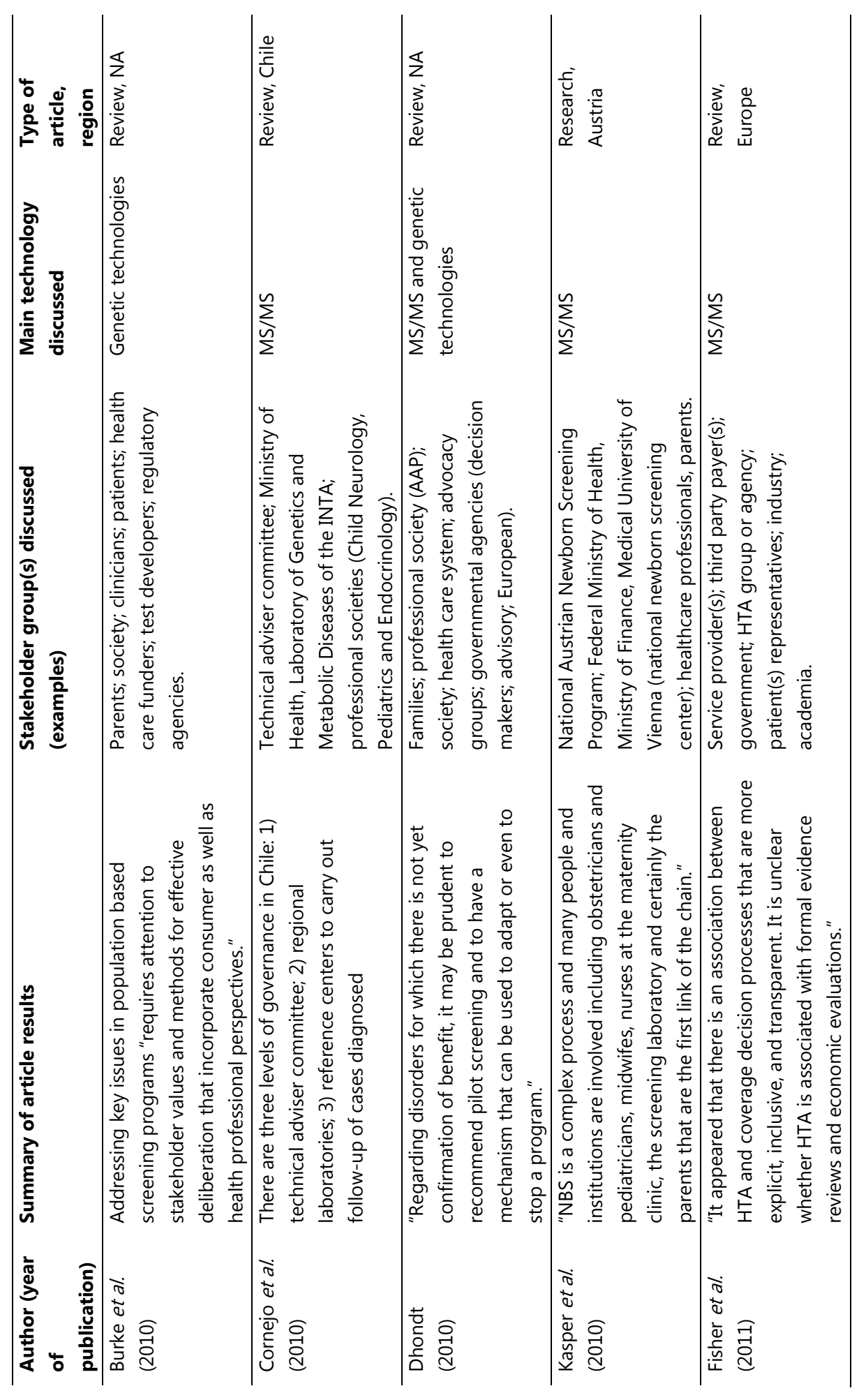




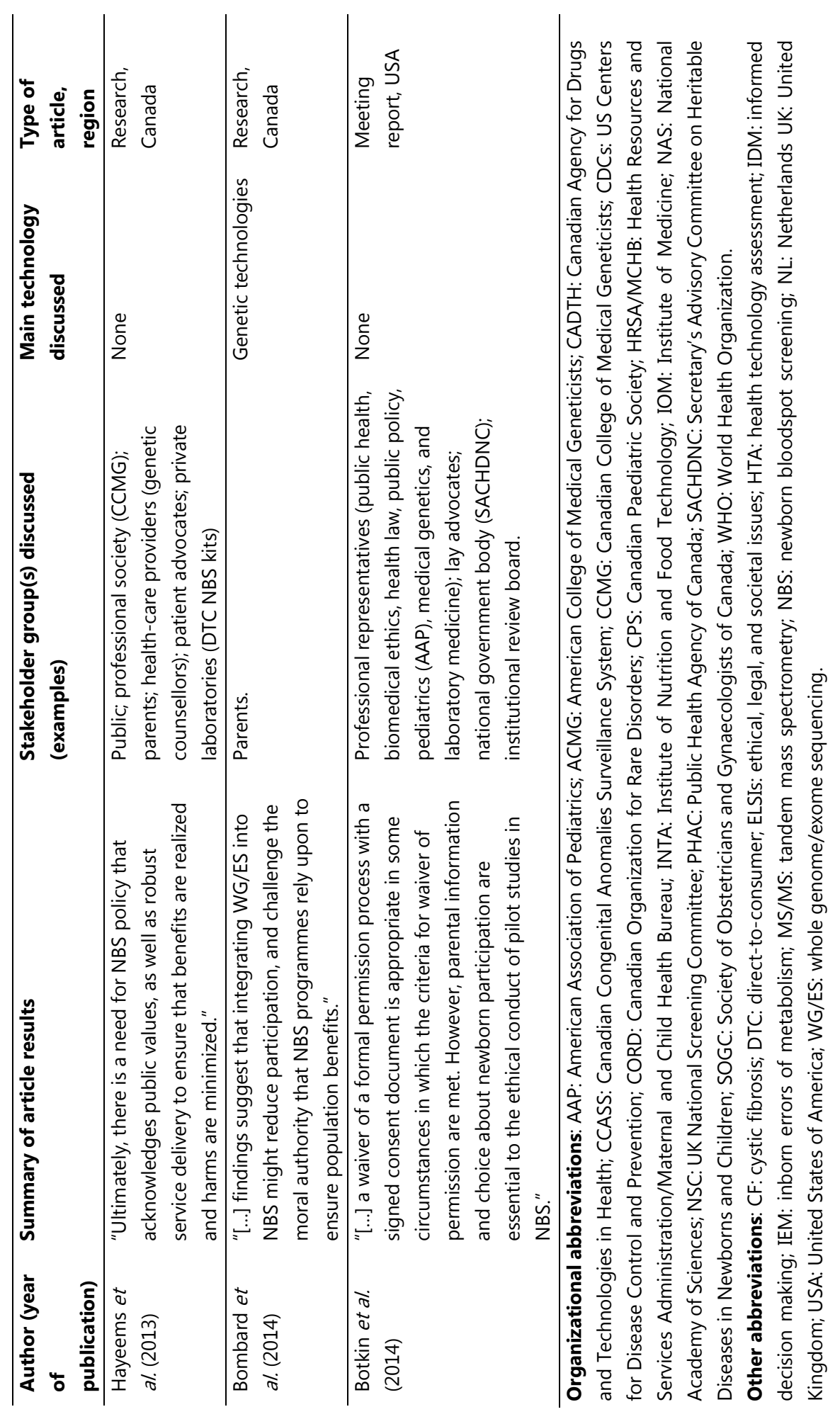




\section{Assessment and advice}

Predominantly criteria are used to assess conditions once they are nominated for screening, instead of also using criteria to determine which conditions should be considered for screening in the first place. Within the literature reviewed, the assessment of nominated diseases centred around the appropriateness of using criteria originating from the Wilson and Jungner principles, which include the a) condition, b) test, c) treatment, and d) screening programme (Bailey et al. 2006; Elliman et al. 2002; Plass et al. 2009). A specific aspect that was criticized is the fact that the Wilson and Jungner principles are developed to evaluate individual diseases, while modern day technology pushes towards the possibility and sometimes the need to evaluate groups of diseases at once (Arn 2007; Petros 2012).

Another aspect that was highlighted, was the aim of screening, who benefits and how this influences the assessment of criteria (Bailey et al. 2006; Grosse et al. 2006). In general three groups were mentioned as main beneficiaries of NBS: benefit for the child, the family, and/or society (Bailey 2009). When the aim of screening moves away from the child and towards any of these different groups, it has profound consequences for the diseases screened for (Bombard et al. 2010; Grosse et al. 2006). For example, the definition of 'treatment' within screening criteria can be stretched to 'intervention', or even 'providing information' or 'support', and might go towards 'surveillance' (Bailey 2009). With regard to decision making, shifting the aim of screening from being focused on delivering medical benefits to the newborn will lead to a vast increase in the number of conditions that are eligible for screening.

Finally, as a core validation of any screening programme, the benefits of screening should outweigh the harms. While this is a repeated theme through the articles, there is no agreed-upon threshold for benefit (Bailey et al. 2006; Elliman et al. 2002; Grosse et al. 2006). As described above, what benefit is, to whom, and how it should be weighed in decision making is open to interpretation, and should be specified in evaluation reports (Burke et al. 2010; Clayton 1999; Potter et al. 2008). Harms or costs of NBS that need to be factored in to the balance are also a complex construct, since NBS is a broad system, and changing one part of the system influences the whole chain of action (Grosse et al. 2006; Hubbard 2007). Advice is often provided through guidelines. Guidelines can be provided by government-affiliated institutions, government advisory bodies or professional organizations (Bombard et al. 2010). Guidelines should include information to cover all the aspects in the NBS-system: screening; follow up; diagnosis; management; evaluation; and education (Dhondt 2010; Fischer et al. 2011; Therrell 2001).

\section{Decision and implementation}

Authors suggested that innovations in NBS should be implemented in a research paradigm, to facilitate data collection for policy decisions, and gain informed consent 
from parents participating with their child(ren) in the study (Arn 2007; Botkin et al. 2014; Clayton 1999; Grosse et al. 2006). Pilot studies are vital to the development of a strong evidence base to support decision making regarding the addition of new conditions. Currently, decisions often need to be made based on incomplete information (Grosse et al. 2006).

Once a condition is ready for universal implementation in the programme, an implementation plan focussing on the different levels on which NBS operates and the information needed on each level should be developed (Atkinson et al. 2001; Comeau et al. 2005; Cornejo et al. 2010). Issues across programmes are similar when looking at implementation and can mainly be found in five fields: education, finances, logistics, politics, and culture (Dhondt 2010; Therrell 2001). These fields range beyond the public health policy in the sense that also the follow-up in the clinical setting will need to be coordinated, such as a knowledge gap in professionals (Dhondt 2010). An aspect that is often not made explicit in guidelines is a possible underlying aim of screening, often informing parents about reproductive risk and/or long-term follow-up (Bombard et al. 2010). Moreover, when the preferred technology moves toward genome-based technologies, issues in the fields of privacy and confidentiality, residual specimen storage and usage policies, and educational material become even more pressing (Bombard et al. 2014).

\section{Evaluation and quality assurance}

A screening programme needs constant maintenance. Quality assurance to keep the programme under close monitoring is highly relevant (Bailey 2009; Elliman et al. 2002; Grosse et al. 2006). Quality assurance approaches assess performance against defined targets, they provide essential ongoing assessment of feasibility, cost, and equitable delivery of testing (Bailey et al. 2006; Burke et al. 2010; Comeau et al. 2005). Therefore quality assurance programmes should be developed and aim at evaluating the system of NBS (Arn 2007). They are vital to continuously monitor the success of a program, especially to evaluate the addition of conditions. Some authors suggest principles for quality assurance, such as clear guidelines on responsibilities throughout the chain of NBS, and standards on aspects regarding confidentiality and storage of blood spot specimens (Atkinson et al. 2001). These aspects could fall into key features of a quality assurance programme, which can consist of standard setting; training; and performance measurement (Elliman et al. 2002). Based on the evaluation, a system can be put in place to ensure quality and stop screening for a specific condition when appropriate (Dhondt 2010). 


\section{Future perspectives}

A final aspect highlighted in the literature is the need to undertake continuous horizon scanning, and ready programs for future development. This facilitates timely translation of innovations, which will allow for best available health care for citizens. A main concern identified in several articles, is the lack of data to be able to make an evidence-based decision. The need for interoperable databases is argued, so sufficient data can be collected on diseases included and nominated for inclusion in NBS (Bailey et al. 2006; Bailey et al. 2008; Botkin et al. 2014). Furthermore, one of the issues within in NBS is the longstanding question about parental choice, and how to make sure the information provided enables them to participate in informed decision making (Bailey 2009; Grosse et al. 2006; Hayeems et al. 2013). Some authors suggest that written consent seems necessary when implementing DNA testing (Dhondt 2010). Since these tests hold the potential to gain predictive information for adult-onset disorders, and carrier status, they unravel complex ELSIs, such as issues related to privacy and confidentiality (Bombard et al. 2014).

Though NBS programs hold potential for expansion, some authors stress the importance of applying targeted analyses to prevent decreasing participation rates (Bombard et al. 2014). NBS programs' future developments will be strongly influenced by the extent to which governments are willing to accept NBS as a public health service, rather than a public health emergency (Grosse et al. 2006). NBS traditionally falls within a model of public health emergency, where immediate action is needed after screening to prevent irreversible harm to the newborn (Bailey et al. 2006; Grosse et al. 2006). This is in contrast with the model of a public health service, where screening will provide screening as a service to families and infants, justified by broader benefits than solely preventing irreversible harm to the newborn (Bailey et al. 2006; Grosse et al. 2006). Before NBS can progress to such an extent, a considerable number of unanswered questions are identified and further work is needed to address the specific challenges.

\section{Discussion}

The articles reviewed highlight that the face of NBS is changing. Importantly, this review highlights that such change should occur in an environment that safeguards the programs, and supports their future development. In line with this, authors advocated a structured approach to decision making. The overarching process of decision making and policy development in NBS should be a transparent, structured, and evidence-based process, according to several authors (Benkendorf et al. 2010; Grosse et al. 2006; Hayeems et al. 2013). Our study shows gaps that exist in reporting policy development in international scientific journals. While NBS is implemented worldwide, with sometimes multiple NBS programs within one nation (Therrell et al. 2015), the literature search only showed reports from seven different countries - predominantly the USA (table 2). This could hamper monitoring the quality of NBS programs worldwide, and learning 
experiences between countries (Fischer \& Rogowski 2014). Ultimately this slows down the process of harmonization of best practice NBS programs and equality in health care access for parents and their newborns globally.

Besides transparency, a structured approach to policy making in NBS is also suggested (Fischer et al. 2011; Grosse et al. 2006). Decisions in NBS are becoming increasingly complex with genetic technologies on the horizon, and the numerous ELSI associated with the implications of genetic technologies. Genetic applications can be considered controversial in relation to privacy, and there are no a straightforward answers for the associated issues (Avard et al. 2010). Therefore, ELSI associated with genetics in NBS cannot be solved solely by government bodies or experts in science or medicine, but also need public support (Avard et al. 2010).

In the articles in the current review, the four stakeholder groups suggested by Andermann et al. (2010) are all mentioned as stakeholders in decision making for NBS (table 2): society, medicine, industry and government (Andermann et al. 2010). It was striking that the majority of the articles were not written by public health experts, such as health policy or community medicine experts, but by authors with clinical oriented affiliations (figure 1). Government was mentioned most often as stakeholder group; ultimately governments' decisions are an essential step in the translation of knowledge (NCATS 2015). However, it is widely acknowledged that engaging consumers in decision making is fundamental to modern healthcare agenda setting and program design (Avard et al. 2010; EURORDIS 2015). It seems that currently advocacy groups or professionals play a role in ad hoc agenda setting, instead of standardized roles in different phases of decision making. This is noteworthy, since Hiller et al. (1997) concluded almost twenty years ago that "Greater public participation would result in more representative policymaking and could enhance the quality of services provided by newborn-screening programs." (Hiller et al. 1997)

Our results suggest most countries have not found a structured approach to include relevant stakeholders in different phases of policy making. This means that governments miss an essential component of sound policy-making. Involving different stakeholder groups enables to cut across the range of issues stakeholders find relevant. Moreover, by balancing competing influences and demands, ultimately support for implementation can be created through stakeholder engagement. Fisher et al. (2011) found the participation of stakeholders to be higher in countries that make use of an HTAframework (Fischer et al. 2011), so using HTA in NBS policy making could aid in the structured approach to stakeholder involvement. Furthermore, specific tools to evaluate genetic tests have been developed, such as the Evaluation of Genomic Applications in Practice and Prevention (EGAPP) initiative (Teutsch et al. 2009). However, evidence-based guidelines are rare, and adequate support is needed for translation of genetic technologies (Khoury et al. 2007). 
In addition to both a transparent and structured approach involving different stakeholder groups, authors raised that an evidence-base should inform decisions in NBS policy (Grosse et al. 2006; Teutsch et al. 2009). This issue will become more pressing since rare diseases are increasingly considered for NBS and evidence is more difficult to generate for rare diseases. Issues regarding an evidence-based approach can also be found in the consideration of conditions and data on the appropriateness of adding a condition to NBS. Horizon scanning should be implemented to ensure the nomination of relevant conditions to consider for screening on population level. This will prevent ad hoc consideration and possible implementation of conditions that may seem highly relevant for a small group of the population, while unnecessarily burdening a large group in the population.

If a condition seems promising for screening of population level, but there is not sufficient evidence, the condition can first be introduced as a study (Arn 2007). In the USA the BabySeq pilot study has been started to gain insight in the added value of genome sequencing to NBS (Nowogrodzki 2015). However, international databases could be essential to gather enough data on rare conditions. To establish such a network, clear standards on data collection should be agreed on (GA4GH 2015). Not only for new conditions, but also for the long term follow up (LTFU) of current conditions standards are needed according to some authors, to evaluate NBS programs (Hinton et al. 2014; Hoff et al. 2007). Establishing databases internationally will pose a significant challenge for policy makers, since this presents a range of issues on data coordination, such as standardized identifiers, but also cross-border privacy regulations (Hoff 2008).

Our study has several limitations, data from the USA was clearly overrepresented since 13 of the 27 articles addressed NBS in the USA. Furthermore, a sample of 27 articles might not be representative for international policy making in NBS, especially since policy documents were not part of the current scope. However, this approach did illustrate that policy information from a range of countries is not easily accessible. Nonetheless, this review shows relevant aspects in policy making, and addresses gaps in the current processes.

In the future a transparent, structured, and evidence-based approach to policy making will only become more urgent with the challenges of genetic technologies. A framework to enable stakeholder involvement, and accessible information from different countries in scientific literature should be strived for. Only through combining international knowledge supported by different stakeholder groups, can NBS policies be harmonized to ensure equity in access to early care for relevant conditions. Further, only by making careful and considered decisions, can we ensure that NBS of the future is as successful as the programs we know today. 


\section{References}

ACMG. 2006. Newborn Screening: Toward a Uniform Screening Panel and System.

Andermann A, Blancquaert I, Beauchamp S, Costea I. 2011. Guiding Policy Decisions for Genetic Screening: Developing a Systematic and Transparent Approach. Public Health Genomics, 14: 9-16.

Andermann A, Blancquaert I, Déry V. 2010. Genetic screening: a conceptual framework for programmes and policymaking. J Health Serv Res Policy, 15: 9097.

Arn PH. 2007. Newborn Screening: Current Status. Health Affairs, 26: 559-566.

Atkinson K, Zuckerman B, Sharfstein JM, et al. 2001. A Public Health Response to Emerging Technolgy: Expansion of the Massachusetts Newborn Screening Program. Public Health Reports, 116: 122131.

Avard D, Stanton Jean M, Grégoire G, Page M. 2010. Public involvement in health genomics: the reality behind the policies. International Journal of Consumer Studies, 34: 508-524.

Bailey DB. 2009. The Blurred Distinction between Treatable and Untreatable Conditions in Newborn Screening. Health Matrix, 19: 141-153.

Bailey DB, Beskow LM, Davis AM, Skinner D. 2006. Changing Perspectives on the Benefits of Newborn Screening. MRDD Research Reviews, 12: 270-279.

Bailey DB, Skinner D, Davis AM, Withmarsh I, Powell C. 2008. Ethical, Legal, and Social Concerns About Expanded Newborn Screening: Fragile $\mathrm{X}$ Syndrome as a Prototype for Emerging Issues. Pediatrics, 121: e693-e704.

Benkendorf J, Goodspeed T, Watson MS. 2010. Newborn screening residual dried blood spot use for newborn screening quality improvement. Genet Med, 12: -.
Bombard Y, Miller FA, Hayeems RZ, Avard D, Knoppers BM. 2010. Reconsidering reproductive benefit through newborn screening: a systematic review of guidelines on preconception, prenatal and newborn screening. European Journal of Human Genetics, 18: 751-760.

Bombard Y, Miller FA, Hayeems RZ, et al. 2014. Public views on participating in newborn screening using genome sequencing. Eur J Hum Genet, 22: 1248-1254.

Borowski HZ, Brehaut J, Hailey D. 2007. Linking evidence from health technology assessments to policy and decision making: The Alberta Model. Intl. J. of Technology Assessment in Health Care, 23: 155-161.

Botkin JR, Lewis MH, Watson MS, et al. 2014. Parental Permission for Pilot Newborn Screening Research: Guidelines From the NBSTRN. Pediatrics, 133: e410-e417.

Burke W, Laberge A-M, Press N. 2010. Debating Clinical Utility. Public Health Genomics, 13: 215-223.

Buse K, Mays N, Walt G. 2005. Making health policy. Maidenhead: Open University Press.

Clayton EW. 1999. What Should Be the Role of Public Health in Newborn Screening and Prenatal Diagnosis? Am J Prev Med, 16: 111-115.

Comeau AM, Parad R, Gerstle R, et al. 2005. Challenges in Implementing a Successful Newborn Cystic Fibrosis Screening Program. J Pediatr, 147: S89-S93.

Cornejo V, Raimann E, Cabello JF, et al. 2010. Past, present and future of newborn screening in Chile. J Inherit Metab Dis, 33: S301-S306.

Cornel MC, Rigter T, Weinreich SS, et al. 2012. Newborn screening in Europe - Expert Opinion document. European Commission 
Dezateux C. 1998. Evaluating newborn screening programmes based on dried blood spots: future challenges. British Medical Bulletin, 54: 877-890.

Dhondt J. 2010. Expanded newborn screening: social and ethical issues. J Inherit Metab Dis, 33: S211-S217.

Elliman DAC, Dezateux C, Bedford HE. 2002. Newborn and childhood screening programmes: criteria, evidence, and current policy. Arch Dis Child, 87: 6-9.

EURORDIS. 2015. The Voice of Rare Disease Patients in Europe.

Fischer KE, Grosse SD, Rogowski WH. 2011. The role of health technology assessment in coverage decisions on newborn screening. Intl. J. of Technology Assessment in Health Care, 27: 313-321.

Fischer KE, Rogowski WH. 2014. Funding Decisions for Newborn Screening: A Comparative Review of 22 Decision Processes in Europe. Int. J. Environ. Res. Public Health, 11: 5403-5430.

GA4GH. 2015. Global Alliance for Genomics \& Health.

Grosse SD, Boyle CA, Kenneson A, Khoury MJ, Wilfond BS. 2006. From Public Health Emergency to Public Health Service, The Implications of Evolving Criteria for Newborn Screening Panels. Pediatrics, 117: 923-929.

Hayeems RZ, Miller FA, Bombard Y, et al. 2013. Expectations and values about expanded newborn screening: a public engagement study. Health Expectations.

Health Council of the Netherlands. 2015. Neonatal screening: new recommendations. ISBN 978-94-6281050-1 edn. The Hague: Health Council of the Netherlands.

Hiller EH, Landenburger G, Natowicz MR. 1997. Public Participation in Medical Policy-Making and the Status of Consumer Autonomy: The Example of Newborn Screening Programs in the
United States. American Journal of Public Health, 87: 1280-1288.

Hinton CF, Mai CT, Nabukera SK, et al. 2014. Developing a public health-tracking system for follow-up of newborn screening metabolic condition: a fourstate pilot project structure and initial findings. Genet Med, 16: 484-490.

Hoff T. 2008. Long-term follow-up culture in state newborn screening programs. Genet Med, 10: 396-403.

Hoff T, Ayoob M, Therrell BL. 2007. Long-term Follow-up Data Collection and Use in State Newborn Screening Programs. Arch Pediatr Adolesc Med, 161: 994-1000.

Howard HC, Knoppers BM, Cornel MC, et al. 2015. Whole-genome sequencing in newborn screening? A statement on the continued importance of targeted approaches in newborn screening programmes. Eur J Hum Genet.

Hubbard HB. 2007. Policy Issues Related to Expanded Newborn Screening: A Review of Three Genetic/Metabolic Disorders. Policy Politics Nursing Practice, 8: 201209.

Kasper DC, Ratschmann R, Metz TF, et al. 2010. The National Austrian Newborn Screening Program - Eight years experience with mass spectrometry. Past, present, and future goals. Wien Klin Wochenschr, 122: 607-613.

Khoury MJ, Gwinn M, Yoon PW, et al. 2007. The continuum of translation research in genomic medicine: how can we accelerate the appropriate integration of human genome discoveries into health care and disease prevention? Genet Med, 9: 665674.

Little J, Potter B, Allanson J, et al. 2008. Canada: Public Health Genomics. Public Health Genomics, 12: 112-120.

Metternick-Jones SC, Lister KJ, Dawkins HJS, White CA, Weeramanthri TS. 2015. Review of current international decision-making 
processes for newborn screening: lessons for Australia. Frontiers in Public Health, 3. Moyer VA, Calong N, Teutsch SM, Botkin JR. 2012. Expanding Newborn Screening: Process, Policy, and Priorities. Hastings Center Report, 28: 32-39.

NCATS. 2015. National Center for Advancing Translational Sciences. NIH.

Nowogrodzki A. 2015. Should Babies Have Their Genomes Sequenced? : MIT Technology Review.

Oosterwijk O. 2015. Response advice Neonatal Screening. Soest: VSOP.

Petros M. 2012. Rivisting the Wilson-Jungner cirteria: how can supplemental criteria guide public health in the era of genetic testing? Genet Med, 14: 129-134.

Plass AMC, van El CG, Pieters T, Cornel MC. 2009. Neonatal Screening for Treatable and Untreatable Disorders: Prospective Parents' Opinions. Pediatrics, 125: e99e106.

Pollitt RJ. 2006. International perspectives on newborn screening. J Inherit Metab Dis, 29: 390-396.

Pollitt RJ. 2007. Introducing new screens: Why are we all doing different things? J Inherit Metab Dis, 360: 423-429.

Pollitt RJ. 2009. Newborn blood spot screening: New opportunities, old problems. J Inherit Metab Dis, 32: 395399.

Potter BK, Avard D, Entwistle V, et al. 2009. Ethical, Legal, and Social Issues in Health Technology Assessment for Prenatal/Preconceptional and Newborn
Screening: A Workshop Report. Public Health Genomics, 12: 4-10.

Potter BK, Avard D, Wilson BJ. 2008. Newborn Blood Spot Screening in Four Countries: Stakeholder Involvement. Journal of Public Health Policy, 29: 121-142.

Roberts JS, Dolinoy DC, Tarini BA. 2014. Emerging Issues in Public Health Genomics. Annu. Rev. Genomics Hum. Genet., 15: 461-480.

Schippers EI. 9 July 2015. Kamerbrief: Neonatale hielprikscreening. Den Haag: Ministery of Health, Wellfare, and Sport.

Simopoulos AP. 2009. Genetic Screening: Programs, Priniciples, and Research Thirthy Years Later. Public Health Genomics, 12: 105-111.

Teutsch SM, Bradley LA, Palomaki GE, et al. 2009. The Evaluation of Genomic Applications in Practice and Prevention (EGAPP) initiative: methods of the EGAPP working group. Genetics in Medicine, 11: 3-14.

Therrell BL. 2001. U.S. Newborn Screening Policy Dilemmas for the Twenty-First Century. Molecular Genetics and Metabolism, 74: 64-74.

Therrell BL. 2008. Considerations in Choosing Screening Conditions : One (US) Approach. Ann Acad Med Singapore, 37: 22-26.

Therrell BL, Padilla CD, Loeber JG, et al. 2015. Current status of newborn screening worldwide: 2015. Seminars in Perinatilogy, 39: 171-187.

WHO. 2015. Governance. Health Systems. World Health Organization. 


\section{Chapter 7}

Public involvement in policy development for newborn bloodspot screening: goals, definitions, mechanisms, levels, and evaluation
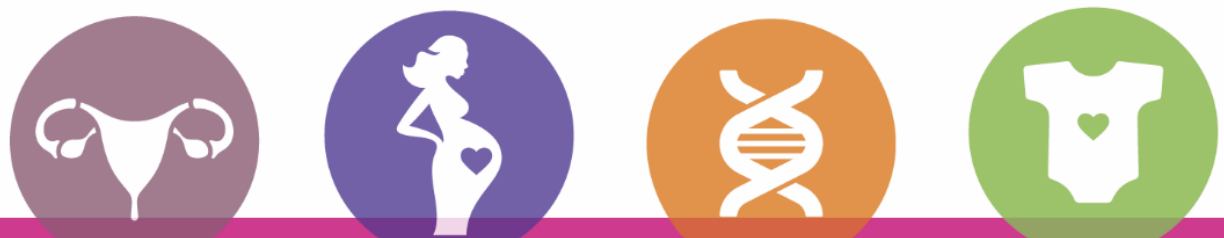

In preparation

Marleen E. Jansen

Carla E. van EI

Martina C. Cornel 


\begin{abstract}
Background/context: A technology push from next generation sequencing (NGS) puts pressure on the normative values that shape newborn bloodspot screening (NBS) programs to date, possibly changing the purpose. A shift in the aim of NBS has implications for the public, however, the public is not structurally involved in NBS policy decisions, and often represented by patient advocates.
\end{abstract}

Objective: To summarize different key elements for public involvement in policy making, focused on NBS.

Search strategy: A rapid review of literature was performed on the search terms newborn, screening, public or patient involvement, genetics, and decision making. Furthermore, a snowball method was applied where the references of the resultant articles were checked for additional relevant articles.

Main results: Five key topics were summarized: the goals of public involvement, how to define 'public', which mechanisms exist for it, on what levels it can prove to be valuable, and relevant indicators to evaluate the value. Most literature focused on public involvement in general, and the literature discussing NBS illustrated that the involvement is often through patient representatives, takes place in an ad hoc manner, and focuses on informing rather than deliberating.

Discussion and conclusions: Though public involvement does not take place in a structured of transparent manner in current NBS policy making, tools are available to develop such involvement. It is relevant to shape such involvement to gain relevant views from the public, and also debate whether NBS is the right program to implement the possibilities from NGS. 


\section{Introduction}

Advances in genomics are contributing to the growing understanding of the role genes have as underlying cause in an increasing number of diseases. ${ }^{1,2}$ To translate this growing understanding of genetic data into health benefits for the population, implementing genetic technologies in population screening programs has been proposed as a major strategy. ${ }^{3}$ Worldwide several population screening programs are in place, and newborn bloodspot screening (NBS) is a well-known example of a successful program that includes screening for genetic disorders. ${ }^{4}$ NBS screens newborns in the first days of life for a range of serious conditions aiming at direct clinical benefit for the child through preventing mortality, morbidity and disability. 5,6

Recently in many countries an expansion of the conditions screened for in NBS programs has taken place under influence of the implementation of tandem mass spectrometry (MS/MS). ${ }^{4} 7 \mathrm{MS} / \mathrm{MS}$ facilitated screening for multiple conditions at once and at a costeffective level., Emerging next generation sequencing (NGS) technologies offer even more opportunity than MS/MS to screen for a wider range of conditions. ${ }^{3,} 6$ NGS is currently used to a limited extent in NBS, but the majority of conditions screened for could in theory be tested with genetic technologies. ${ }^{3,8}$ Moreover, the costs and time frame of analyses with NGS are decreasing, the use of the technology in research and clinical practice is increasing ${ }^{6}$, and the knowledge on rare conditions is expected to develop in parallel. ${ }^{9}$

Not all conditions that could be screened for through NGS fit within the traditional aim of NBS, their consequences for the newborn are for example not preventable through clinical intervention. The technological possibility of screening for a broad range of conditions, has in some countries shifted the aim of NBS. ${ }^{10}$ Grosse et al. describe this as a paradigm shift from NBS as a public health emergency to a public health service ${ }^{11}$, i.e. screen to prevent serious health consequences for the newborn, but also to provide a service to families and newborns through screening by aiming for family benefits, such as providing information on reproductive options. ${ }^{11,12}$ Due to the technological possibilities from NGS and the consequent technology push, policy makers are faced with complex issues in decision making: implementing screening for rare and untreatable conditions would change the normative framework for NBS.

To discuss the aim of NBS and the normative framework for this purpose, incorporating the views of different stakeholders is highly relevant to balance their perspectives. ${ }^{13}$ Several stakeholders are involved in the NGS technology push by including it in the agenda to expand NBS, especially patient advocates, health care professionals, and industry. 7, 14, 15 However, another important stakeholder group for population screening programs is the public, and whether this group is represented by patient advocacy is unsure. ${ }^{14,16,17}$ Policy decisions impact on the lives of many citizens and the government is accountable for its decisions.18 Public involvement is considered a core function of health policy making, and an essential attribute of successful policy making. ${ }^{14,} 19,20$ 
Complex issues centered around people's values should be deliberated with the public, recent examples on public trust in the retention of blood spot cards illustrate that support cannot always be implied when for example the samples are used to evaluate the quality of screening tests or research using anonymized samples could improve rare disease understanding. ${ }^{21,} 22$ NBS currently faces the challenge of potentially shifting normative frameworks under the influence of a technology push from NGS. When these possibilities shift the aim of screening beyond clinical benefits for the newborn, the views of the public on aspects such as receiving carriership information, or future disability of their child should be deliberated on their implications. For example questions on whether or not the need to know this information and how to act on it could cause distress, and might decrease participation rates to NBS programs. ${ }^{9}$

To date, public involvement does not always take place in a structured, evidence-based or transparent way in NBS, as in other domains related to public health decision making. It seems that decision makers have yet to figure out an approach to ensure meaningful public involvement. Therefore, we summarize different key elements in public involvement regarding16: the goals of public involvement, how to define 'public', which mechanisms exist to facilitate public involvement, on what levels it can prove to be valuable, and relevant indicators to evaluate the value of public involvement. The landscape of NBS continues to change and develop, therefore considering public involvement in policy making is important to keep NBS programs feasible and successful.

\section{Methods}

To gather relevant literature a rapid review of scientific literature was performed. As search terms newborn, screening, public or patient involvement, genetics, and decision making were used. Only articles in English were included. Furthermore, a snowball method was used by checking the selected articles' references for articles to include in further reading. The information was structured based on five main topics presented by Avard et al. (2010). ${ }^{16}$ The key elements from their review focus on five questions ${ }^{16}$ :

1. What is the goal of the public involvement?

2. How is 'the public' defined?

3. Which mechanism(s) can be used for public involvement

4. On what level will the public be involved?

5. What indicators are relevant to evaluate public involvement?

Furthermore, information on translation of public involvement into the practice of policy making for NBS was summarized to illustrate where potential improvement could be studied and ultimately take place. 


\section{Results}

24 publications were initially identified of which 6 were included, and 8 articles were added through a snowball method. Each of the aspects described by Avard et al. (2010) is summarized in the following sections. ${ }^{16}$ The aspects are complemented with information from the resultant articles from the rapid review to compare the range of answers in the literature for the relevant topic.

\section{What is the goal of the public involvement?}

In their review Avard et al. (2010) described four recurring themes in the goals of public involvement in national policy statements: identifying risks and benefits; educating the public; responding to core ethical principles of respect for participants including responsibility, equity, rights, ethics and democracy, by aiming for dialogue and cooperation; and promoting governance and demonstrating transparency and openness. ${ }^{16}$

Van El et al. (2012) discuss in line with these themes the need to increase public knowledge about genetic technologies and the possiblities. ${ }^{23} \mathrm{~A}$ gap in knowledge between stakeholders is also summarized by Burton et al. (2009). ${ }^{24}$ However, Burton et al. (2009) also stress that not only the public can be informed by other stakeholders, but that other stakeholders also have "wide knowledge gaps" for the information that the public might find relevant, due to their different backgrounds. ${ }^{24}$ The public can offer access to unexploited knowledge ${ }^{18}$, and public perspectives can add key dimensions that otherwise might be overlooked in evaluations. ${ }^{25}$ Furthermore, public fears about genetics can be addressed by explaining common misconceptions through an open and transparent governance process. ${ }^{18}$

Responding to core ethical principles and respect for the public is highly relevant. The government can show accountability to the public about new policies by informing the public, since government bodies are politically accountable for their decisions on allocation of public funds. ${ }^{20}$ This was illustrated by Avard et al. (2008) in an earlier study, through addressing the goal of the right of the public to be involved in decisions that impact their lives. ${ }^{18}$ In that review Avard et al. (2008) also described themes on transparency and openness, where it was argued that ensuring a timely and fruitful approach in stakeholder involvement could assist in building trust in science and governments by addressing confidentiality of genetic data. ${ }^{18}$ Abelson et al. (2007) described the fact that the public's confidence in Canada's health system was diminishing, has made governments put principles of accountability and transparency on par with principles of universality and equity. ${ }^{20}$ 


\section{How is 'the public' defined?}

The definition of 'public' was characterized by Avard et al. (2010) ${ }^{16}$ through describing three aspects: the general public or citizens; groups or individual patients; and an accurate representation of a population through diversity. ${ }^{16}$ Diversity would need to cover different incomes, geographical region, ethnicity, religion, and age.16 The distiction between the general public and patient representatives was also highlighted in the earlier review from Avard et al. (2008) ${ }^{18}$, and found resonance in the study from Gagnon et al. (2011). ${ }^{25}$ Furthermore, Degeling et al. (2015) defined three groups of 'public': citizens; consumers; and advocates (table 1$).{ }^{14}$

Tabel 1. Types of public and a short description of who is included in each group.

\section{Who is in this public?}

Citizens (pure public)

Consumers (affected public)

Advocates (partisan public)
Individuals; naïve citizen as subject of education, and then, potentially as decision maker. This type of public is generally not affected by the condition under debate.

Individuals, participants are the authentic expert; they have experience with the condition or service that is discussed.

Representatives of interest groups, political organisations including groups with technical expertise. They can inform on potential barriers and arguments from a strategic perspective.

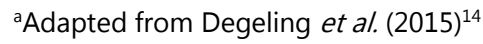

Noteworthy is that the different publics cannot be regarded as a homogenous group, and hold a variety of positions of expertise, power, and commitment. ${ }^{14}$ Therefore they cannot be regarded as interchangeable, and involving 'the public' brings up the question of the difference between citizen values and consumer prefences. ${ }^{20}$ All authors highlighted the different motivation or attentiveness of the different groups to participate in policy debates. Often in research it is not clear if the public based their decisions on their own preferences or community interest. ${ }^{14}$ For example, the general public will bring more general concerns to the table, while the patient representatives will focus on experiences with the disease. ${ }^{18}$ The latter group may put less emphasis on falsepositives, treatment side-effects, or parental worry. ${ }^{15}$ In general, when the public is involved, this stakeholder group is interchangeable with patient advocates.

\section{On what level will the public be involved?}

The involvement of the public can be on a low level of influence or a high level of influence. In their review of national policy statements, Avard et al. (2010) found when 
the public is mainly involved through education and informing, the influence can be regarded as low. ${ }^{16}$ However, when the public is involved through active engagement or partnering, this influence can be regarded as high. ${ }^{16}$ Gagnon et al. (2011) discussed a view on level on involvement by dividing it into two domains: research domain or health technology assessment (HTA) domain. ${ }^{25}$ The research domain focused on conducting research to gain information, the HTA domain discussed going through the process of policy making. The research domain builds on consulting with the public: gathering perspectives, experiences or preferences - often from patients. ${ }^{25}$ The HTA domain focused more on participation in various stages of the policy process regarding: selection of technologies to be assessed (prioritization); evidence assessment; or dissemination of findings through commenting on the clarity of draft versions of reports. ${ }^{25}$ Degeling et al. (2015) state that public participation is increasingly a feature of research in healthcare priority setting. ${ }^{14}$

Active engagement of the public is on a high level when the public can directly influence decisions through voting., 20 It was found by Fischer et al. (2014), that service providers and governments were most frequently involved in decisions on expanding NBS programs, as summarized in table 2. Service providers, i.e. laboratories processing the heelprick cards, were involved in $95 \%$ of decisions on funding for NBS. In $68 \%$ of the countries, patients were reported to be involved. However, patients were usually involved to provide information, decisions were made through voting by government and payer (table 2).

Table 2. Level of involvement of three stakeholder groups decision making in in European countries. $^{a}$

\begin{tabular}{ccc}
\hline \multicolumn{3}{c}{ Stakeholders } \\
\hline Service provider(s) & Patients & Government \\
$(\mathrm{n}=20)$ & $(\mathrm{n}=22)$ & $(\mathrm{n}=17)$
\end{tabular}

\section{Type of involvement}

\begin{tabular}{llll}
\hline No involvement & $1(5 \%)$ & $7(32 \%)$ & $3(18 \%)$ \\
Information provision & $17(85 \%)$ & $14(64 \%)$ & $5(30 \%)$ \\
Voting & $2(10 \%)$ & $1(4 \%)$ & $9(53 \%)$
\end{tabular}

${ }^{a}$ Adapted from Fisher et al. $(2014)^{7}$

Abelson et al. (2007) furthermore differentiate between a stratification of the level of involvement as an ad hoc or an institutionalized approach. ${ }^{20}$ The latter has a more on- 
going nature, and has booked successes in the United Kingdom and Denmark. ${ }^{20}$ The Danish system has been established in 1995 and focuses on "public understanding of science". ${ }^{20}$ It has pioneered in using consensus conferences and scenario workshops for controversial topics, such as electronic patient records and gene therapy. ${ }^{20}$ Overall, most countries discussed in literature did not show involvement on a high level.

\section{Which mechanism(s) can be used for public involvement?}

Avard et al. (2010) looked at two practical aspects for public participation in policy making: different tools that could be applied and factors that can influence which tool might be appropiate. In the review of 2008, Avard et al. made the distinction between direct and indirect mechanisms of involvement. ${ }^{16}$ In general, indirect involvement included one way communication through consulation or surveys. ${ }^{16}$ On the other hand, direct involvement focused on two-way communication through workshops, dialogue, and deliberative and consensus conferences.16 A similar variety of mechanisms was also summarized by Abelson et al. (2007) who mentioned participation, publicity, and deliberation. ${ }^{20}$ Degeling et al. (2015) also characterized two-way communication as a deliberative process, which at a minimum should facilitate: balanced factual information; consideration of a sufficiently diverse range of perspectives; and the opportunity for a free and open discussion on relevant claims through debate with the involved stakeholders. ${ }^{14}$ An example mentioned in their study is a citizen jury, which usually was shaped as a 1-2 day(s) event where a single jury of 9-16 people was involved, based on random selection from the population. ${ }^{14}$

Looking at the course of public involvement in the Netherlands, Van El et al. (2012) found that patient organizations were in the past not always explicitly involved in debates on genetic screening. Therefore they voiced themselves through the media on several occasions, when new policies were debated or implemented..$^{23}$ A specific tool that was studied by Kohler and Martinez (2015) in Brazil was a Participatory Health Council (PHC) ${ }^{26}$ : "deliberative and permanent bodies of Brazil's Unified Health System, present in each sphere of the government (municipal, state, and national) and part of the basic structure of the Ministry of Health, the Secretary of Health of all states, and the Federal District of all municipalities" In their study, Kohler and Martinez (2015) found that this council was not effective, because they failed to facilitate inclusive and participatory involvement. ${ }^{26}$ They were not able to reach out to the most marginalized groups in society. Furthermore, it seemed that the members of the PHC would need training and education to fulfill their tasks. ${ }^{26}$ Abelson et al. (2007) also highlighted that meaningful direct participation is not guaranteed when public representatives are included. ${ }^{20}$ 
What indicators are relevant to evaluate public involvement?

In the national policy documents Avard et al. (2010) studied, they focused on acceptance criteria and process criteria. ${ }^{16}$ The acceptance criteria would measure if the process is successful in terms of achieving the goals of public involvement. The process criteria would measure how the public was involved and how this involvement was experienced. ${ }^{16}$ Overall, outcomes of involvement are studied to a limited extent, without consistent terminology, definitions, designs and tools to evaluate and measure effectiveness. ${ }^{18}$

\section{Translation to NBS}

The goal of eliciting the information needs and preferences of the public, was put in context for NBS by Lipstein et al. (2010). ${ }^{15}$ They studied the influence on the decision making of parents regarding the condition that are suitable for newborn screening, based on the experience the parents had with their child. Their study showed that parents who visited a clinical geneticist have different preferences and information needs than parents who attended a primairy care facility. ${ }^{15}$ Both groups showed different degrees of support when asked about screening for a broad variety of conditions: the parents recruited from the primary care clinic were less likely to support this type of screening. ${ }^{15}$

It is relevant to keep differences in mind between the affected public and the 'pure' public (table 2), because often in NBS policy making processes, the input from patient representatives is sought through includig parents of affected children. ${ }^{15}$ Involving the public in NBS policy development was also discussed by Bailey et al. (2008). They concluded that the public should be involved in debating the aims of NBS and the characteristics of the system that would achieve those aims. ${ }^{27} \mathrm{~A}$ survey by Weinreich et al. showed support for a hypothetical offer of Pompe screening not only among those who have personal experience of the disease but also among the general public. ${ }^{28}$ In a cross-country comparison in Europe, it was found that the involvement of patient organizations varied across countries. 22 jurisdictions expanded their NBS program between 2006-2011. ${ }^{29}$ In 18 of these jurisdictions patient advocacy groups were present, and 10 jurisdictions (56\%) included them in the decision to expand the NBS program, 8 (44\%) did not (table 3). ${ }^{29}$ How these patient advocacy groups were involved in the decisions on policy changes for NBS was unclear, as well as whether these advocacy groups were specifically organized for a specific disease. ${ }^{30}$ 
Table 3. Overview of countries or jurisdictions that had an existing patient advocacy group in 2011 and which countries included them in the revision of their NBS program. $(n=30)^{a}$

\begin{tabular}{llll}
\hline & $\begin{array}{l}\text { Patient advocacy } \\
\text { group involved } \\
(\mathbf{n}=\mathbf{1 0})\end{array}$ & $\begin{array}{l}\text { Patient advocacy } \\
\text { group not } \\
\text { involved }(\mathbf{n}=\mathbf{8})\end{array}$ & $\begin{array}{l}\text { No policy changes } \\
\text { indicated between }\end{array}$ \\
$\mathbf{2 0 0 6 - 2 0 1 1}(\mathbf{n}=\mathbf{1 2})$
\end{tabular}

${ }^{a}$ Adapted from Current Practices in NBS in European countries ${ }^{29}$

\section{Discussion}

Debating the aim and system of NBS programs is on the policy agenda of several countries, and in this article we highlighted key considerations for public involvement in policy making. Most literature focused on involving the public for policy processes in general, and little information was found specifically for NBS. This suggests that there is room for improvement to apply the tools and information available with regard to structured, evidence-based, and transparent approaches for public involvement in policy making for NBS.

Governments need to balance different perspectives, and ultimately they need to decide whether to develop, implement, or continue a genetic screening program. ${ }^{3}$ Especially relevant for NBS is the consideration of the value of screening primarily in relation to the technology-push: the utility, acceptability, feasibility, and access to screening need to be demonstrated before a technology can be introduced. ${ }^{3}$ To discuss these aspects, public debate is essential in modern democracies to address values and practices that governmental policies imply. ${ }^{23}$ The goal of public involvement in NBS policy development was not clearly stated in the articles that discussed NBS, but since the public was generally represented by patient advocacy groups, the goal presumably was to act as advisor. ${ }^{14}$ The highly relevant involvement of patient representatives as proxy for the public does pose the question if they represent citizen values or patient preferences. ${ }^{14,20}$

Public involvement is not suitable for all decisions processes, nor is it feasible. ${ }^{20}$ Deliberative methods are advised for policy questions on complex issues. Issues can be regarded as complex due to central importance of people's values or the number of 
people affected by the policy decision. ${ }^{14}$ Since NBS is offered to all newborns, it clearly affects a considerable amount of people. Furthermore, due to the discussions of stretching the aim of NBS to also include rare and untreatable conditions ${ }^{8,11}$, people's values have been increasingly become important. Values-oriented questions about the governance and planning of health services, such as genetic testing, call for deliberation between stakeholders. ${ }^{14}$ Since there is little information on the mechanisms of public involvement in NBS policy development, a relevant structure for public involvement into these processes remains to be studied, as well as indicators to evaluate the added value of the information from the public to policy making. ${ }^{25}$

Including the public in deliberative processes is also criticized by some authors. ${ }^{14,20}$ There are worries about the degree to which an individual or a small group represents the views and interests of the public legitimately or accurately, and how to approach this heterogeneity. Furthermore, questions on the representation of the public in policy discussion remain, such as: do the involved representatives have sufficient expertise to participate in policy discussion; and do the representatives actually influence the process or are they used to legitimate a pre-decided policy outcome? ${ }^{14,20}$

Concerns on the representativeness of the public in NBS policy making are legitimate, because often the representatives are advocates of patient associations or parents with an affected child. This group might have different views on relevant conditions for NBS. They will focus more on experiences with the disease, and may put less concerns on falsepositives, treatment side-effects, or parental worry. ${ }^{15}$ Weinreich et al. (2012) however elicited very similar attitudes. ${ }^{28}$ Hence, only involving advocates with a patient perspective to discussion on NBS may have strong implications for the views included, and put emphasis on conditions that may seem highly relevant for a small group of the population, while burdening the population at large.

The advent of genetic technologies, such as NGS, and their possibilities to screen for rare and untreatable conditions, have often also raised the question if NBS is the right program to screen for certain conditions. Alternatives should be weighed into the equation to ensure that the proposed program maximizes health benefit. ${ }^{3}$ With regard to NBS, it can be important to inform the public on alternatives to NBS. Examples that are often mentioned are preconception carrier screening (PCS) and prenatal screening (PNS). NBS has been concluded to have a complementary paradigm compared to PCS and $\mathrm{PNS}^{5}$, so it may prove beneficial to consider all three programs when developing a structured policy process with systematic public involvement. It remains to be studied and debated whether the newborn period is the appropriate time to screen for a range of conditions with NGS, and if they are deemed to be relevant to screen for, when this should be done. ${ }^{6}$

In conclusion, there is some involvement of the public in policy making for NBS. However, this involvement is often ad hoc, focusses mainly on patient advocacy, and usually only includes providing information. NBS policy could benefit from public involvement 
through deliberative methods to ensure feasible and successful programs. Nonetheless, the call for public involvement is momentarily vague, and many questions remain unanswered regarding the goals, level, definition, mechanisms, and evaluation of public involvement. ${ }^{16,} 20$ Regardless, government alone cannot determine which technologies "a publicly funded health plan can justify morally, afford economically, and use to good purpose". ${ }^{20}$ Therefore it is important that it is evaluated how to approach public involvement. ${ }^{31}$ An adequate model will account for public values and perspectives at different stages of policy making for NBS, and may also prove beneficial for PCS and PNS. 


\section{References}

1. Collins FS, McKusick VA. Implications of the human genome project for medical science. JAMA. 2001; 285: 540-4.

2. Guttmacher $A E$, Porteous ME, McInerney JD. Educating health-care professionals about genetics and genomics. Nat Rev Genet. 2007; 8: 151-7.

3. Andermann A, Blancquaert I, Beauchamp S, Costea I. Guiding Policy Decisions for Genetic Screening: Developing a Systematic and Transparent Approach. Public Health Genomics. 2011; 14: 9-16.

4. Therrell BL, Padilla CD, Loeber JG, Kneisser I, Saadallah A, Borrajo GJC, et al. Current status of newborn screening worldwide: 2015. Seminars in Perinatilogy. 2015; 39: 171-87.

5. Bombard $Y$, Miller FA, Hayeems RZ, Avard D, Knoppers BM. Reconsidering reproductive benefit through newborn screening: a systematic review of guidelines on preconception, prenatal and newborn screening. European Journal of Human Genetics. 2010; 18: 751-60.

6. Howard HC, Knoppers BM, Cornel MC, Wright Clayton E, Senecal K, Borry P, et al. Whole-genome sequencing in newborn screening? A statement on the continued importance of targeted approaches in newborn screening programmes. Eur J Hum Genet. 2015.

7. Fischer $K E$, Rogowski $W H$. Funding Decisions for Newborn Screening: A Comparative Review of 22 Decision Processes in Europe. Int J Environ Res Public Health. 2014; 11: 5403-30.

8. Grosse SD, Rogowski WH, Ross LF, Cornel MC, Dondorp WJ, Khoury MJ. Population Screening for Genetic Disorders in the 21st Century: Evidence, Economics, and Ethics. Public Health Genomics. 2010; 13: 106-15.
9. Hayeems RZ, Miller FA, Bombard $Y$, Avard D, Carroll JC, Wilson BJ, et al. Expectations and values about expanded newborn screening: a public engagement study. Health Expectations. 2013.

10. Moyer VA, Calong N, Teutsch SM, Botkin JR. Expanding Newborn Screening: Process, Policy, and Priorities. Hastings Center Report. 2012; 28: 32-9.

11. Grosse SD, Boyle CA, Kenneson A, Khoury MJ, Wilfond BS. From Public Health Emergency to Public Health Service, The Implications of Evolving Criteria for Newborn Screening Panels. Pediatrics. 2006; 117: 923-9.

12. Bailey DB, Beskow LM, Davis AM, Skinner D. Changing Perspectives on the Benefits of Newborn Screening. MRDD Research Reviews. 2006; 12: 270-9.

13. WHO. Governance. Health Systems: World Health Organization; 2015.

14. Degeling C, Carter SM, Rychetnik L. Which public and why deliberate?-A scoping review of public deliberation in public health and health policy research. Social Science \& Medicine. 2015; 131: 114-21.

15. Lipstein EA, Nabi E, Perrin JM, Luff $D$, Browning MF, Kuhlthau KA. Parents' Decision-Making in Newborn Screening: Opinions, Choices, and Information Needs. Pediatrics. 2010; 126: 696-704.

16. Avard $D$, Stanton Jean $M$, Grégoire $G$, Page M. Public involvement in health genomics: the reality behind the policies. International Journal of Consumer Studies. 2010; 34: 508-24.

17. Bombard Y, Miller FA, Hayeems RZ, Barg C, Cressman C, Carroll JC, et al. Public views on participating in newborn screening using genome sequencing. Eur J Hum Genet. 2014; 22: 1248-54. 
18. Avard D, Grégoire G, Jean S M. Involving the public in public health genomics: a review of guidelines and policy statements. 2008.

19. Li KK, Abelson J, Giacomini M, Contandriopoulos D. Conceptualizing the use of public involvement in health policy decision-making. Social Science \& Medicine. 2015; 138: 14-21.

20. Abelson J, Giacomini $M$, Lehoux $P$, Gauvin F-P. Bringing 'the public'into health technology assessment and coverage policy decisions: from principles to practice. Health policy. 2007; 82: 37-50.

21. $\mathrm{MDH}$. Minnesota Department of Health to begin destroying newborn blood spots in order to comply with recent Minnesota Supreme Court ruling. Minnesota Department of Health; 2012.

22. RCPI. Preserving archived Newborn Screening Bloodspot Cards. Royal College of Physicians of Ireland; 2013.

23. Van El CG, Pieters T, Cornel MC. Genetic screening and democracy: lessons from debating genetic screening criteria in the Netherlands. J Community Genet. 2012; 3: 79-89.

24. Burton $\mathrm{H}$, Adams $M$, Bunton $\mathrm{R}$, SchroderBack P. Developing Stakeholder Involvement for Introducing Public Health Genomics into Public Policy. Public Health Genomics. 2009; 12: 11-9.

25. Gagnon $M-P$, Desmartis $M$, LepageSavary D, Gagnon J, St-Pierre M, Rhainds $\mathrm{M}$, et al. Introducing patients' and the public's perspectives to health technology assessment: A systematic review of international experiences. International journal of technology assessment in health care. 2011; 27: 3142.
26. Kohler JC, Martinez MG. Participatory health councils and good governance: healthy democracy in Brazil? International journal for equity in health. 2015; 14: 21.

27. Bailey DB, Skinner D, Davis AM Withmarsh I, Powell C. Ethical, Legal, and Social Concerns About Expanded Newborn Screening: Fragile X Syndrome as a Prototype for Emerging Issues. Pediatrics. 2008; 121: e693-e704.

28. Weinreich $S S$, Rigter $T$, van El CG, Dondorp WJ, Kostense PJ, van der Ploeg AT, et al. Public support for neonatal screening for Pompe disease, a broadphenotype condition. Orphanet J Rare Dis. 2012; 7: 15.

29. Burgard P, Cornel M, Di Filippo F, Haege G, Hoffmann GF, Lindner M, et al. Report on the practices of newborn screening for rare disorders implemented in Member States of the European Union, Candidate, Potential Candidate and EFTA Countries. EU Tender "Evaluation of population newborn screening practices for rare disorders in Member States of the European Union. 2011: 53-7.

30. Burgard P, Rupp K, Lindner M, Haege G, Rigter T, Weinreich SS, et al. Newborn screening programmes in Europe; arguments and efforts regarding harmonization. Part 2 - From screening laboratory results to treatment, followup and quality assurance. J Inherit Metab Dis. 2012; 35: 613-25.

31. Gauvin F-P, Abelson J, Giacomini M, Eyles J, Lavis JN. Moving cautiously: Public involvement and the health technology assessment community. International journal of technology assessment in health care. 2011; 27: 439 


\section{Chapter 8}

\section{General discussion}

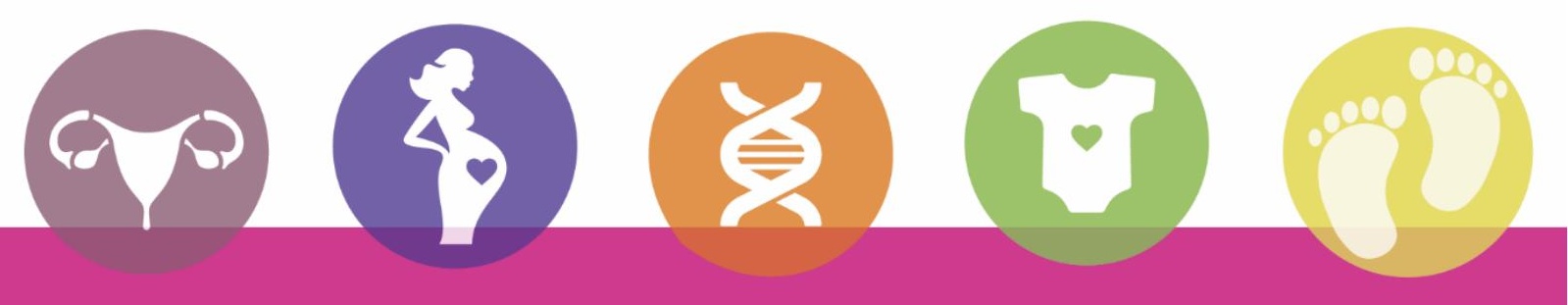




\section{Background and objectives}

Healthcare is expected to increasingly use genome-based information and strive for personalized medicine. ${ }^{1,2}$ However, to not only strive for personalized diagnosis, treatment, and prevention, but also ensure translation of genome-based information, structured evaluative methods are needed. ${ }^{3}$ Therefore the broad aim of this thesis is to explore new developments both in clinical and population health services, discussed in the context of Public Health Genomics. ${ }^{4}$ Clinical health services are illustrated in part I through the screening for $C$. trachomatis-associated tubal factor infertility (TFI) and possible test developments. Part II addresses population health services by discussing policy debates in newborn bloodspot screening (NBS), driven by the possibilities from new technologies including tandem mass spectrometry and next generation sequencing (NGS).

In the following sections the main findings in this thesis will be discussed, compared to relevant literature, and considerations will be given to the applied methodologies. Furthermore, the findings will be placed in context by presenting recommendations both for practical implications as well as future research. After illustrating these aspects, concluding remarks will be provided.

\section{Main findings}

\section{Part I - Clinical screening: prediction of tubal factor infertility}

Current screening for TFI with a $C$. trachomatis antibody test (CAT) can be improved ${ }^{5}$ to minimalize time to a correct diagnosis and prevent unnecessary laparoscopies (figure 1). Addition of biomarkers to CAT to analyze the immunological response to a $C$. trachomatis infection have shown promising results ${ }^{6,7}$; therefore a serological biomarker is studied in chapter 2 and a genetic biomarker in chapter 3. In chapter 2 we could not confirm the promising results from an earlier study to improve the screening for TFI. However, our study did highlight the relevance of testing with CAT for double sided TFI. As was found by other authors, $C$. trachomatis is an important cause of TFI, and therefore remains an important indicator ${ }^{8}$, but innovation is needed to improve screening for TFI with a CAT.912.

Alternatively to adding serological markers to CAT, genetic markers could prove valuable in identifying high risk women for TFI. ${ }^{6}$ Significant steps have been taken in defining which variants are relevant for $C$. trachomatis-associated TFI. ${ }^{13,14}$ In chapter 3 a trend was observed for a genetic variant in the gene region coding for $H L A-A$. When participants were stratified according to the severity of their symptoms after a $C$. trachomatis infection, the group with the highest level of symptoms had the lowest proportion of women with the genetic variant. These results contribute to a considerable body of evidence on the relevance of immunogenetic factors in the development of TFI after $C$. trachomatis infection. ${ }^{6,15,16}$ Because there is a range of genetic variants that have been 
found to partially contribute the development of TFI, in the future combining the relevant variants in one test could be evaluated on its accuracy, such as clinical validity and utility. ${ }^{17}$

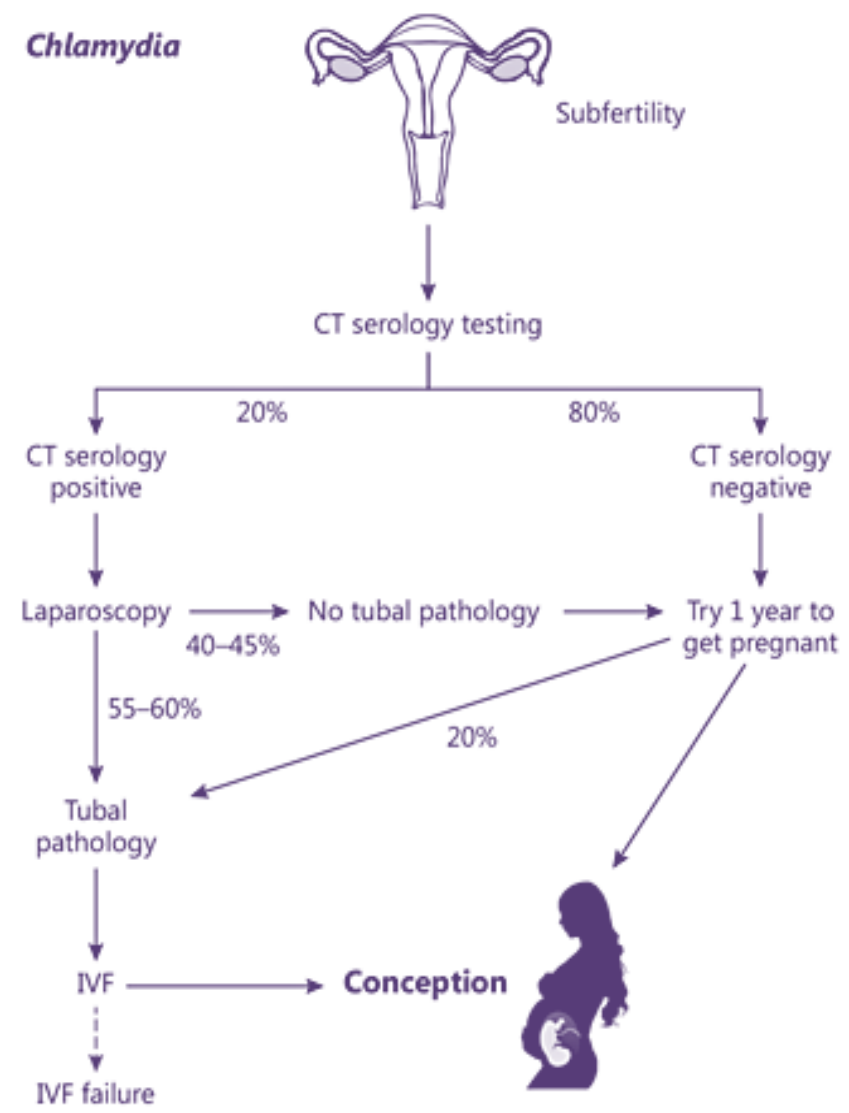

Figure 1. Overview of the current diagnostic pathway of tubal factor infertility based on Chlamydia trachomatis antibody testing, including an estimation of the false positives (40-45\%) and false negatives (20\%).

Successful test development entails more than high test accuracy. ${ }^{17}$ Ultimately to translate a genetic test into successful implementation, stakeholder support is needed. ${ }^{18}$ Therefore, chapter 4 studies the attitude of gynecologists towards the implementation of a genetic test in fertility care to explore barriers and facilitators for successful implementation. Overall, the study highlights that gynecologists seem to be positive about the possible added value of a genetic test, but - as has been found in other studies $^{19}$ - that proven clinical utility and cost-effectiveness are important prerequisites. To gain support from health care professional, future research into the economic implications of adding a genetic assay to fertility work up should be conducted. Economic 
evaluation is needed especially because genetic tests are still considered as too expensive, while genetic tests have been found to be neither inferior or superior to other medical tests regarding cost-effectiveness. ${ }^{20}$ Furthermore, since the respondents stated that they would need training before the implementation of a genetic test, their education needs should be elicited to support them in effectively using the test. Other reviews have also highlighted the need to inform health care professionals as an important aspect. ${ }^{2}$ Moreover, not only health care professionals are relevant stakeholders in the successful implementation of a genetic test in fertility care, other stakeholder groups such as patients and health insurance companies should also be included in the development process. ${ }^{2,21}$

\section{Part II - Population screening: newborn bloodspot screening}

The landscape of NBS has changed significantly in the past years, mostly under the influence of technological advancements..22,23 Recent innovations in genome-based technologies imply the possibility to change the number and type of conditions that can be screened for even more. ${ }^{24,25}$ The comparison in chapter 5 highlights that debates are ongoing on how to decide what the role of governments and the purpose of programs should be. ${ }^{26}$ If the purpose of the program is expanded to include benefits beyond direct clinical benefits for the newborn, this will also expand the number of conditions implemented. Many countries or jurisdictions do not seem prepared to implement a wider range of conditions: the government does not regard it as their role to screen for conditions that do not have a clear clinical benefit for the infant in the newborn period, and the infrastructure is also often not available. ${ }^{27}$ NBS programs should only be expanded if the infrastructure can be implemented to support a program's quality and equality, and if the government can account for redefining the purpose of NBS.

There are different approaches to decide on the implementation or adjustment of a screening program. In chapter 6 the steps that policy makers need to go through are summarized in the context of NBS. The review highlighted that a structured, evidencebased, and transparent framework to approach policy making in NBS should be strived for, but is hardly ever documented in the scientific literature. Historically, expansion of NBS was often an ad hoc process, driven by technological developments in a test, treatment, or disease understanding. ${ }^{28,29}$ In the United States a technology-driven approach towards evaluating conditions for NBS has led to a significant expansion. And also the Netherlands are embarking on an exploration of an optional NBS program for rare and untreatable conditions, initiated by the Minister of Health, Welfare and Sport ${ }^{30}$, and welcomed by the Dutch Genetic Alliance (VSOP) ${ }^{31}$. Whether NBS is the right program to screen for these conditions remains to be studied; it can be argued that the considerations for NBS should remain condition and population focused instead of technology driven and initiated by individuals. 
The opportunities from technological developments such as NGS, and the influence of different stakeholder groups make policy processes increasingly complex. Decision for publicly funded programs impact citizens' lives, and call for stakeholder involvement to discuss issues, gather insights, and build support. ${ }^{32,33}$ In this process, governments need to facilitate transparent decision making on accepting or rejecting conditions for NBS. Currently different stakeholder groups are represented in NBS, but these groups are not always involved in a structured way, and whether they represent all relevant groups can be disputed. Highlighted in chapter 7 is the fact that - while NBS is a population screening program - if the public is represented in decision making this is at best through patient advocacy. ${ }^{33}$ This can highly impact on the views brought to the table ${ }^{34}$, and therefore resonate in the considerations for decisions on conditions to add to NBS programs. It is not always the case that the different publics have different views ${ }^{35}$, but when policies for a population screening program are developed, the goals and definition should be made clear to the participating stakeholders, so it is clear to them and to the decision makers what perspective they are taking on the issue: their own preferences or community interest.

\section{Methodological considerations}

\section{Part I - Clinical screening: prediction of tubal factor infertility}

In part I two main types of research methods were applied; quantitative association analysis between biomarkers and disease outcome, and mixed methods to develop and conduct a survey. A limitation of the studies on the association for TFI between CAT combined with CRP (chapter 2) and the SNP-analysis (chapter 3 ) is the limited statistical power to make firm conclusion based on the findings. However, since other studies have found promising results in both fields, the utility of this research should not be disregarded. In chapter 2 the proportion of women who had TFI or double sided TFI was small, nonetheless all women in our sample had undergone a laparoscopy, which is the most reliable measure for TFI. In current practice only women who have a medical indication undergo laparoscopy and often this indication is a positive CAT or medical history implying expected fertility problems, which points towards referral bias. In line with the referral bias, the study also most likely deals with selection bias, since the women are not a random sample. In a future study an international multicenter study could increase the sample size to facilitate sufficient sample sizes in the cases and controls.

The limitations in chapter 3 are comparable to chapter 2, though in chapter 3 an additional limitation is the fact that the precise function of the SNP under study is not known yet. Regardless of these limitations, a trend was observed that suggests a possible contributing immunogenetic function for a G>A SNP in the gene region coding for $H L A$ $A$. Since our cohort was small and we have only studied one SNP, next research steps would be to enlarge the study population and the SNPs under study. Promising results 
have been found in host genetic factors, and studying the value of a combined SNP-test could confirm the results from this body of evidence. In such a study, the economic implications should also be considered, which was also pointed out in chapter 4 as the most relevant factor for support from gynecologists for a genetic test.

The questionnaire for chapter 4 was developed with key opinion leaders in the field of obstetrics and gynecology, to ensure coverage of the most relevant topics regarding genetic tests in fertility care. The study population only included Dutch Academic Hospitals, which may have influenced the attitudes of the respondents. We were able to cover $75 \%$ of the Dutch Academic Hospitals, suggesting that our results should give a fair estimation of the attitudes in Dutch Academic Hospitals. Not all the health care professionals in our sample were gynecologists (in training), 39\% checked the "Other" box in the questionnaire, mostly specifying that they were 'IVF specialist' or 'fertility doctor'. This may have influenced the validity in terms of eliciting the attitude of solely gynecologists, but has given us an informative heterogeneous sample of professionals that are involved in fertility care. In the questionnaire some respondents commented that they did not always feel that they had enough information or knowledge to give informed answers on the questions. This only stresses the need to involve and inform them as the development of a possible combined SNP-test progresses to gather their views and gain support for successful implementation.

\section{Part II - Population screening: newborn bloodspot screening}

The studies in part II are all conducted in a structured manner, aiming to cover the most important high level topics currently under discussion in policy making for NBS. Unfortunately, relevant information may have been missed due to limitations on countries included and language barriers beyond Dutch, English, or German. In chapter 5 a unique combination between scientific literature and policy documents is presented. An international comparison between the resultant programs was not conducted, because not all policy documents were in place before the development of the current programs but were drafted for future decision making. The factors in both scientific literature and policy documents, did provide relevant topics to consider for policy makers facing the challenge of possible changes in NBS programs.

In chapter 6 it was found that while articles focusing on the United States of America (USA) were overrepresented which may have been a limitation for our study, it does show a gap in the publication of literature on decision making in other countries that have NBS programs in place or are in the process of developing them. Chapter 7 showed that while developing NBS programs, careful consideration should be given to the stakeholders that should be involved. While the study was a rapid review and touches on the surface of the complex issues in involving the public in NBS policy making, the study was able to highlight that currently mechanisms to involve the public are lacking. Only few studies 
showed information on the involvement of the public in NBS, and the ones that did showed that public involvement is usually ad hoc.

With the advent of NGS in health care services, stakeholder involvement for relevant applications in population screening could be initiated by governments through involving them in priority setting. By weighing the community, scientific, and medical interest, follow-up processes can be facilitated on relevant innovations, such as debating the aim of NBS and the infrastructure supporting a program in line with the values and needs of different stakeholders. Not only does the government need to decide on their role in NBS, but the process to get to this decision is fraught with potentially competing interests and should follow a structured, evidence-based, and transparent approach. Furthermore, especially in the dynamic of new developments in genome-based knowledge and increasing pressure on NBS programs, considering alternatives instead of NBS to screen for certain condition- such as preconception carrier or prenatal screening - should be debated with the public.

\section{Implications for practice}

In the studies conducted, it was found that often not all relevant stakeholders are involved in the development of tests or policy making and shaping the support system. Stakeholders should be involved not only in providing information, but also in influencing research and policy agendas bottom up. Including all relevant stakeholder groups as soon as possible is complex both in research and policy making, however striving to include patients and the public as well as professionals is essential to exchange knowledge. Often the public is not consistently involved in policy making for population health services, while these decisions may have impact on their lives. Furthermore, involving the public has been recognized as an activity that will help shape the health system, build greater trust in science and in governments, and provide access to unexploited knowledge. ${ }^{36}$ Denmark has booked successes by involving the public through consensus conferences and scenario workshops ${ }^{37}$, which exemplifies that input from a public panel is possible and can prove valuable for policy developments.

Through managing these processes in an evidence-based manner, improved health outcomes for the population are expected. To ensure that the technologies meet the standards of the relevant stakeholders, both on tests characteristics as well as on ELSI, continuous communication between them is essential. Challenges between timely translation and ensuring safeguards regarding ELSI are always on the horizon for genome-based tests, and stakeholders should carefully consider how to approach the implementation process of innovations in health care services. Several international organizations have provided guidelines on stakeholder involvement ${ }^{37}$, and Avard et al. $(2010)^{32}$ and Degeling et al. (2015) ${ }^{33}$ have for example recently reviewed public involvement in health care decision making. Combining these considerations can have significant practical implications regarding: 
- Facilitating knowledge exchange between stakeholders, both nationally and internationally.

- Acknowledge views of different stakeholders and direct research and policy taking into consideration relevant perspectives.

- Reconsider frameworks to translate innovations into practice.

\section{Recommendations for future research}

In fertility care, considerable improvement is aimed for in the stratification of high risk women for developing TFI after $C$. trachomatis infection to improve stratification of these women for laparoscopy and possibly in vitro fertilization. To be able to improve the steps to a correct diagnosis, research in larger cohorts is needed regarding the markers that can adequately predict the course of a $C$. trachomatis infection. Furthermore, since host genetic factor play an important role in the clinical presentation of $C$. trachomatis, other genetic factors besides immunogenetic factors can also contribute to the screening for TFI in addition to CAT. Because both immunogenetic and possibly other genetic factors play an important role in developing C. trachomatis-associated TFI, healthcare professionals should also stay informed about these innovations. Future research should continue to involve them, and also aim to elicit their needs regarding training and infrastructure support. Moreover, not only the insights from health care professionals are relevant, but also from other actors, such as the patient, the health insurance companies, and the test developer. These stakeholder groups can be involved in research continuing in line with promising findings on host genetic factors ${ }^{15}$, such as:

- Explore a test that combines several relevant SNPs

- Elicit needs in infrastructure and information support

- Development of training and education tools

To ensure swift translation of relevant genome-based tests in NBS, the whole translational pathway should be carefully considered. In this thesis the focus was on approaching policy making, but NBS is facing more challenges. The test characteristics need to be elicited, and consumers should stay informed on the possibility of direct-toconsumer tests and their risks. Within the reviews in this thesis, more information is needed from different countries to explore the discrepancies in policy making and programs, possibly leading to inequality in health care access for relevant health care interventions. Moreover, studies are needed engaging different stakeholders to elicit valuable mechanisms to involve them in NBS policy making. When stakeholder involvement is organized, often the public is missing as a stakeholder. Also debate is needed on the role of governments, accountability of funding towards NBS and under what terms, and whether the newborn period is the right time to screen for all conditions. A recent paper by Henneman et al. (2015) argued that primary school (9-11 years) could 
be an appropriate time to screen for familial hypercholesterolaemia. ${ }^{38}$ Combining the insights can inform research projects including:

- Shaping stakeholder involvement to elicit values and principles for NBS.

- Discussing whether NBS is the right time to screen, and what suitable alternatives are.

- Develop an adequate horizon scanning and evaluation tool to ensure timely translation of relevant innovations into NBS or alternative programs.

\section{Conclusion}

The studies in this thesis show that genome-based knowledge and its implications are still high on the agenda for health care practice and policy. The findings suggest that in clinical practice the implementation of genetic tests will continue to find their way to improve health outcomes for the patients, prerequisite an accurate and cost-effective test and an adequate infrastructure to support health care professionals. However, before the genetic tests investigated in this thesis can be implemented in fertility care, more information is needed on the test characteristics, and development of sufficient training and support is needed for gynecologists and other health care professionals involved in fertility care. Increasingly funding is available to support research into prove of principles for new tests in health care, but these funding structures often lack the availability of financial support to study relevant implementation factors. Funding to enable stakeholder involvement and economic evaluations are essential to develop genetic tests that can live up to the expectations.

Regarding changing landscape in NBS and the possible introduction of genome-based tests, the reviews in this thesis present several key topics that are approached very differently. Not only NBS programs, but also NBS policy making is highly heterogeneous, and to facilitate harmonization amongst countries, sharing information and knowledge is very relevant. In the USA a study to sequence the genome of newborns has started, and discrepancies between countries and even jurisdictions are expected to increase if governments do not engage with stakeholders to agree on adequate policy approaches to safeguard NBS programs. The developments in sequencing techniques do show promising test innovation that could improve the health of infants early on in life. Therefore ensuring frameworks that will facilitate swift translation of proven relevant genome-based information should be enabled. 


\section{References}

1. FDA. Personalized Medicine. 2015; http://www.fda.gov/scienceresearch/special topics/personalizedmedicine/default.htm. Accessed 27 October 2016.

2. Horgan $D$, Jansen $M$, Leyens $L$, et al. An index of barriers for the implementation of personalised medicine and pharmacogenomics in Europe. Public health genomics. 2014;17(6):287-298.

3. Wilson BJ, Nicholls SG. The Human Genome Project, and recent advances in personalized genomics. Risk management and healthcare policy. 2015;8:9.

4. PACITA. European Future Panel on Public Health Genomics. 2011; http://www.pacitaproject.eu/public-healthgenomics/. Accessed 27 October 2015.

5. Price MJ, Ades $A E$, Welton $N J$, et al. How much tubal factor infertility is caused by Chlamydia? Estimates based on serological evidence corrected for sensitivity and specificity. Sex Transm Dis. 2012;39(8):608613.

6. Menon S, Timms P, Allan A, et al. Human and Pathogen Factors Associated with Chlamydia trachomatis-Related Infertility in Women. Clinical Microbiology Reviews. 2015;28(4):969-985.

7. den Hartog JE, Land JA, Stassen FR, Kessels AG, Bruggeman CA. Serological markers of persistent $C$. trachomatis infections in women with tubal factor subfertility. Hum Reprod. 2005;20(4):986-990.

8. Horner PJ, Wills GS, Reynolds R, et al. Effect of time since exposure to Chlamydia trachomatis on chlamydia antibody detection in women: a corss-sectional study. Sex Transm Infect. 2013;89:398-403.

9. Tiitinen $A$, Surcel $H-M$, Halttunen $M$, et al. Chlamydia trachomatis and chlamydial heat shock protein 60-specific antibody and cellmediated responses predict tubal factor infertility. Hum Reprod. 2006;21(6):15331538.

10. Wang J, Chen L, Chen F, et al. A chlamydial type III-secreted effector protein (Tarp) is predominantly recognized by antibodies from humans infected with Chlamydia trachomatis and induces protective immunity against upper genital tract pathologies in mice. Vaccine. 2009;27(22):2967-2980.

11. Wills GS, Horner PJ, Reynolds R, et al. Pgp3 Antibody Enzyme-Linked Immunosorbent Assay, a Sensitive and Specific Assay for Seroepidemiological Analysis of Chlamydia trachomatis Infection. Clinical and Vaccine Immunology. 2009;16(6):835-843.

12. Hjelholt A, Christiansen G, Johannesson TG, Ingerslev $\mathrm{HJ}$, Birkelund $\mathrm{S}$. Tubal factor infertility is associated with antibodies against Chlamydia trachomatis heat shock protein 60 (HSP60) but not human HSP60. Hum Reprod. 2011;26(8):2069-2076.

13. Branković I, van Ess EF, Noz MP, et al. NOD1 in contrast to NOD2 functional polymorphism influence Chlamydia trachomatis infection and the risk of tubal factor infertility. Pathogens and Disease. 2015;73(1):1-9.

14. Malogajski J, Brankovic I, Verweij SP, et al. Translational Potential into Health Care of Basic Genomic and Genetic Findings for Human Immunodeficiency Virus, Chlamydia trachomatis, and Human Papilloma Virus. Biomed Research International. 2013:10.

15. Asner S, Morré S, Bochud PY, Greub G. Host factors and genetic susceptibility to infections due to intracellular bacteria and fastidious organisms. Clinical Microbiology and Infection. 2014;20(12):1246-1253.

16. Lal JA, Malogajski J, Verweij SP, et al. Chlamydia trachomatis infections and subfertility: opportunities to translate host pathogen genomic data into public health. Public health genomics. 2013;16(1-2):50-61.

17. CDC. Genomic testing - ACCE Model Process for Evaluation Genetic Tests. 2010; 
http://www.cdc.gov/genomics/gtesting/AC

CE/. Accessed 27 October 2015.

18. Baars MJ, Henneman L, Ten Kate LP. Deficiency of knowledge of genetics and genetic tests among general practitioners, gynecologists, and pediatricians: a global problem. Genet Med. 2005;7(9):605-610.

19. Freedman $A N$, Wideroff $L$, Olson $L$, et al. US physicians' attitudes toward genetic testing for cancer susceptibility. Am J Med Genet A. 2003;120A(1):63-71.

20. Hatz MM, Schremser K, Rogowski W. Is Individualized Medicine More CostEffective? A Systematic Review. PharmacoEconomics. 2014;32(5):443-455.

21. Andermann A, Blancquaert I, Déry V. Genetic screening: a conceptual framework for programmes and policy-making. J Health Serv Res Policy. 2010;15(2):90-97.

22. Howard HC, Knoppers BM, Cornel MC, et al. Whole-genome sequencing in newborn screening? A statement on the continued importance of targeted approaches in newborn screening programmes. Eur J Hum Genet. 2015.

23. Andermann A, Blancquaert I, Beauchamp $S$, Costea I. Guiding Policy Decisions for Genetic Screening: Developing a Systematic and Transparent Approach. Public Health Genomics. 2011;14:9-16.

24. Bailey DB, Skinner D, Davis AM, Withmarsh I, Powell C. Ethical, Legal, and Social Concerns About Expanded Newborn Screening: Fragile $X$ Syndrome as a Prototype for Emerging Issues. Pediatrics. 2008;121:e693e704.

25. Bailey DB. The Blurred Distinction between Treatable and Untreatable Conditions in Newborn Screening. Health Matrix. 2009;19:141-153.

26. Grosse SD, Boyle CA, Kenneson A, Khoury MJ, Wilfond BS. From Public Health Emergency to Public Health Service, The Implications of Evolving Criteria for
Newborn Screening Panels. Pediatrics. 2006;117(3):923-929.

27. Bombard Y, Miller FA, Hayeems RZ, Avard D, Knoppers BM. Reconsidering reproductive benefit through newborn screening: a systematic review of guidelines on preconception, prenatal and newborn screening. European Journal of Human Genetics. 2010;18:751-760.

28. Fischer KE, Grosse SD, Rogowski WH. The role of health technology assessment in coverage decisions on newborn screening. Intl. J. of Technology Assessment in Health Care. 2011;27(4):313-321.

29. Loeber G, Webster D, Aznarez A. Quality evaluation of newborn screening programs. Acta Paediatr Suppl. 1999;432:3-6.

30. Schippers EI. Kamerbrief: Neonatale hielprikscreening. 9 July 2015; http://www.rijksoverheid.nl/documenten-

en-

publicaties/kamerstukken/2015/07/09/kam erbrief-over-neonatale-

hielprikscreening.html. Accessed 14 July 2015.

31. Oosterwijk O. Response advice Neonata Screening. 2015; http://www.vsop.nl/vsop/media/upload/pa ges/file/Nieuws/Brief aan minister Schippe rs betreffende reactie advies neonatale scr een .pdf. Accessed 28 OCtober 2015.

32. Avard D, Stanton Jean $M$, Grégoire G, Page M. Public involvement in health genomics: the reality behind the policies. International Journal of Consumer Studies. 2010;34(5):508-524.

33. Degeling C, Carter SM, Rychetnik L. Which public and why deliberate?-A scoping review of public deliberation in public health and health policy research. Social Science \& Medicine. 2015;131:114-121.

34. Lipstein EA, Nabi E, Perrin JM, Luff $D$, Browning MF, Kuhlthau KA. Parents' Decision-Making in Newborn Screening: 
Opinions, Choices, and Information Needs. Pediatrics. 2010;126:696-704.

35. Weinreich SS, Rigter T, van El CG, et al. Public support for neonatal screening for Pompe disease, a broad-phenotype condition. Orphanet J Rare Dis. 2012;7:15.

36. Abelson J, Giacomini M, Lehoux P, Gauvin FP. Bringing 'the public'into health technology assessment and coverage policy decisions: from principles to practice. Health policy. 2007;82(1):37-50.
37. Avard D, Grégoire G, Jean S M. Involving the public in public health genomics: a review of guidelines and policy statements. 2008.

38. Henneman L, McBride CM, Cornel MC, Duquette D, Qureshi N. Screening for Familial Hypercholesterolemia in Children: What Can We Learn From Adult Screening Programs? Paper presented at: Healthcare2015. 
Chapter 9

Summary

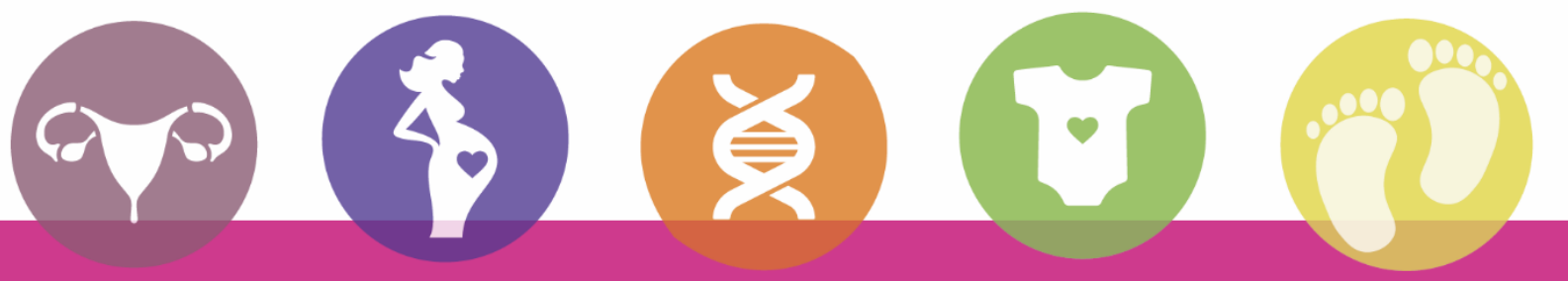




\section{Public Health Genomics}

In recent years disease understanding has expanded through the development of new technologies. Chapter 1 describes that one of the major breakthroughs in modern day biology was the sequencing of the human genome in the Human Genome Project. Genes play an important role in our bodies' disease defense mechanisms, but also in our predisposition to develop diseases. Information on genotype-phenotype interaction could inform new diagnostic, treatment, and prevention opportunities. However, before implementation of genetic technologies into health care would get the essential support from stakeholders, several questions will need to be answered. Especially Analytical validity, Clinical validity, Clinical utility, and Ethical, legal, and societal implications are relevant for the assessment of genetic tests that could be used in specific health care settings.

To integrate genome-based knowledge and technologies into public policy and health services Public Health Genomics (PHG) has emerged as a field of expertise. The studies presented in this thesis fall within this research field. PHG has a broad scope for relevant technologies and their responsible implementation into healthcare. In this thesis the focus will be on two types of genetic screening: in clinical practice and in population health. Chapters 2 - 4 will describe screening to identify women with a high risk of tubal factor infertility (TFI), and chapters $\mathbf{5}$ - $\mathbf{7}$ focus on possible changes in newborn bloodspot screening (NBS) due to debate driven by innovation in genetic technologies. Both parts discuss possibilities for genetic and non-genetic technologies, with emphasis on stakeholder involvement in decisions about implementation.

\section{Chlamydia trachomatis associated tubal factor infertility}

Current standard practice to identify women with a high risk of TFI is an antibody screening test for the bacterium Chlamydia trachomatis, because $C$. trachomatis is the most important cause of female infertility. The sensitivity of the $C$. trachomatis antibody test (CAT) to diagnose TFI is estimated to lie between 28 and $62 \%$, which leaves considerable room for improvement. Improving the identification of high risk women aims to prevent unnecessary laparoscopies: the best test available to diagnose TFI, but a costly and invasive procedure.

In chapter 2 we investigated whether adding a complementary serological biomarker to CAT could improve screening: a high sensitivity (hs) test for $\mathrm{C}$-reactive protein (CRP). CRP is a biomarker for the level of persistence of an infection, which may indicate a longer time period in which the $C$. trachomatis bacteria and/or inflammatory response could have damaged the fallopian tubes. We replicated an earlier study with promising results regarding the addition of $\mathrm{CRP}$ as a marker for persistent infection in an independent sample. In our sample of 176 women with fertility complaints, we were not able to confirm the results from the earlier study, i.e. we did not find a statistically significant association between the combination of CAT and hsCRP in the prediction of TFI. Since C. trachomatis 
is specifically associated with distal adhesions of the fallopian tubes, we also tested in chapter $\mathbf{2}$ for the association on double sided distal adhesions with each of the tests separately (solely CAT and solely hsCRP), and with the two tests combined. For this outcome we found a statistically significant association between solely the CAT and double sided TFI. We did not have enough statistical power to be conclusive on either of the analyses, however our study does indicate that the prediction of double sided TFI could benefit from CAT, but that other grades of TFI might need different biomarkers.

One of the potential biomarkers to screen for the course of a $C$. trachomatis infection could be a host genetic test, by analyzing genetic biomarkers relevant for the host's immune response. Changes in the smallest building block of our DNA - single nucleotide polymorphisms (SNPs) - can have significant influence on the expression and function of molecules in our bodies. Almost $40 \%$ of the differences in clinical presentation of $C$. trachomatis infection are estimated to be explained by genetic variation. SNPs can make an immune response more or less reactive or effective, and influence the course of a $C$. trachomatis infection. Chapter $\mathbf{3}$ discusses the value of a SNP-analysis in predicting the development of TFI after an immune response to $C$. trachomatis infection. The analyzed SNP located in a gene region coding for the Human Leukocyte Antigen type $\mathrm{A}(H L A-A)$. The $H L A-A$ receptor is involved in the recognition of pathogen peptides and initiates an immune response through activating $\mathrm{CD} 8^{+} \mathrm{T}$-cells. The study described in chapter 3 shows that a SNP $(\mathrm{G}>\mathrm{A})$ in the $H L A-A$ gene region has a protective effect on the development of complications after a $C$. trachomatis infection. We observed a trend of a decreasing proportion of women carrying this SNP analyzed against an increasing degree of complications: women with mild symptoms had the largest proportion of G>Avariation, while among the women with double sided tubal pathology none had the G>Avariation. The statistical power was not sufficient to make firm conclusions on the role of the SNP, but we hypothesize that carrying the SNP might lead to a weaker affinity of the $H L A-A$ molecule to a $C$. trachomatis-derived peptide, resulting in a less effective antigen presentation to $\mathrm{CD} 8+\mathrm{T}$ cells. Therefore the immune response will be less aggressive, which could lead to less adhesions in the fallopian tubes.

Our study in chapter 3 results in a hypothesis for genetic biomarkers to predict the severity of symptoms after a C. trachomatis infection, and contributes to a considerable body of evidence for the role of immunogenetics in predicting the course of a $C$. trachomatis infection. Therefore, chapter $\mathbf{4}$ focuses on the support amongst gynecologists to use a genetic test in their routine fertility work-up in the future. Ultimately the impact of genetic tests on clinical practice depends on clinicians' decisions to order genetic tests, and they play an essential role in interpreting and explaining the results to their patients. To study the attitude of clinicians towards genetic tests, we used a questionnaire based on interviews with experienced gynecologists in the Netherlands to explore the barriers and facilitators in a sample from $75 \%$ of the Dutch Academic Hospitals. In the questionnaire conducted in chapter $\mathbf{4}$ clinicians were asked to score a 
range of statements on barriers and facilitators. $61.7 \%$ of respondents stated that the addition of a genetic test to CAT would increase the screening accuracy for TFI. They regarded clinical utility as the most import indicator of the quality of a genetic test. Furthermore, almost $95 \%$ of the clinicians scored cost-effectiveness as an important factor to gain their support, therefore comprehensive research about the potential economic implications of the introduction of genetic tests should be the next important step in the implementation strategy.

\section{The changing landscape in newborn bloodspot screening}

The perspectives and support of stakeholders is not only essential in clinical practice, but also in health policy making. Genetic tests offer a range of possibilities for population screening programs, and are specifically debated in NBS. Implementing genetic tests in a publicly funded program, while there is not always consensus on the benefits aimed for, can be controversial and calls for careful consideration of the implications on the whole system of NBS. It is especially relevant to take a closer look at the policy processes and decision making in NBS, since most countries use the Wilson and Jungner screening principles as a starting point to shape their NBS program, but currently the resultant programs are highly different.

Chapter $\mathbf{5}$ focusses on factors that influence decision making in NBS. This chapter aims to understand what factors influence NBS criteria and how conditions are assessed against them. Through a systematic review of scientific literature, combined with a structured analysis of policy documents it offers unique insights into the international landscape of NBS. We found five key topics that are discussed in scientific literature, and have different approaches amongst programs: the beneficiary of NBS, definition of criteria, the way conditions are assessed, level of evidence required, and recommendations after assessment. In the considerations of these topics in chapter $\mathbf{5}$, it was found that also in NBS policy government policy lags behind the scientific debate. However, the purpose of NBS is under discussion in both mediums, and evidence-based and transparent decision making is needed to shape programs in the future. Differences in the five key topics have the potential to result in increased disparity across NBS internationally. The criteria and their use in the assessment of conditions are responsible for shaping the programs; therefore understanding how they are used in different ways internationally provides an insight into what NBS might hold in the future. Ultimately, governments need to decide on the role they see for NBS, and agree on an approach to decision making in line with this role.

Evidence-based and transparent decision making is also the focus in chapter $\mathbf{6}$, however the structure of such a process is also discussed. Historically, expansion of NBS programs often followed an ad hoc consideration of conditions, instead of a structured, transparent, and evidence-based approach. With the expectation of further expansion of NBS programs with the advent of more genetic technologies, it is important to have robust 
policy making practices in place, to safeguard the programs. In chapter $\mathbf{6}$ the elements to approach policy making are structured based on the steps in the policy cycle: a) agenda setting, b) policy advice, c) policy decision, d) implementation, and e) evaluation. In the literature search conducted, the relevant content for each policy step highlighted a framework for future decisions within the changing international landscape of NBS. Policy making in NBS could benefit from moving towards a process that has its origin in health technology assessment (HTA), such as following a process of horizon scanning for evidence based nominations of relevant conditions for NBS. Furthermore, HTA frameworks focus on structurally engaging stakeholders in policy making, such as government, health care professionals, and the public, which is fundamental to modern healthcare. Support for implementation can only be created by balancing competing influences and demands from different perspectives. Ultimately, enhancing international transparency, learning experiences, and harmonization is needed for equity in access to early care for relevant conditions for infants in all countries.

As discussed in chapters $\mathbf{5}$ and 6, introducing new genetic technologies in NBS could have great implications on the programs worldwide. In current NBS policy processes, different stakeholders are involved. Chapter 7 focusses on involvement of the public in NBS policy making; the goals of public involvement, on what levels it can prove to be valuable, how to define 'public', which mechanisms exist to facilitate public involvement, and relevant indicators to evaluate the value of public involvement. From the reviewed literature it was clear that the public is not always structurally involved in policy making. Since government policies have the potential to impact people's life, accountability towards to public is important to guarantee support. Moreover, when policy is formed through a process with more stakeholder participation it can be found to be more feasible. The results in chapter $\mathbf{7}$ describe that public involvement is often ad hoc. Public involvement in NBS centers around patient advocacy, and usually only includes providing information. Only involving patient advocates in the discussion on NBS can have strong implications for the views included, and puts emphasis on conditions that may seem highly relevant for a small group of the population. Chapter $\mathbf{7}$ concludes that deliberating with the public is essential, but that the framework to do so needs to be clear on the goals, level, definition, mechanisms, and evaluation. Furthermore, whether NBS is the appropriate program to include all diseases that patient advocates bring to the table, remains to be discussed. Since preconception carrier screening and prenatal screening can be considered to have similar paradigms to NBS, developing a public involvement approach to suit all three programs could prove valuable in ensuring improved health outcomes for the population.

\section{Improving health outcomes through responsible translation}

Both clinical and population health care services are expected to incorporate more genetic information in the future. Chapter $\mathbf{8}$ summarizes the main findings of this thesis 
and the implications for practice. The studies in this thesis contribute to the evidence and expectations of the added value of genetic information. Key topics are highlighted that need to be addressed to facilitate structured consideration and translation of genetic knowledge. In either clinical or population health care services deliberation with relevant stakeholders is of utmost importance to ensure swift implementation of relevant genetic information. Only through transparent development and decision making essential information can be gathered on all aspects of a test that could be used in a specific setting, including the infrastructure and stakeholders involved, to ultimately ensure improved health outcomes for the target population. 


\section{Chapter 10}

\section{Samenvatting}

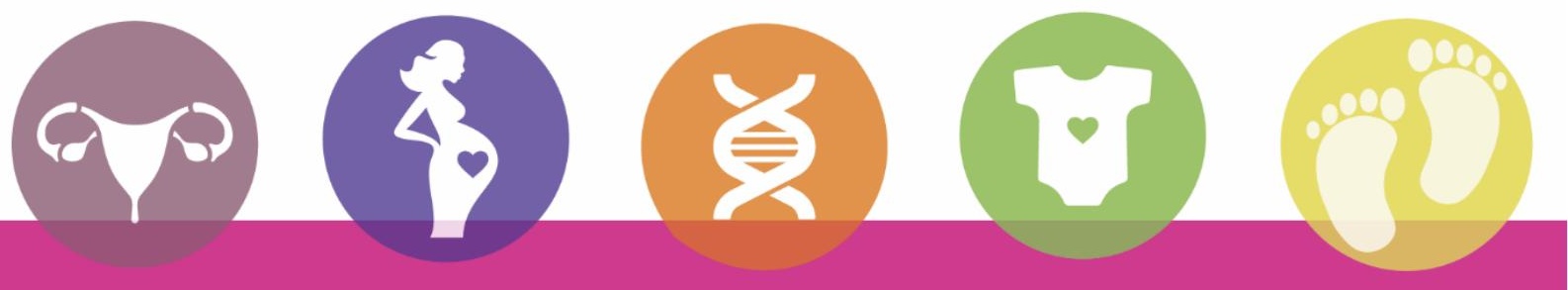




\section{Public Health Genomics}

Recentelijk is ons begrip over ziekten uitgebreid door de ontwikkeling van nieuwe technologieën. Chapter $\mathbf{1}$ beschrijft dat één van de grote doorbraken het in kaart brengen van het menselijk genoom was (sequencing) in moderne biologie was. Genen spelen een belangrijke rol in ons lichamelijke mechanismen voor ziektebestrijding, maar ook voor ziekteontwikkeling. Informatie over genotype-fenotype interacties kunnen daarom nieuwe diagnostiek, behandeling en preventiemogelijkheden aan het licht brengen. Voordat dit echter mogelijk is, zal de implementatie van genetische technologie de essentiële ondersteuning van stakeholders moeten krijgen. Hiervoor zullen een aantal vragen over deze technologieën beantwoord moeten worden. Vooral de Analytische validiteit, Klinische validiteit, Klinische utiliteit en Ethische, wettelijke en sociale implicaties zijn relevant voor de beoordeling of een genetische test gebruikt kan worden in specifieke sectoren van de gezondheidszorg.

Om kennis gebaseerd op genetische informatie en technologieën te integreren in publiek beleid en gezondheidsservices is een nieuw veld van expertise ontstaan: Public Health Genomics (PHG). De studies die in dit proefschrift gepresenteerd worden vallen binnen dit onderzoeksgebied. PHG heeft een brede blik op relevante technologieën en hun verantwoordelijke implementatie in de gezondheidszorg. In dit proefschrift zal de focus liggen op twee types van genetische screening: in de klinische praktijk en in populatiescreening. Chapter $\mathbf{2}-\mathbf{4}$ zullen screening beschrijven die gericht is op het identificeren van vrouwen met een hoog risico op tubapathologie en daaraan gerelateerd infertiliteit (TFI). In chapter $\mathbf{5}$ - 7 ligt de focus op mogelijke veranderingen in neonatale hielprikscreening (NBS) door debatten gedreven door innovatie in genetische technologieën. Beiden delen bespreken mogelijkheden voor genetische en nietgenetische technologieën, met een accent op het betrekken stakeholders in beslissingen over implementatie.

\section{Chlamydia trachomatis en TFI}

Momenteel is de standaardzorg om vrouwen met een hoog risico op TFI te identificeren door te testen voor antilichamen tegen de bacterie Chlamydia trachomatis, omdat $C$. trachomatis de belangrijkste oorzaak is van vrouwelijke infertiliteit. De sensitiviteit van deze $C$. trachomatis antilichamentest (CAT) is geschat tussen 28 en $62 \%$ te liggen, wat ruimte voor verbetering laat. De verbetering van de correcte identificatie van hoog-risico vrouwen voor TFI is erop gericht om onnodige laparoscopieën te voorkomen: de best beschikbare manier om TFI te diagnosticeren, maar ook een kostbare en ingrijpende procedure.

In chapter 2 hebben we onderzocht of het toevoegen van een extra serologische marker aan de CAT de screening zou verbeteren: een high sensitivity (hs) test voor C-reactive protein (CRP). CRP is een biomarker voor de mate waarin een infectie persistent gebleken is in een persoon, wat een langere tijd suggereert waarin de C. trachomatis bacteriën 
en/of de ontstekingsreactie de tubae beschadigd kan hebben. We hebben een eerdere studie met veelbelovende resultaten gerepliceerd in een onafhankelijke steekproef. In onze steekproef van 176 vrouwen met fertiliteitsklachten waren wij niet in staat om de resultaten van de eerdere studie te bevestigen, m.a.w. wij vonden geen statistisch significante associatie tussen de combinatie van CAT en hsCRP in de voorspelling van TFI. Aangezien C. trachomatis vooral geassocieerd is met distale adhesies van de tubae, hebben we in chapter $\mathbf{2}$ ook getoetst op de associatie tussen iedere testconditie en de uitkomst (alleen CAT en alleen hsCRP), en voor de twee testen gecombineerd. Voor deze uitkomst vonden wij een statistisch significant verband tussen alleen de CAT en dubbelzijdige tubapathologie. Vanwege de steekproefgrootte zijn wij niet in staat om sluitende conclusies te geven op ieder van de analyses, maar onze studie suggereert wel dat voorspelling van dubbelzijdige TFI voordeel kan hebben van de CAT, maar dat andere gradaties van tubapathologie mogelijk andere biomarkers nodig hebben.

Eén van de mogelijke biomarkers om te screenen op het verloop van een $C$. trachomatis infectie zijn genetische varianten van de gastheer die relevant zijn voor de immuunreactie. Veranderingen in de kleinste bouwstenen van ons DNA - single nucleotide polymorphisms (SNPs) - kunnen een significante invloed hebben op de expressive en functie van de molecule in ons lichaam. Het is geschat dat bijna $40 \%$ van de verschillen in de klinische presentatie van $C$. trachomatis infecties verklaard kan worden door genetische variatie. SNPs kunnen een immuunreactie meer of minder reactief of effectief maken en beïnvloeden het verloop van een $C$. trachomatis infectie.

Chapter 3 bespreekt de toevoegende waarde van een SNP-analyse in het voorspellen van het ontwikkelen van TFI na een immuunreactie tegen $C$. trachomatis. De geanalyseerde SNP ligt in een genenregio die codeert voor het Human Leukocyte Antigen type A ( $H L A-A)$. De $H L A-A$ receptor is betrokken bij de herkenning van eiwitten van pathogenen en initieert een immuunreactie door $C D 8^{+}-\mathrm{T}$-cellen te activeren. De studie beschreven in chapter 3 laat zien dat een SNP (G>A) in de HLA-A genenregio een mogelijk beschermend effect heeft tegen de ontwikkeling van complicaties na een $C$. trachomatis infectie. Wij observeerden een trend waarbij een afname in het aantal vrouwen dat deze SNP droeg afgezet was tegen een toenemende mate van complicaties: vrouwen met milde symptomen hadden de grootste proportie van de G>A-variant, terwijl geen van de vrouwen met dubbelzijdige tubapathologie deze variant had. De statische power was niet hoog genoeg om ferme conclusies te trekken over de rol van de SNP, maar wij hypothetiseren dat de SNP mogelijk tot een zwakkere affiniteit van de HLA-A molecuul naar de eiwitstructuur van $C$. trachomatis leidt, waardoor er minder effectieve antigenpresentatie naar $\mathrm{CD}^{+}-\mathrm{T}$-cellen plaatsvindt. Daardoor kan de immuunreactie minder agressief zijn, wat minder adhesies in de tubae tot gevolg kan hebben.

Onze studie in chapter $\mathbf{3}$ resulteerde in een hypothese over genetische biomarker om de ernst van de symptomen van een $C$. trachomatis infectie te voorspellen en draagt bij aan een bewijslast voor de rol van immunogenetica in het voorspellen van het verloop van 
een $C$. trachomatis infectie. Daarom ligt in chapter 4 de focus op de steun onder gyneacologen om een dergelijke genetische test te gebruiken in hun dagelijkse werkzaamheden in de toekomst. Uiteindelijk zal de impact van genetische testen op de klinische praktijk voor een belangrijk deel afhangen van het besluit van clinici om een dergelijke test te bestellen, daarnaast spelen zij een essentiële rol in het interpreteren en uitleggen van de testresultaten. Om de attitude van clinici jegens genetische testen te bestuderen hebben wij een vragenlijst gebruikt. De vragenlijst is gebaseerd op interviews met ervaren gynaecologen uit Nederland. De interviews en de resulterende vragenlijst richtten zich op de mogelijke barrières en faciliterende factoren die gynaecologen ervaren te identificeren. In een steekproef in $75 \%$ van de Nederlandse Academische Ziekenhuizen werden zij gevraagd om hun mening weer te geven in een aantal vragen en stellingen. $61.7 \%$ van de respondenten gaf aan dat de toevoeging van een genetische test aan de CAT de accuraatheid van de screening voor TFI zou verbeteren. Verder beschouwden zij klinische utiliteit als de belangrijkste indicator voor de kwaliteit van een genetische test. Daarnaast scoorde bijna 95\% van de clinici kosteneffectiviteit als een belangrijke factor om hun steun te krijgen voor een genetische test. Een belangrijke vervolgstap in onderzoek is daarom om de potentiële economische implicaties van de introductie van een genetische test in kaart te brengen.

\section{Veranderingen in het landschap van NBS}

De perspectieven en steun van stakeholders zijn niet alleen essentieel in de klinische praktijk, maar ook in de ontwikkeling van gezondheidsbeleid. Genetische testen bieden verschillende mogelijkheden voor populatiescreeningprogramma's en worden vaak besproken in de context van NBS. Het implementeren van genetische testen in een publiek gefinancieerd programma kan controversieel zijn en vraagt om voorzichtige overwegingen van de implicatie op het hele systeem van NBS. Het is vooral interessant om in meer detail naar de beleidsprocessen en besluitvorming in NBS, aangezien de meeste landen de principes van Wilson en Jungner gebruiken als een vertrekpunt om hun NBS-programma vorm te geven, maar momenteel zijn de resulterende programma's behoorlijk verschillend.

Chapter 5 richt zich op de facturen die besluitvorming in NBS beïnvloeden. In dit hoofdstuk proberen we te begrijpen welke factoren NBS criteria beïnvloeden en hoe aandoeningen m.b.v. deze criteria geëvalueerd worden. Door een systematische review van de literatuur, gecombineerd met een gestructureerde analyse van beleidsdocumenten biedt het hoofdstuk unieke inzichten in het internationale landschap van NBS. We hebben vijf hoofdonderwerpen gevonden die in de wetenschappelijke literatuur besproken worden en die verschillend benaderd worden in programma's: wie er voordeel heeft van de screening; de definitie van screening criteria; hoe aandoeningen geëvalueerd worden; het niveau van bewijs dat vereist is; en de aanbevelingen die gegeven worden na de evaluatie. Tijdens de overwegingen van deze onderwerpen in 
chapter 5 werd er gevonden dat het beleid in NBS deels achterloopt op het wetenschappelijke debat, hoewel het programma in beide media besproken wordt. Voor de toekomst zijn transparante besluitvormingsprocessen nodig gebaseerd op wetenschappelijk bewijs (evidence-based). Verschillen in de vijf hoofdonderwerpen hebben de potentie om in toenemende discrepanties te zorgen tussen NBS-programma's internationaal. De criteria en hun gebruik in de evaluatie van aandoeningen zijn verantwoordelijk voor de vormgeving van de programma's; daarom is het belangrijk om te begrijpen hoe zij op verschillende manieren worden toegepast internationaal. Uiteindelijk moeten overheden beslissen welke rol zij zien voor NBS en consensus bereiken hoe zij dit doel zullen benaderen.

Transparante en evidence-based besluitvorming staan ook centraal in chapter $\mathbf{6}$, hoewel in dit hoofdstuk de structuur van een dergelijke besluitvormingsproces besproken wordt. In het verleden volgde uitbreiding van NBS-programma's vaak een ad hoc overweging van aandoening in plaats van een gestructureerde, transparante en evidence-based benadering. Met de verwachting dat NBS-programma's in de toekomst verder zullen uitbreiden met de opkomst van genetische technologieën, is het belangrijk om robuuste beleidsprocessen te hebben om de programma's te waarborgen. In chapter 6 worden deze elementen besproken aan de hand van de beleidscyclus: a) agenda setting, b) beleidsadvies, c) beleidsbesluit, d) implementatie, en e) evaluatie. In het uitgevoerde literatuuronderzoek zijn voor ieder element relevante aspecten gevonden in een raamwerk voor toekomstige besluitvorming in de dynamiek van NBS. Beleidsontwikkeling voor NBS zou voordeel kunnen doen door naar een proces te bewegen dat de oorsprong vindt in health technology assessment (HTA). HTAbenaderingen maken bijvoorbeeld gebruik van horizon scanning voor bewijs voor relevante aandoeningen voor NBS, daarnaast richt HTA zich op het structureel betrekken van stakeholders in beleidsontwikkeling, zoals de overheid, gezondheidszorgprofessional en het publiek. Steun voor implementatie kan alleen gecreëerd worden door conflicterende belangen te balanceren. Het verbeteren van internationaal transparantie, leerervaringen, en harmonisatie is nodig om gelijke toegang tot gezondheidszorg vroeg in het leven te bewerkstelligen voor alle pasgeboren baby's.

Zoals besproken in chapter 5 en $\mathbf{6}$ kan het introduceren van nieuwe genetische technologieën in NBS grote implicaties hebben op programma's wereldwijd. In huidige NBS beleidsprocessen zijn verschillende stakeholders betrokken. Chapter 7 richt zich op het betrekken van het publiek in beleidsontwikkeling; de doelen van publieke betrokkenheid, op welke niveaus het waardevol kan zijn, hoe 'publiek' gedefinieerd zou moeten worden, welke mechanismen er bestaan om publieke betrokkenheid te faciliteren, en welke indicatoren relevant zijn om de betrokkenheid te evalueren. Uit de bestudeerde literatuur was het duidelijk dat het publiek niet altijd gestructureerd betrokken is in beleidsontwikkeling. Aangezien overheidsbeleid mogelijk mensen hun leven beïnvloed, is verantwoordelijk richting het publiek belangrijk om steun te 
garanderen. Bovendien, wanneer beleid ontwikkeld is door een proces met meer stakeholders betrokken wordt het vaak als meer haalbaar ervaren. De resultaten in chapter 7 beschrijven dat publieke betrokkenheid vaak ad hoc geregeld is. Publieke betrokkenheid in de beleidsontwikkeling voor NBS centreert zich vaak rondom patiëntrepresentatie en betreft daarnaast vaak alleen het geven van informatie in plaats van actief meebeslissen. Alleen patiëntrepresentatie bewerkstelligen in de beleidsontwikkeling, kan sterke gevolgen hebben voor de perspectieven die in de ontwikkeling meegenomen worden en legt de nadruk op aandoeningen die heel relevant zijn voor een kleine groep van de gehele bevolking. Chapter 7 concludeert dat overleggen met het publiek essentieel is, maar dat er een raamwerk nodig is met duidelijke doelen, niveaus, mechanismen, definities, en evaluatie. Bovendien staat het nog ter discussie of NBS het juiste moment is om voor alle mogelijke ziekten te screening die ter discussie gebracht worden. Aangezien preconceptie carrierscreening en prenatale screening beschouwd kunnen worden binnen hetzelfde paradigma, een benadering voor publieke betrokkenheid die geschikt is voor alle drie de programma's kan waardevol zijn in het verzekeren van verbeterde gezondheidsuitkomsten voor de bevolking.

\section{Gezondheidsuitkomsten verbeteren door verantwoordelijke translatie}

Het gezondheidszorgaanbod zowel in ziekenhuizen als in populatiescreening wordt verwacht om meer genetische informatie te gaan gebruiken in de toekomst. Chapter $\mathbf{8}$ vat de belangrijkste bevinden van dit proefschrift samen en biedt een overzicht van de implicaties voor de praktijk. De studies in dit proefschrift dragen bij aan het bewijs en de verwachtingen over de toevoegende waarde van genetische informatie. Hoofdonderwerpen worden onderstreept die behandeld moeten worden om een gestructureerde overweging en translatie van genetische kennis. Zowel in de klinische praktijk als in screeningsbeleid is het uitermate belangrijk om stakeholders te betrekken in het ontwikkelingsproces om relevante genetische informatie te implementeren. Alleen door transparante ontwikkelings- en besluitvormingsprocessen kan essentiële informatie verzameld worden over alle aspecten van een test die in een specifieke context gebruikt kan worden, inclusief de infrastructuur en betrokken stakeholders, om uiteindelijk verbeterde gezondheidsuitkomsten voor de doelgroep te bewerkstellingen. 


\section{Chapter 11}

\section{Dankwoord/Acknowledgements}

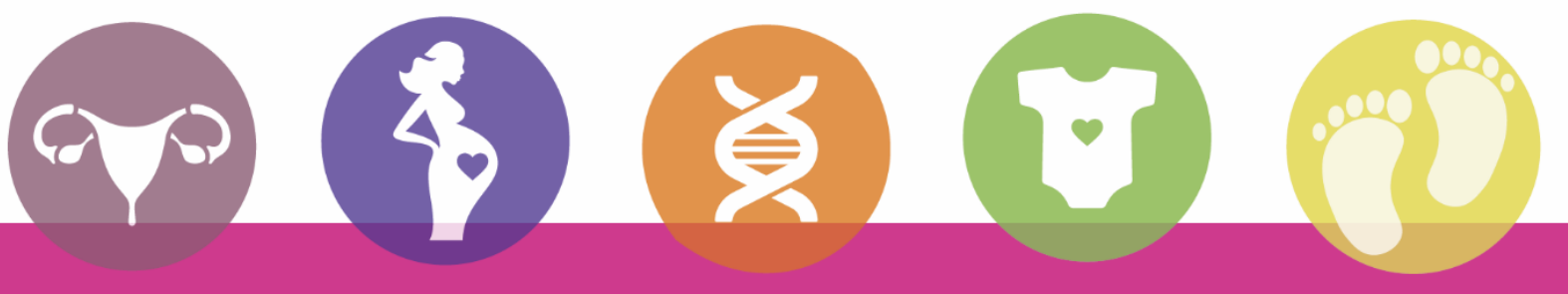




\section{De optelsom van een zeer leerzame Nederlandse en Australische omgeving én een sociaal netwerk met geweldige mensen hebben ertoe geleid dat er een mooi proefschrift tot stand is gekomen. Ik ben trots en blij dat ik in de afgelopen jaren met jullie hebben mogen samenwerken en samen niet-werken.}

Allereerst wil ik mij graag tot mijn promotieteam richten; Servaas, Martina, Sander en Henk. Ik wil jullie allen bedanken voor de begeleiding tijdens het schrijven van dit proefschrift en het onderzoek dat eraan vooraf ging. Zonder jullie feedback, inzet en 'even sparren' waren de ideeën die voor het onderzoek tot vorm kwamen nooit zo goed uit de verf gekomen. Tijdens het gehele proces heb ik veel van jullie geleerd en kon ik altijd terecht met een vraag of een (erg) ruwe versie van een geschreven stuk. Ik heb met veel plezier bij jullie afdelingen gewerkt en kijk ernaar uit om in de toekomst elkaar weer tegen te komen.

De beoordelingscommissie, professoren Didi Braat, Nils Lambalk, Paul Savelkoul, en Guido de Wert, hartelijk dank voor goedkeuren van mijn proefschrift na een kritische beoordeling.

Carla, Caroline en Jolande, hartelijk dank voor jullie feedback (soms) op afstand. Het was erg behulpzaam om jullie expertise te hebben voor de artikelen waar we aan hebben samengewerkt en jullie boden altijd een frisse blik op nieuwe versies van de manuscripten.

My colleagues Ivan, Jelena, and Elena, thank you for your input in the articles we worked on together and the chats and laughs. Yvonne, bedankt voor alle antwoorden op vragen waar ik mee aankwam, je wist altijd waar ik terecht kon en waar het mogelijk was loste jij de problemen vaak snel op. Jan-Henk, we hebben nooit samen aan artikelen gewerkt, maar we hebben wel altijd in hetzelfde promotie-schuitje gezeten. Bedankt voor de relativerende gesprekken en veel succes met de laatste loodjes!

Mijn paranimfen en lotgenoten Dagmar en Gaston, super dat jullie mij hebben geholpen met de verdediging in goede banen leiden, ik kijk uit naar jullie verdedigingen! Behalve paranimfen zijn jullie ook gedurende mijn promotietraject van onmisbare waarde geweest en altijd beschikbaar om even een koffiemomentje in te lassen. Deze uiteenlopende gesprekken waren vaak het duwtje in de rug of de rem die ik nodig had om weer gemotiveerd aan de slag te gaan.

A warm thank you to the people from my home away from home; Perth. The department of prof. Hugh Dawkins welcomed me with open arms and the Office of Population Health Genomics has been an amazing environment to work at. Not only did I learn a lot from 
all of you, but also soccer practices, morning teas and wonderful lunches were valuable experiences for me.

A big and special thanks to Karla! I am certain that my time in Australia would not have been as awesome if it wasn't for you. Not only have you introduced me to working in a great team, but you made sure that I felt welcome and at home.

Mijn lieve vrienden; wat hebben jullie mij allemaal gesteund de afgelopen jaren! Patricia, ondanks je drukke agenda en onmogelijke schema's vind je toch tijd om met mij af te spreken, al is het maar voor een knuffel op Utrecht Centraal juist als ik het nodig had, Loes, Maartje en Suzanne altijd in om een drankje te doen en een nieuw tentje uit te proberen, Elianne, Karen, Manon en Michelle voor heerlijke meidenavondjes waar we gelukkig allemaal nog regelmatig tijd voor kunnen vinden in onze agenda's, Kirsten, Niels, Nina, Onno en Remco, als we elkaar zien is het altijd weer feest, mooi om te zien hoe we allemaal 'grote mensen' aan het worden zijn, het team van ExTra; Auke, Jermaine, Martine, Monica, Willeke nemen nooit een blad voor de mond en een reality check zo nu en dan is nooit weg, tijdens de vergaderingen en projecten die we aangaan werk ik altijd met veel plezier met jullie samen en ik ben erg benieuwd wat de toekomst voor ons in petto heeft. De VWC - Ingrid, Joyce, Maaike, Marleen J, Marloes - ik kijk altijd uit naar onze VWC-avonden en de weekendjes die we plannen overtreffen altijd mijn verwachtingen (Maaike en Marleen, tijd om een volgend weekendje te plannen!), Nynke, wat zal ik onze spontane afspraken en elkaar naar de sportschool slepen missen! Ik vermoed dat ik het niet te lang zonder cocktails met jou hoef te stellen. Last but not least, mijn lieve (meer dan) huisgenootjes Miri en Stephke, regelmatig kopjes thee, even wat eten, samen sporten, 'hoe was je dag' hebben mij door veel turbulente tijden gesleept en ik ga ervan uit dat we de Roomies Sinterkerst traditie in ere houden en houd mij ook zeker aanbevolen voor een nieuwe editie van Roomies on tour!

Mijn lieve familie, papa, mama, Martin\&Diane, Remco\&Mariska, Daniëlle, oma\&oom Rein, oma\&oom Piet, die altijd voor mij klaar staan met een helpende hand, een knuffel, een luisterend oor, ontzettend bedankt! Zonder jullie steun had ik nooit slopende werkweken overleefd, was een paar keer heen-en-weer verhuizen niet gelukt en had ik vele malen langer gemaald over keuzes. Wat een heerlijk gevoel om altijd een warm nest te hebben om naar thuis te komen.

My dear William, thank you for always being patient with me, giving me solid advice, but also feedback when I lost focus. Your love and support have been amazing and even though you are at the other side of the world far too often, I always feel that you are there for me for FaceTiming at impossible hours and keeping me motivated. 


\title{
Appendix
}

\author{
Valorization
}

Curriculum Vitae

Extended Curriculum Vitae

List of authors and affiliations 


\section{Valorization}

Additionally to contributing to knowledge in the scientific field, it is also important for research to contribute to society through the information and knowledge it gathers. Therefore, the research presented in this thesis will be contextualized in a societal perspective in this section, referred to as 'valorization'. Maastricht University defines valorization as a "process of creating value from knowledge, by making knowledge suitable and/or available for social (and/or economic) use and by making knowledge suitable for translation into competitive products, services, processes and new commercial activities". Five topics are considered important, and will be addressed on the following pages:

1. Relevance:

2. Target groups:

3. Services:

4. Innovation:

5. Implementation:
What is the social and/or economic relevance of your research results?

To whom are your research results of interest and why? Into which concrete products, services, activities etc. will your results be translated and shaped?

To what degree can your results be called innovative in respect to the existing range of products, services, activities etc.?

How will this/these plan(s) for valorization be shaped?

The overarching topic in this thesis is Public Health Genomics, which aims "to integrate genome-based knowledge and technologies into public policy and into health services" (see Chapter 1, Section 1. 'Translation of genomic technologies into healthcare' - page 1). Creating value from knowledge on research into genetic information has been one of the major hallmarks of modern medicine. Personalized Medicine is increasingly strived for, and PHG plays an important role in translating technologies to healthcare. One could say that PHG works to find how we can ensure that relevant applications are available to the population and are translated accordingly. Thus, in itself PHG focusses on valorization by translating evidence-based genetic information into practice. The two topics in this thesis - Chlamydia trachomatis-induced infertility and newborn bloodspot screening are no exceptions to these efforts. For each of the five abovementioned topics a link will be illustrated between (one of) our research areas and the valorizing potential it has.

\section{Relevance}

The studies in this thesis contribute to scientific knowledge on disease mechanisms into potential predictive factors by researching possible variables that play a role in the development of infertility after a chlamydial infection. In addition, the results also offer insight that may lead to improvement of the diagnostic process. This improvement would have direct benefit for women attending clinics that offer fertility care; from their initial visit to the clinic to an accurate diagnosis. When this research matures and a test grasping 
the most relevant genetic variants can successfully be implemented in clinical practice, this knowledge can prevent unnecessary invasive procedures in women, such as laparoscopies, and diminish their psychological stress from uncertain predictions. These genetic variants would go beyond solely the recognition $C$. trachomatis and inflammatory processes followed after infection, since there are other bacterial sexually transmitted diseases (STDs) like $C$. trachomatis that have a similar immune response. Furthermore, research into the attitude of gynecologists to use genetic information has already showed us what gynecologists find important as test characteristics and that they would need additional training to have their knowledge on a genetic test on point. Both these aspects offer direct factors to focus on in the continuation of research and test development to increase to chances of a swift implementation of a genetic test with important predictive factors in the development of infertility after a chlamydial infection.

To continue with an the example for newborn bloodspot screening, not only scientific information, such as a lack of reporting from a variety of countries has been found, but also lack of including a different range of stakeholders in policy development processes. For example, prospective parents will benefit from a structured, transparent, and evidence-based approach in decision making for newborn screening because they can feel secure about safeguards of an evidence-based screening program focused on goals and benefits important to them. Combining these perspectives will in the end offer all stakeholders a program that has taken their views into consideration. In a broader perspective the frameworks for stakeholder involvement in policy making could be an example for different government initiatives.

\section{Target groups}

One of the first groups that comes to mind as a target group to benefit from our research results will be people in the phase of wanting to start a family; either when they are having difficulties conceiving or when they are prospective parents. Not only relevant information for parents will ultimately result from a decision making process as illustrated in this thesis, also other stakeholder groups will be enabled to express the barriers and facilitators they experience in the responsible translation of genetic information into health care (see for example Chapter 6. Decision making in newborn screening needs a transparent approach with structured multidisciplinary stakeholder engagement in all phases, page 79).

\section{Services}

A concrete example of making our research results available for social and economic use would be a genetic array to test for relevant variants to predict the course and outcome of a Chlamydia trachomatis infection in women with fertility issues. Since this test would aim to more accurately predict which women are likely to suffer from tubal factor 
infertility, it also aims to decrease the amount of unnecessary laparoscopies. Through these aims both a social and economic goal are served. Women would be spared the burden of undergoing an invasive procedure, while health care costs and productivity losses can also be reduced by minimizing invasive procedures.

\section{Innovation}

While genetic information has been predicted to offer a considerable breakthrough for health care through treatments and diagnostics, these expectations are not realized in health care yet. Currently most applications of genetic tests can be found in cancer diagnostics and treatment. Furthermore, genetics has played a major role in fertility health care for example in prenatal genetic diagnostics, but has not been applied yet in the diagnosis of infertility. Since PGD is usually only performed in a small group of people, developing and implementing an additional genetic test for infertility diagnosis would present an innovative approach to this condition. Moreover, the test has the potential to be used for a wider set of women suffering from fertility complaints.

In the field of newborn bloodspot screening this thesis offers several suggestions to innovate in the current policy making processes. For example, the research presented in chapter 7 offers a starting point for governments to consider public participation in policy development. Moreover, a topic that is addressed throughout the chapters on newborn bloodspot screening, is the aim of newborn bloodspot screening. The studies in this thesis give several suggestions how to address this question, and pay attention to the still - innovative view that the aim of newborn screening might benefit from a shift towards including family benefits. Nonetheless, these considerations should be made in a structured and transparent process, which is not always in place in countries or jurisdictions. Chapter 6 offers insights to policy makers about to embark on developing or revising a newborn bloodspot screening program to apply such an approach, in order to innovate decision making for newborn bloodspot screening towards a safe program, supported by stakeholders.

\section{Schedule and implementation}

For each of the topics several links have been made with the possibilities for valorization. This last topic focuses on shaping these plans for valorization. With regard to developing a genetic test to be added into the fertility work-up, first steps have been made for implementation through the stakeholder research we conducted. To ensure a successful and swift implementation of a genetic test in daily practice for gynecologists and other fertility specialists, more stakeholders will need to be involved to identify barriers and facilitators. Furthermore, more research is needed to gain information on the associations between different genetic variants and the risk of infertility after a Chlamydia trachomatis infection and other sexually transmitted infections causing tubal damage. Through this 
research, important factors such as the analytical validity, clinical validity, clinical utility can be studied. Combined with research on the ethical, legal and societal implications of the test successful implementations plans incorporating these essential factors can be developed. 


\section{Curriculum Vitae}

Marleen Jansen was born on the 28th of January 1989, in Haarlem, the Netherlands. She attended secondary school at Herbert Vissers College in Nieuw-Vennep. She completed her Gymnasium in 2007, after which she started her Bachelor studies Health Sciences at VU University, Amsterdam, the Netherlands. During her three years as a bachelor student she joined several committees and the board of her study association, completed the $\mathrm{VU}$ University Honours Programme, and co-founded a company that offers support to high school student through training programs (ExTra). To continue her studies, Marleen enrolled at Maastricht University for the Master Health Sciences Research, from which she graduated in 2012. After her graduation, Marleen started working as a Junior Researcher at the Institute for Public Health Genomics of Maastricht University and TubaScan Ltd in Amsterdam. During her time as a Junior Researchers she collaborated with several colleagues to write the manuscripts that are presented in this thesis. Furthermore, she worked in Perth, Australia for half a year at the Office of Population Health Genomics at the Screening Policy Section. After defending her thesis, Marleen will continue her scientific career as a researcher at the department Community Genetics and Public Health Genomics of VU University Medical Center in a joint project with the National Institute for Public Health and the Environment.

Marleen Jansen is op 28 januari 1989 geboren te Haarlem. Ze behaalde haar gymnasiumdiploma (Natuur \& Techniek en Natuur \& Gezondheid) aan het Herbert Vissers College in Nieuw-Vennep in 2007. In hetzelfde jaar is Marleen gestart met de bacheloropleiding Gezondheidswetenschappen aan de Vrije Universiteit, Amsterdam. Gedurende haar jaren als een bachelorstudent is Marleen actief geweest bij haar studievereniging in verschillende commissies en in het bestuur als secretaris. Verder heeft zij met succes het Honours Programme van de Vrije Universiteit afgerond en is zij medeoprichter geweest van een VOF die onderwijsondersteuning aanbiedt aan middelbare scholieren (ExTra). Om haar studie vervolgen is Marleen in 2010 begonnen met de Master Health Sciences Research aan Maastricht University. Nadat zij hier in 2012 haar diploma voor in ontvangst genomen heeft, is zij begin 2013 bij het Institute for Public Health Genomics van Maastricht University gaan werken als Junior Onderzoeker en bij TubaScan Ltd in Amsterdam. Gedurende haar tijd als Junior Onderzoeker heeft zij met verschillende collega's samengewerkt om de manuscripten voor te bereiden die in dit proefschrift te lezen zijn. Bovendien heeft zij een half jaar bij het Office of Population Health Genomics in Perth (Australië) gewerkt, bij de Screening Policy Section. Na de verdediging van haar thesis zal Marleen haar wetenschappelijke carrière voortzetten als wetenschappelijk onderzoeker bij de afdeling Community Genetics and Public Health Genomics van VU medisch centrum Amsterdam in een samenwerkingsverband met het Rijksinstituut voor Volksgezondheid en Milieu. 


\section{Extended Curriculum Vitae}

\section{Publications}

Published

2015

Jansen ME, Branković I, Spaargaren J, Ouburg S, Morré SA. Potential protective effect of a G>A SNP in the 3'UTR of $H L A$-A for Chlamydia trachomatis symptomatology and severity of infection. Pathogens and Disease 2015. pii: ftv116

2014

Horgan $D^{*}$, Jansen $\mathbf{M}^{*}$, Leyens $L^{*}$, Lal JA, Sudbrak $R$, Hackenitz E, Bußhoff $U$, Ballensiefen W, Brand A. (*Shared first authorship) An index of barriers for the implementation of personalised medicine and pharmacogenomics in Europe. Public Health Genomics. 2014;17(5-6):287-98

Under review or in preparation

Jansen ME, van Ess EF, Ouburg S, Land JA, Morré SA. Prediction of tubal factor infertility based on Chlamydia trachomatis antibody testing combined with C-reactive protein as a marker for persistent infection. To be submitted to: Human Reproduction

Malogajski J, Jansen ME, Ouburg S, Ambrosino E, Terwee CB, Morré SA. The attitudes of Dutch gynecologists towards the addition of genetic testing in screening of tubal factor infertility. Submitted to: Journal of Genetic Counseling

Jansen ME, Metternick-Jones SC, Lister KJ. International differences in the evaluation of conditions for newborn screening: a review of scientific literature and policy documents. Submitted to: European Journal of Public Health

Jansen ME, van Kranen HJ, Lister KJ, Cornel MC. Decision making in newborn screening needs a transparent approach with structured multidisciplinary stakeholder engagement in all phases. Submitted to: Health Policy and Planning.

Jansen ME, van El CE, Cornel MC. Public involvement in policy development for newborn bloodspot screening: goals, definitions, mechanisms, levels, and evaluation. To be submitted to: Health Expectations 


\section{Presentations}

Poster

Screening criteria and decision making in newborn bloodspot screening: review of scientific literature and policy documents. HGSA 2015, Perth WA \& GROW Science day 2015, Maastricht NL

Duo Immunogenetics of Chlamydia trachomatis infections: translation into presentation public health. Plenary Meeting GROW, Maastricht NL

Seminar Going beyond Wilson and Jungner? - An international comparison of NBS criteria. G\&C seminar. Maastricht NL

Colloquium Going beyond Wilson and Jungner? - An international comparison of NBS criteria and insight into the Australian experience. VU University Medical Center. Amsterdam NL

\section{Workshops}

2015

2014

2013

'Whole-population preconception carrier screening', Glasgow UK

'Beleidsadvisering NIPT - JongGR', Den-Haag NL

'A national framework for newborn bloodspot screening in Australia', Perth WA

'Changing practices of informed consent in neonatal screening',

\section{Conferences}

2015

2014

2013 Bilthoven NL

'Rare Diseases and Indigenous Genetics - HGSA', Perth WA

'Genetics Retreat 2014', Kerkrade NL

'Neonatale screening en farmacogenetica', Maastricht NL

'9th Annual Amsterdam Chlamydia Meeting', Amsterdam NL

'Expanded carrier screening', Leuven BE

'Wat worden we wijzer van genetisch testen?', Utrecht NL

\section{Grants and funding}

2014 - 2015 Mobility for young researchers, Haak Bastiaanse Kuneman Stichting,

Vrije Universiteit, Amsterdam

Short Term Scientific Mission - EU Pancreas, COST Action, European Commission

Pilot Project - Newborn Screening: developments in policy worldwide APOGEE-Net CanGèneTest

\section{Certificates}

2015

2013

University Teaching Qualification, Maastricht University NL

Problem Based Learning, Maastricht University NL

\section{Education}

$2013-2015$

Tutor, mentor, trainer for bachelor and master students Health Sciences, Maastricht University NL

2011 - current Founder and partner (CFO) ExTra, Breda NL 


\section{List of authors and affiliations}

Ambrosino, E.

Brankovic, I.

Cornel, M.C.

El, van, C.E.

Ess van, E.F.

Jansen, M.E.

Kranen van, H.J.

Land, J.A.
Institute for Public Health Genomics, Department of Genetics and Cell Biology, School for Oncology and Developmental Biology (GROW), Faculty of Health, Medicine and Life Sciences, Maastricht University, Maastricht, The Netherlands

Institute for Public Health Genomics, Department of Genetics and Cell Biology, School for Oncology and Developmental Biology (GROW), Faculty of Health, Medicine and Life Sciences, Maastricht University, Maastricht, The Netherlands

Department of Clinical Genetics, Section Community Genetics and EMGO Institute for Health and Care Research, VU University Medical Center, Amsterdam, the Netherlands

Department of Clinical Genetics, Section Community Genetics and EMGO Institute for Health and Care Research, VU University Medical Center, Amsterdam, the Netherlands

Laboratory of Immunogenetics, Department of Medical Microbiology and Infection Control, VU University Medical Center, Amsterdam, The Netherlands

Institute for Public Health Genomics, Department of Genetics and Cell Biology, School for Oncology and Developmental Biology (GROW), Faculty of Health, Medicine and Life Sciences, Maastricht University, Maastricht, The Netherlands

Institute for Public Health Genomics, Department of Genetics and Cell Biology, School for Oncology and Developmental Biology (GROW), Faculty of Health, Medicine and Life Sciences, Maastricht University, Maastricht, The Netherlands

Center for Nutrition, Prevention and Health Services, National Institute for Public Health and the Environment, Bilthoven, the Netherlands

Department of Obstetrics and Gynaecology, University Medical Center Groningen, University of Groningen, Groningen, The Netherlands 
Lister, K.J.

Metternick-Jones, S.C. Screening Policy Section, Office of Population Health Genomics, Department of Health, Government of Western Australia, Perth, Australia

Morré, S.A.

Ouburg, S.

Spaargaren, J.

Terwee, C.B.

Screening Policy Section, Office of Population Health Genomics, Department of Health, Government of Western Australia, Perth, Australia

Institute for Public Health Genomics, Department of Genetics and Cell Biology, School for Oncology and Developmental Biology (GROW), Faculty of Health, Medicine and Life Sciences, Maastricht University, Maastricht, The Netherlands

Laboratory of Immunogenetics, Department of Medical Microbiology and Infection Control, VU University Medical Center, Amsterdam, The Netherlands

Laboratory of Immunogenetics, Department of Medical Microbiology and Infection Control, VU University Medical Center, Amsterdam, The Netherlands

Laboratory of Immunogenetics, Department of Medical Microbiology and Infection Control, VU University Medical Center, Amsterdam, The Netherlands

Department of Epidemiology and Biostatistics and the EMGO Institute for Health and Care Research, VU University Medical Center, Amsterdam, the Netherlands 

0000000000 